Check for updates

Cite this: Mater. Adv., 2021, 2, 3806

Received 4th September 2020, Accepted 23rd April 2021

DOI: 10.1039/d0ma00681e

rsc.li/materials-advances

\title{
Recent developments in sustainable corrosion inhibitors: design, performance and industrial scale applications
}

\author{
Chandrabhan Verma, (D) ${ }^{a}$ Eno E. Ebenso, (D) ${ }^{b}$ M. A. Quraishi (D) and \\ Chaudhery Mustansar Hussain (D) *C
}

\begin{abstract}
Recently, research studies in the fields of science and engineering are directed towards the synthesis, design, development, and consumption of environment-friendly chemical species to replace traditional toxic chemicals. This is because of the escalating demands of conservation understanding and stringent ecological rules. Currently, various environment-friendly alternatives derived from natural resources such as biopolymers, plant extracts, chemical medicines (drugs), etc. are widely used to replace toxic corrosion inhibitors. Moreover, various biopolymers in their pure and modified forms are extensively employed as environment-friendly corrosion inhibitors. Compounds derived through multicomponent reactions (MCRs), and microwave (MW) and ultrasound (US) irradiations are also considered as environment-friendly alternatives. Polyethylene glycol (PEG) and ionic liquids (ILs) possess low vapor pressure and are regarded as designer environment-friendly alternatives. The chemicals synthesized using green solvents such as water, ILs and supercritical $\mathrm{CO}_{2}$ can also be regarded as environmentfriendly chemical species. A comprehensive literature survey reveals that these compounds are extensively utilized as metallic corrosion inhibitors in various corrosive electrolytes. Overall, this review provides a summary of several major reports on environment-friendly corrosion inhibitors.
\end{abstract}

\section{Introduction}

\subsection{Corrosion inhibition: current trends and challenges}

Metallic materials are widely used for various applications, for example, as constructional materials, especially in the petroleum, oil and gas industries. ${ }^{1,2}$ However, most of the metals in their pure form are thermodynamically unstable, and therefore they readily undergo corrosive degradation by the reaction of constituents of the surrounding environment. Corrosion causes huge safety concerns and economic damage. According to the recent estimation of the NACE (National Association of Corrosion Engineers), the global cost of corrosion is around US\$2.5 trillion, which constitutes about $3.5 \%$ of the world's GDP. The cost of corrosion may be of direct or indirect type. ${ }^{3-5}$ The direct cost of corrosion includes the repair, storage and replacement of the corroded metallic equipment, modifying alloys into metals

\footnotetext{
${ }^{a}$ Interdisciplinary Research Center for Advanced Materials, King Fahd University of Petroleum and Minerals, Dhahran, 31261, Saudi Arabia

${ }^{b}$ Institute for Nanotechnology and Water Sustainability, College of Science, Engineering and Technology, University of South Africa, Johannesburg, South Africa

${ }^{c}$ Department of Chemistry and Environmental Science, New Jersey Institute of Technology, Newark, NJ 07102, USA. E-mail: Chaudhery.m.hussain@njit.edu
}

and vice versa. The cost associated with nickel plating and galvanization can also be regarded as the direct cost of corrosion. ${ }^{6,7}$ Apart from the above, economic losses associated with the synthesis, characterization and application of compounds as corrosion inhibitors are also integrated as the direct cost of corrosion. The indirect costs of corrosion include the leakage of liquids (petroleum) and gases from transport pipelines that adversely affect the performance of machineries and transport efficiency. Contamination of rusts and scales (corrosion products) can also adversely affect the quantity of the materials (liquids and gases) to be transported. These corrosion products can also reduce transport efficiency and the performance of machineries by choking the valves and joints. Obviously, the leakage of the transported petroleum based liquids and gases is associated with various environment related problems because of their toxicity.

In view of the above, several methods of corrosion mitigation have been developed by corrosion scientists and engineers. One of the oldest (before 1960) methods of corrosion mitigation was the implementation of inorganic compounds, mainly nitrites, chromates, borates, molybdates, silicates and zinc salts. ${ }^{8}$ These compounds become effective by forming a highly effective passive film over metal surfaces (passivators) through their adsorption. However, they were replaced by more economical alternatives such as phosphonic acid, gluconates, polyacrylates, 
surface active chelates, polyphosphates, polyphosphonates, phosphonates and carboxylates during 1960-1980. ${ }^{8}$ Generally, these compounds precipitate at the interface of the metal and environment and therefore they are called precipitating inhibitors (precipitators). Nevertheless, after that, ecological considerations came into play and toxic chemicals were replaced by natural alternatives including natural and bio-polymers, bio-surfactants, vitamins, tannins and natural compounds during 1980-1995. Recently (1995 to present), environment-friendly approaches such as the use of rare earth metals (REM), polyfunctional compounds, the synergism of organic/inorganic compounds using REM and the encapsulation of inhibitors are the main areas of focus. ${ }^{9}$ Obviously, these alternatives exhibit very low or no toxicity and high protection effectiveness.

Currently, organic compounds are established as one of the most effective and profitable methods of corrosion inhibition because of their association with E4 (efficiency, economy, ecology and environmental friendliness).$^{10-12}$ Organic corrosion inhibitors are used for different industrial applications (Fig. 1). However, there are numerous challenges of using these compounds. One of the biggest challenges of using organic corrosion inhibitors is their limited solubility, especially in polar electrolytes. ${ }^{13,14}$ Because of their hydrophobic nature, organic corrosion inhibitors, especially compounds containing aromatic rings and non-polar hydrocarbon chains, show limited solubility that adversely affects their protection efficiency. Therefore, current research studies in corrosion science and engineering are oriented towards the development of corrosion inhibitors that contain hydrophilic polar functional substituents in their molecular structures.

The electron rich polar functional substituents enhance the bonding efficiency between the metal surface and organic compounds either directly participating in coordination bonding or increasing the electron density over the active sites of inhibitor molecules. ${ }^{15-17}$ The polar substituents also triggered the protection effectiveness of the organic inhibitors by increasing their hydrophilicity and solubility in polar electrolytes. ${ }^{16,17}$ The nature of the substituents plays a significant role in designing effective corrosion inhibitors. Electron donating substituents (EDS) with a negative Hammett substituent constant are expected to increase the inhibition effect of organic compounds. ${ }^{15,18-20}$ On the other hand, electron withdrawing substituents (EWS) with a positive Hammett substituent constant are expected to decrease the protection effectiveness of the inhibitors. Nevertheless, EWS such as $-\mathrm{CN},-\mathrm{NO}_{2},-\mathrm{COOH},-\mathrm{SO}_{3} \mathrm{H}$, etc. enhance the corrosion

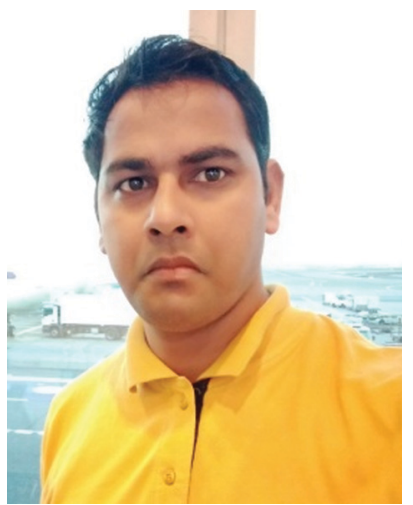

Chandrabhan Verma
Chandrabhan Verma, PhD is a Postdoctoral Fellow at the Interdisciplinary Center for Research in Advanced Materials, King Fahd University of Petroleum and Minerals (KFUPM), Saudi Arabia. He obtained his PhD in Corrosion Science at the Department of Chemistry, Indian Institute of Technology (Banaras Hindu University) Varanasi, India. He is a member of American Chemical Society (ACS). His research is mainly focused on the synthesis and designing of environmental friendly corrosion inhibitors useful for several industrial applications. Dr Verma is the author of several research and review articles in peer-reviewed international journals of ACS, Elsevier, RSC, Wiley and Springer etc. He has total citation of more than 4600 with H-index of 37 and i-10 index of 83. Dr Verma received several national and international awards for his academic achievements.

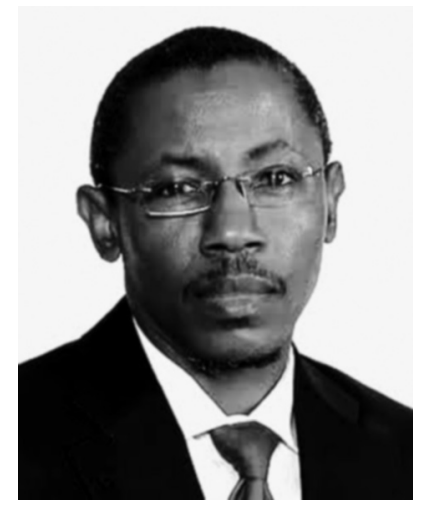

Eno E. Ebenso
Eno E. Ebenso is a research professor of at the Institute of Nanotechnology and Water Sustainability in the College of Science, Engineering and Technology, University of South Africa. He has published extensively in local and international peer-reviewed journals of wide readership with over three hundred (300) publications (articles in newspapers, plenary/invited lectures and conference proceedings not included). He currently has an H-Index of 67 and over 10000 total citations from the Scopus Search Engine of Elsevier Science since 1996. According to the Elsevier SciVal Insights Report (2010-2015), he has a citation impact $10 \%$ above world average; second most prolific author in the field of corrosion inhibition world wide and fifth most downloads of his publications globally in the field of corrosion inhibition. His Google Scholar Citations since 2013 is over 8000 with an H index of 64 and i10-index of 216. His RESEARCHERID account shows H index of 44 with total citations of 5779 and average citation per article of 24.78. He is also a B3 NRF Rated Scientist in Chemistry (South African National Research Foundation). INTERPRETATION - B3: Most of the reviewers are convinced that he enjoys considerable international recognition for the high quality and impact of his recent research outputs. He is a member of International Society of Electrochemistry, South African Chemical Institute (M.S.A. Chem. I.), South African Council for Natural Scientific Professions (SACNASP) (Pri. Sci. Nat)., Academy of Science of South Africa (ASSAf) and a fellow of the Royal Society of Chemistry, UK (FRSC). 


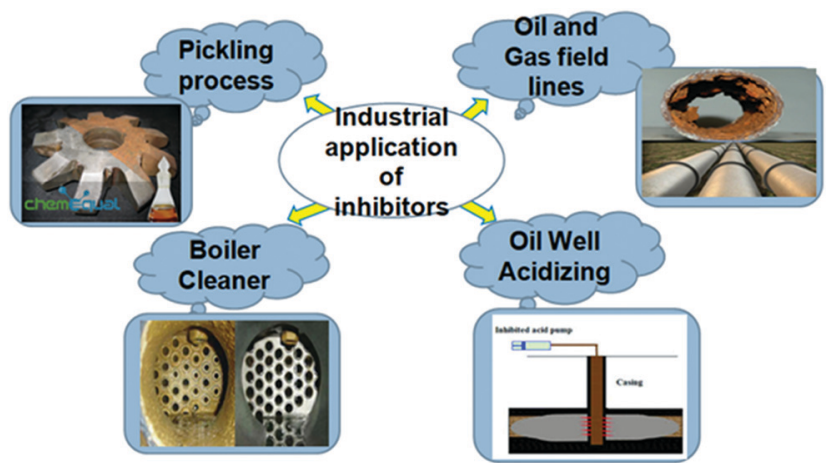

Fig. 1 Applications of organic corrosion inhibitors in different industrial sectors.

inhibition effectiveness of macromolecules and polymers by increasing their solubility in polar electrolytes.

Thermal decomposition represents another challenge of using organic compounds as inhibitors against metallic corrosion. The inhibition efficiency of most of the organic compounds decreases on increasing the temperature. ${ }^{21,22}$ This type of decrease in the inhibition efficiency is attributed to the acid or base catalyzed decomposition and/or rearrangement of the inhibitor molecules, especially at high temperatures. ${ }^{23,24}$ Obviously, the increase in the kinetic energy of the inhibitor molecules on increasing the temperature results in the corresponding decrease in the attractive force between the inhibitor molecules and the metallic surface. ${ }^{23,24}$ This observation reveals that the bonding between the inhibitor molecules and the metallic surface is mostly electrostatic, i.e. physisorption. However, the increase in protection efficiency on increasing the temperature has also been documented. ${ }^{25-27}$ The increase in the inhibition efficiency with the rise in temperature suggests that the interaction between

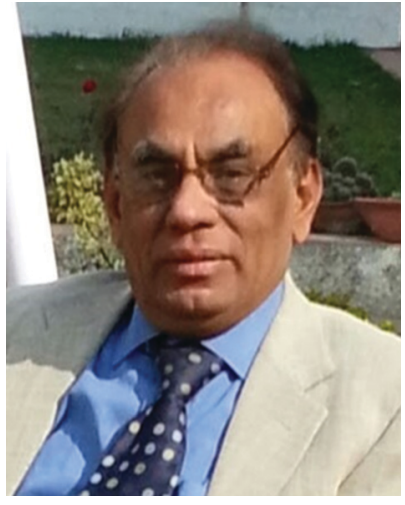

M. A. Quraishi
Dr Mumtaz A. Quraishi is a Chair Professor at the Interdisciplinary Center for Research in Advanced Materials, King Fahd University of Petroleum and Minerals (KFUPM), Saudi Arabia. He obtained PhD in synthetic organic chemistry in 1986 from Kurukshetra University, and awarded DSc in 2004 from Aligarh Muslim University, Aligarh in the field of Corrosion Inhibition of Industrial Metals and Alloys. Before joining KFUPM he was institute Professor at IIT BHU

Varanasi, India. He also served as Head (Chairman), Department of Chemistry, IIT BHU. He has teaching experience more than 35 years. He received several national and international awards. Dr Quraishi is an Associate editor of Current Materials Science, Bentham and a member of Editorial Board of the more than 30 International Journals. Dr Quraishi is a fellow of Royal Society of Chemistry, UK and a member of American Chemical Society. the metal surface and the inhibitor molecules involves chemical bonding, i.e. chemisorption. The literature observation suggests that most of the organic corrosion inhibitors adsorb using a mixed mode of adsorption, i.e. physiochemisorption. ${ }^{28-30}$

\subsection{Assessment of sustainable corrosion inhibitors: OSPAR and REACH commissions}

Because of the rising environmental consciousness and severe ecological policies, decent advancements in the field of corrosion science and engineering are oriented towards the development, synthesis, design and implementation of environment-friendly alternatives to the conventional toxic corrosion inhibitors. ${ }^{31-33}$ Obviously, the environmentally benign nature of a chemical species (or corrosion inhibitor) can be determined by assessing its bioaccumulation ability, biodegradability and the impact of its toxicity on the environment. ${ }^{33-35}$ The Oslo and Paris Commission (OSPAR) and Registration, Evaluation, Authorisation and Restriction of Chemicals (REACH) are the international commissions for the assessment of the above parameters. REACH is a European Union Regulation (EUR) that was dated on 18 December 2006 and came into force on 7 June $2007 . .^{36,37}$ The 849-page EUR addresses the production, design and implementation of chemical substances as well as their impact on the environment and human health. OSPAR, which was formed on 22 September 1992, combines and updates the 1972 Oslo Convention on dumping of wastes at sea and 1974 Paris Convention on marine pollution resulting through land-based sources. $^{38-40}$ These commissions set up some guidelines and indices, in terms of which the toxicity, biodegradability and bioaccumulation ability and their impact on human health and the environment of chemical compounds can be assessed. The toxicity of a chemical compound to be used as a corrosion inhibitor can be assessed using its lethal and ethical

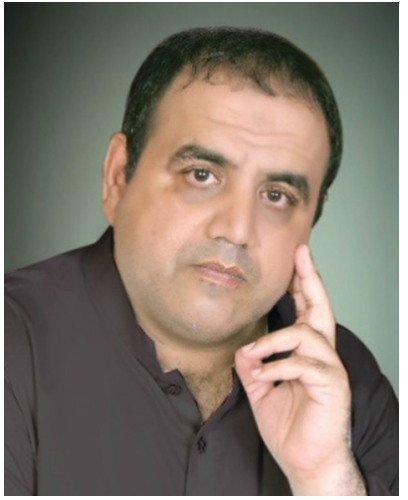

Chaudhery Mustansar Hussain
Chaudhery Mustansar Hussain, PhD is an Adjunct Professor and Director of Labs in the Department of Chemistry \& Environmental Sciences at the New Jersey Institute of Technology (NJIT), Newark, New Jersey, USA. His research is focused on the applications of Nanotechnology \& Advanced technologies \& Materials, Analytical Chemistry, Environmental Management, and Various Industries. Dr Hussain is the author of numerous papers in peer-reviewed journals as well as prolific author and editor of several (around 200 publications with more than 50 books) scientific monographs and handbooks in his research areas published with Elsevier, Royal Society of Chemistry, John Wiley \& sons, CRC, Springer etc. 
concentrations designated as $\mathrm{LC}_{50}$ and $\mathrm{EC}_{50}$, respectively. ${ }^{41,42}$ $\mathrm{LC}_{50}$ represents the concentration of the substance that causes the demise of $50 \%$ of the living population and $\mathrm{EC}_{50}$ denotes the chemical concentration that adversely affects the growth of the living population. ${ }^{43-45}$ Obviously, an inferior $\mathrm{LC}_{50} / \mathrm{EC}_{50}$ magnitude indicates superior sensitive toxicity and vice versa. A chemical with a $\mathrm{LC}_{50} / \mathrm{EC}_{50}$ value greater than $10 \mathrm{mg} \mathrm{kg}{ }^{-1}$ is considered nontoxic. ${ }^{43-45}$ Most of the chemicals spontaneously undergo degradation by microorganisms called decomposers though the process is quite slow and takes several days, months or even years. ${ }^{46} \mathrm{~A}$ chemical can be categorized as environment-friendly if it decomposes $60 \%$ or more in 28 days. ${ }^{47,48}$ Bioaccumulation is the ability of a chemical to gather in a living organism when the source of the chemical is exclusively water. ${ }^{49-51}$ Generally, it is measured in terms of the partition coefficient, designated as $\log K_{\mathrm{OW}}$ or $D^{\mathrm{OW}}$. Generally, $K_{\mathrm{OW}}$ or $D^{\mathrm{OW}}$ represents the ratio of concentrations of a compound in an assortment of two immiscible solvents at equilibrium. Bioaccumulation is a measure in a mixture of water and octanol. For an environment-friendly compound, the $K_{\mathrm{OW}}$ or $D^{\mathrm{OW}}$ value should be equal to or less than $3 .^{52}$

\subsection{Computational chemistry tools for corrosion inhibition studies}

Numerous chemical, electrochemical and surface morphological techniques are widely used for the evaluation of the inhibition performance of corrosion inhibitors. ${ }^{53-55}$ However, these experimental methods have several shortcomings. Generally, these experimental methods are associated with expensive synthesis and the use of toxic chemicals that adversely affect the surrounding environment. ${ }^{56-58}$ These chemicals are synthesized using toxic and expensive starting materials and catalyst using multistep reactions that consume huge amounts of solvents for purification and work-up processes. Discharge of excess amounts of organic solvents and toxic catalysts into the environment causes severe environment related issues. Because of the multistep nature, the syntheses of corrosion inhibitors are associated with the formation of several undesirable side products that can also pollute the environment. Instead of their highly toxic and expensive synthesis, most of the compounds do not give fruitful results and fail in experimental trials. ${ }^{28,59,60}$ In view of this, recently computational chemistry tools have come into play for determining the corrosion inhibition effectiveness of corrosion inhibitors. 5,61,62 The environment-friendly nature of these techniques is associated with the fact that the inhibition effectiveness of compounds can be theoretically predicted before their toxic and expensive synthesis. ${ }^{5,62-64}$ Unlike experimental methods, computational modeling involves the use of computational software for predicting inhibitory efficiency instead of highly expensive instruments. ${ }^{65-67}$

Recently, several computational methods, especially density functional theory (DFT), molecular dynamics (MD) and Monte Carlo (MC) simulations, have emerged as powerful computational chemistry tools for corrosion monitoring. ${ }^{5,61,62}$ DFT simulations represent the most powerful computational tool, which give some vital indices including the energy of frontier molecular orbitals (FMOs; $E_{\mathrm{HOMO}}$ and $E_{\mathrm{LUMO}}$ ) and numerous correlation parameters such as energy band gap $\left(E_{\mathrm{LUMO}}-E_{\mathrm{HOMO}}=\Delta E\right)$, hardness $(\eta)$, electronegativity $(\chi)$, dipole moment $(\mu)$, softness $(\sigma)$, fraction of electron transfer $(\Delta N)$, etc., in terms of which the adsorption ability and corrosion inhibition effectiveness of a compound can be explained. ${ }^{5,61,62,68}$ DFT studies are mostly used to correlate the relative inhibition effect of a series of compounds having similar molecular structures. In general, higher $E_{\mathrm{HOMO}}$, softness $(\sigma)$ and dipole moment $(\mu)$ and lower $E_{\text {LUMO }}, \Delta E$, electronegativity $(\chi)$ and hardness $(\eta)$ values are associated with high inhibition efficiency. ${ }^{61,62}$ One of the most significant indices is the energy band gap $\Delta E$ ( $\left.E_{\mathrm{LuMO}}-E_{\mathrm{HOMO}}\right)$ and its lower value is associated with a higher inhibition efficiency. ${ }^{69,70}$ By studying the anticorrosive effect of chitosan $(\mathrm{CH})$ modified with 4-amino-5methyl-1,2,4-triazole-3-thiol (AMT), the authors reported that both $\mathrm{CH}$ and AMT separately have higher $\Delta E$ values as compared to the $\Delta E$ value of AMT modified $\mathrm{CH}(\mathrm{CH}-\mathrm{AMT})$. This observation suggests that $\mathrm{CH}-\mathrm{AMT}$ is relatively more reactive towards its absorption on the metallic surface as compared to $\mathrm{CH}$ and AMT separately (Fig. 2).$^{71}$ An increase in protection efficiency for a series of corrosion inhibitors with a decrease in the $\Delta E$ value has been reported extensively.

It is important to mention that, during metal and inhibitor interactions, some parts of the inhibitor molecules are involved in bonding with the metallic surface. These parts are called active or adsorption centers. Among the several experimental and computational techniques, the implementation of DFT is established as one of the most significant methods for identifying the active centers of the inhibitor molecule. ${ }^{61,62}$ Localized regions in FMOs (HOMO and LUMO) represent the electron rich centers (active centers) that actively contribute to charge sharing with the metallic surface. ${ }^{72-74}$ Generally, these electron rich centers are aromatic ring(s) and/or polar functional groups. However, the contribution of FMOs in charge sharing with the metallic surface depends greatly on the nature of substituents. ${ }^{15,19}$ In general, substituents with a negative Hammett $(\sigma)$ or Taft $\left(\sigma^{*}\right)$ constant (electron donating) show an increased FMO contribution with an increase in electron density. ${ }^{15,19}$ In contrast, substituents with a positive Hammett $(\sigma)$ or Taft $\left(\sigma^{*}\right)$ constant (electron withdrawing) show a decreased FMO contribution to charge sharing. ${ }^{15,19}$

A study on the inhibitive effect of 2-amino-4-arylquinoline-3carbonitriles (AACs) on mild steel in acidic medium showed that the presence of $-\mathrm{OH}$ (AAC-3) increases the inhibition efficiency and the presence of a $-\mathrm{NO}_{2}$ substituent (AAC-1) decreases the inhibition efficiency as compared to the nonsubstituted compound (AAC-2). ${ }^{75}$

DFT studies revealed that the $-\mathrm{NO}_{2}$ substituent decreases the HOMO contribution, whereas the - $\mathrm{OH}$ substituent increases the HOMO contribution. The FMOs of the AACs are presented in Fig. 3. The negative sign of the Hammett constant for $-\mathrm{OH}$ indicates that it is an electron donor in nature and therefore increases the electron donor (HOMO) contribution and the converse is true for the $-\mathrm{NO}_{2}$ substituent. A similar finding was also observed when studying the inhibition effect of 5-arylpyrimido-[4,5- $b]$ quinoline-diones (APQDs) for MS corrosion in acidic medium. DFT analyses showed that the $-\mathrm{NO}_{2}$ substituent with a positive Hammett constant $(\sigma=+0.78)$ decreases the 


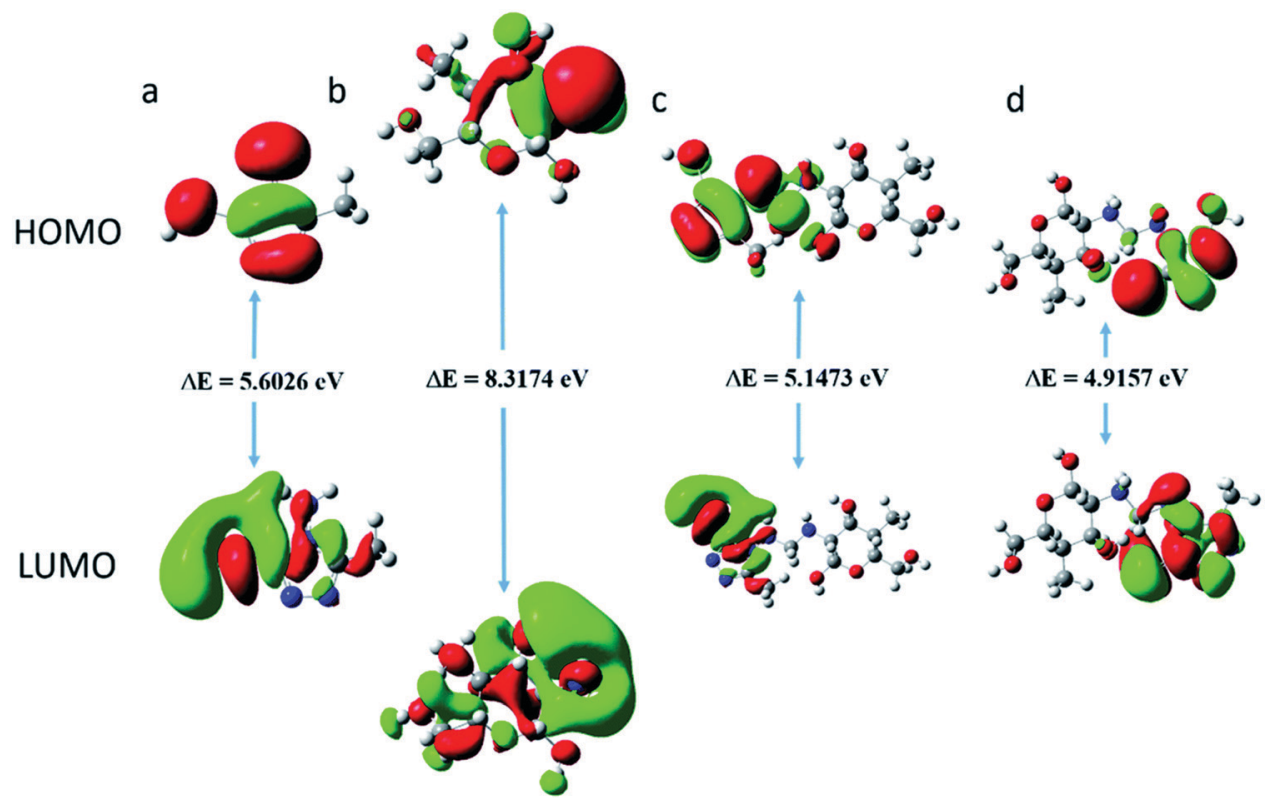

Fig. 2 Presentation of energy band gaps $\left(\Delta E\right.$ : $\left.E_{\mathrm{LUMO}}-E_{\mathrm{HOMO}}\right)$ for (a) 4-amino-5-methyl-1,2,4-triazole-3-thiol (AMT), (b) chitosan (CH), (c) neutral AMT modified $\mathrm{CH}$ and (d) protonated AMT modified $(\mathrm{CH}-\mathrm{MAT}){ }^{71}$

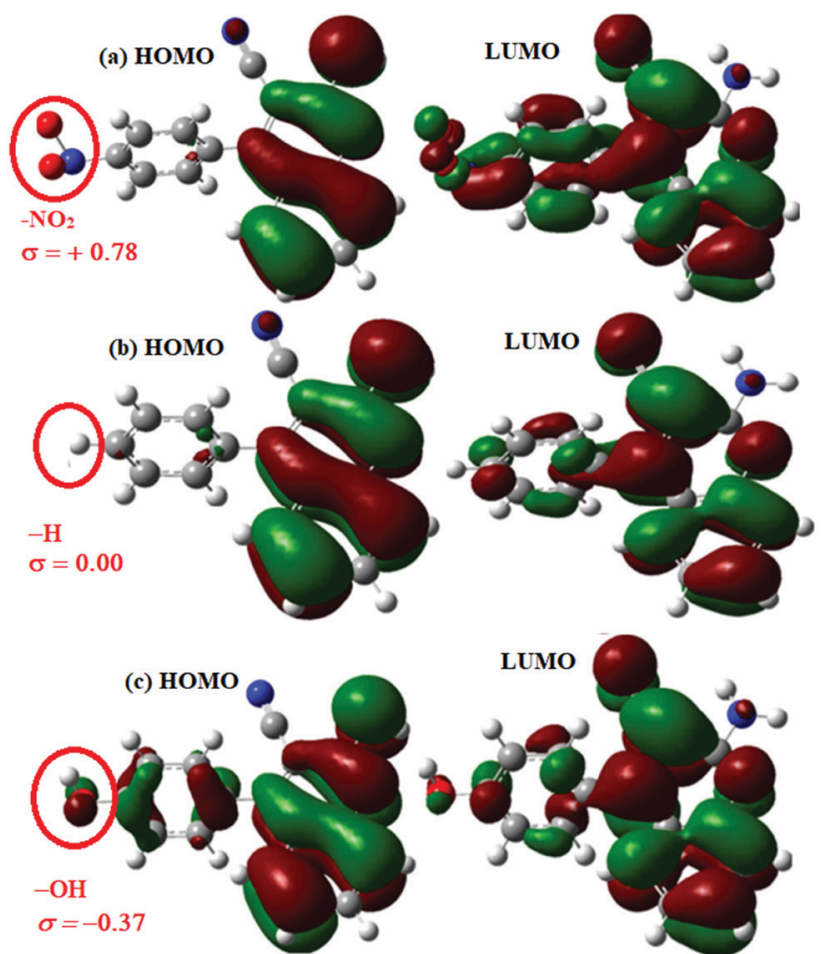

Fig. 3 Frontier molecular orbitals (FMOs) of (a) AAC-1 (-NO2), (b) AAC-2 $(-\mathrm{H})$ and (c) AAC-3 $(-\mathrm{OH})$ derived using the Gaussian 09 software package. $^{75}$

HOMO and LUMO contributions by decreasing the electron density. ${ }^{76}$ Very interestingly only nitrophenyl $\left(-\mathrm{Ph}-\mathrm{NO}_{2}\right)$ moieties are involved in the LUMO because of the electron withdrawing nature of $-\mathrm{NO}_{2}$ (APQD-4). In contrast, the presence of one and two $-\mathrm{OH}$ substituent(s) in APQD-3 and APQD-4, respectively, increase the contributions of both the HOMO and LUMO because of the electron donating nature of $-\mathrm{OH}(\sigma=-0.37){ }^{76}$ The frontier molecular orbital images of APQDs are shown in Fig. 4. A similar finding was also reported in other studies. ${ }^{17,77}$

Other significant computational techniques are molecular dynamics (MD) and Monte Carlo (MC) simulations. ${ }^{5,78-80}$ Using these techniques one can determine the orientation of the inhibitor on the metallic surface. Measurement of the orientation of the inhibitor on the metal surface is an important aspect of corrosion monitoring as an inhibitor with planar orientation covers a larger part of the metallic surface and acts as a superior corrosion inhibitor to an inhibitor with vertical orientation. When an inhibitor approaches the metallic surface, due to the effect of different attractive and repulsive forces it gets polarized and acquires a specific orientation depending upon the nature of the electronic structure of the inhibitor molecules. Nevertheless, substituents play a significant role in determining the orientation of the inhibitor molecules over the metal surface. Generally, electron donating substituents force the inhibitor molecules to obtain vertical orientation and vice versa.

The orientations of four 5-arylpyrimido-[4,5-b]quinoline-diones (APQDs) and glucosamine-based, pyrimidine-fused heterocycles (CARBs) are shown in Fig. 5 and 6. It can be clearly observed that in the presence of the electron withdrawing $-\mathrm{NO}_{2}$ substituent the extent of adsorption (yellow circle) decreased with respect to the adsorption extent of inhibitors with electron donating substituents.

\subsection{Design of effective corrosion inhibitors based on experimental and computational studies}

From the above discussion it is clear that substituents play a significant role in determining the corrosion inhibition effect of organic corrosion inhibitors. Obviously, because of their 


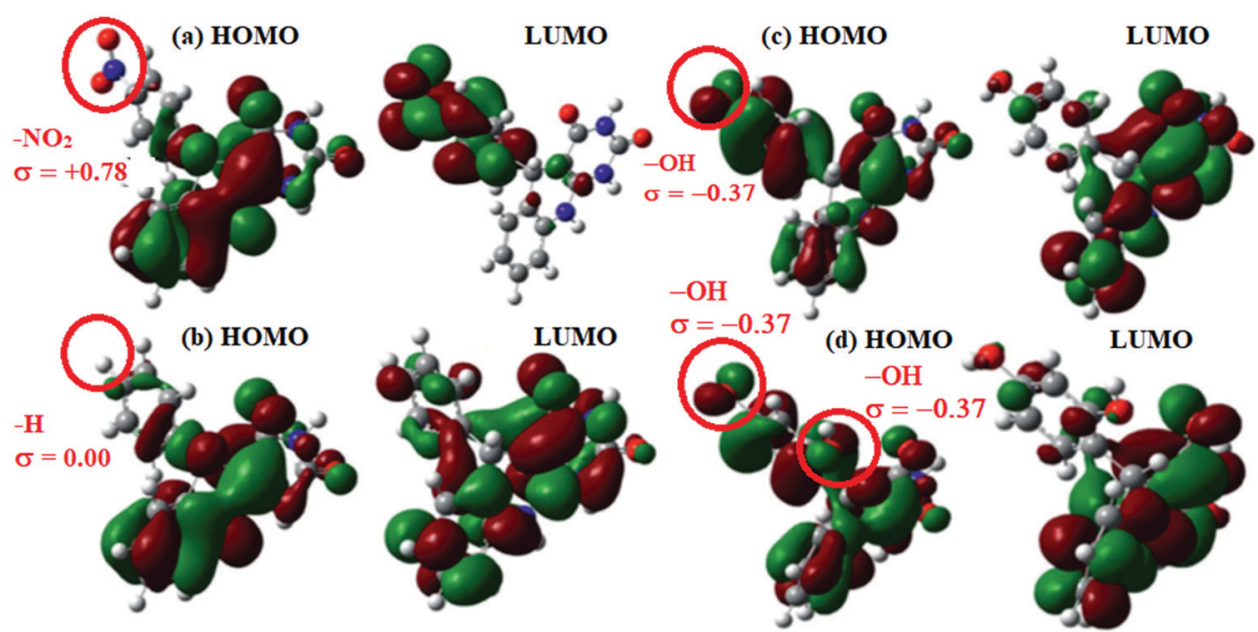

Fig. 4 Frontier molecular orbital images of (a) APQD-1 $\left(-\mathrm{NO}_{2}\right)$, (b) APQD-2 (-H), (c) APQD-3 (-OH) and (d) APQD-4 (2x $\left.-\mathrm{OH}\right)$ derived using the Gaussian 09 software package. ${ }^{76}$

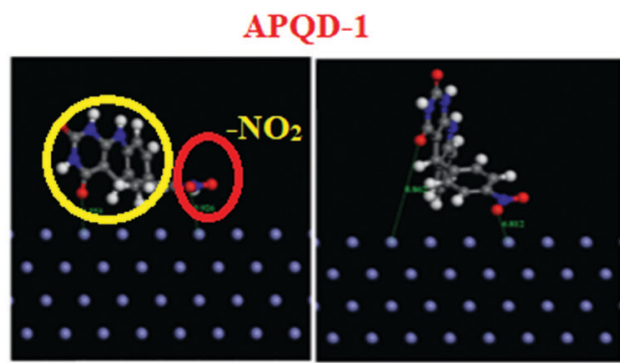

APQD-3
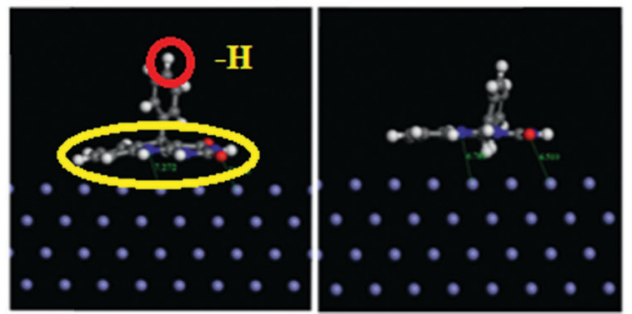

APQD-3

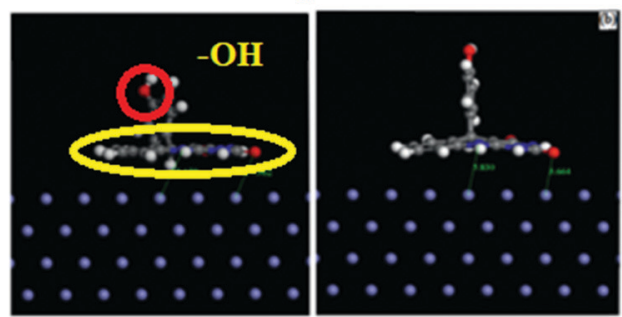

APQD-4

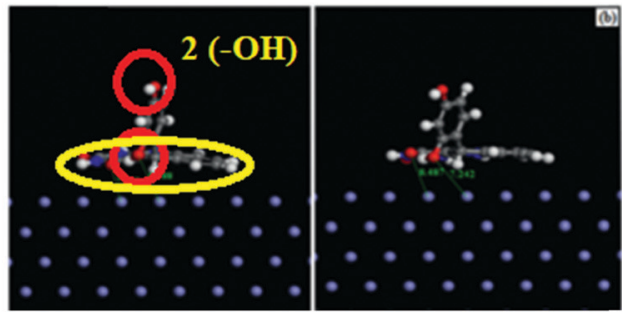

Fig. 5 Top and side views of APQD-1 $\left(-\mathrm{NO}_{2}\right), A P Q D-2(-\mathrm{H}), \mathrm{APQD}-3(-\mathrm{OH})$ and APQD $-4(2 \times-\mathrm{OH})$ on the Fe(110) surface derived using molecular dynamics simulations. ${ }^{76}$

electron donating or electron withdrawing nature, these substituents affect the overall electron density at the donor site(s) of the inhibitor molecules. It is important to mention that the interaction of organic corrosion inhibitors with the metallic surface involves the donor-acceptor (charge sharing) phenomenon. The effect of substituents on the electron sharing tendency of corrosion inhibitors can be assessed through DFT analysis (Fig. 3 and 4). On the other hand, the effect of substituents on the orientation of corrosion inhibitors over the metal surface can be easily assessed through MD or MC simulations (Fig. 5 and 6). Besides computational chemistry tools, the effect of electron donating as well as electron withdrawing substituents on the inhibition efficiency of the substituted aromatic corrosion inhibitors can also be determined using the Hammett substituent constant $(\sigma)$ (or Taft substituent constant, $\sigma^{*}$-for aliphatic cyclic and linear compounds). The various forms of the Hammett equations are presented below: ${ }^{15}$

$$
\begin{gathered}
\log \frac{K_{\mathrm{R}}}{K_{\mathrm{H}}}=\rho \sigma \\
\log \frac{1-\eta \%_{\mathrm{R}}}{1-\eta \%_{\mathrm{H}}}=\rho \sigma \\
\log \frac{\eta \%_{\mathrm{R}}}{\eta \%_{\mathrm{H}}}=\log \frac{C_{\mathrm{rH}}}{C_{\mathrm{rR}}}=\rho \sigma-\log \frac{\theta_{\mathrm{R}}}{\theta_{\mathrm{H}}}
\end{gathered}
$$

In the above equations, $K, \eta \%, \theta$ and $C_{\mathrm{r}}$ represent the equilibrium constant, percentage inhibition efficiency, surface coverage and corrosion rate, respectively. Subscripts " $H$ " and " $R$ " represent the absence and presence of the substituent, “- $\mathrm{R}$ ". $\rho$ is the 

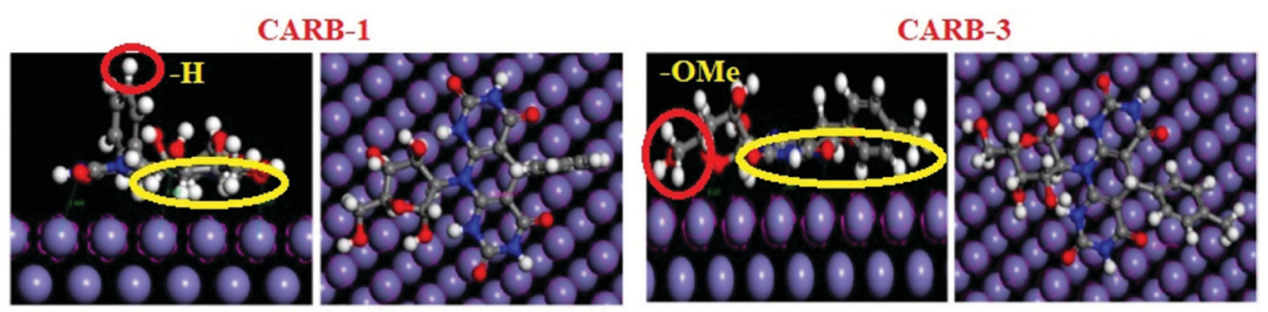

CARB-2
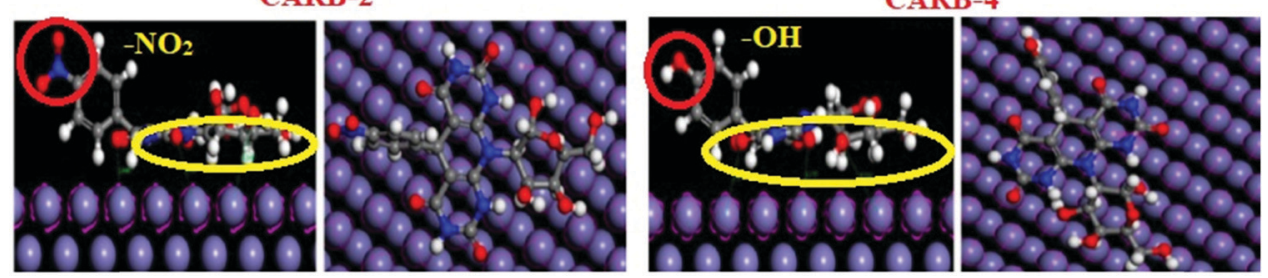

Fig. 6 Top and side views of CARB-1 $\left(-\mathrm{H}_{2}\right)$, CARB-2 $\left(-\mathrm{NO}_{2}\right), \mathrm{CARB}-3(-\mathrm{OH})$ and APQD-4 $(-\mathrm{OMe})$ on the Fe(110) surface derived using Monte Carlo simulations. ${ }^{17}$

reaction parameter and its value mainly depends upon the nature of reaction. $\sigma$ is the Hammett substituent constant and its value reflects the total electron density at the donor (adsorption) site(s). Generally, the negative sign of the Hammett constant is consistent with the electron donating ability of the substituents and vice versa.

It is extensively reported that electron donating substituents such as $-\mathrm{OH}$ (hydroxyl), $-\mathrm{NH}_{2}$ (amino; $1^{\circ}$-amine), $>\mathrm{NH}$ ( $2^{\circ}$-amine), $>\mathrm{N}$ - $\left(3^{\circ}\right.$-amine), $-\mathrm{CH}_{3}$ (methyl), $-\mathrm{OCH}_{3}$ (methoxy), etc. generally increase the corrosion inhibition efficiency of organic compounds, whereas the converse is true for electron withdrawing substituents including $-\mathrm{CN}$ (nitrile), $-\mathrm{NO}_{2}$ (nitro) and $-\mathrm{COOH}$ (carboxyl). ${ }^{15}$ Moreover, the addition of a substituent also affects the overall molecular size of the compound to be used as the corrosion inhibitor. An organic compound with a larger molecular size is expected to be a more effective corrosion inhibitor as compared to the molecule that has a relatively smaller molecular size. Therefore, the effects of the molecular size and substituent on the inhibition efficiency for a specified class of organic compounds differ from case to case. Nevertheless, in most of the previous reports, it is observed that the presence of electron donating substituents increases the corrosion inhibition efficiency of organic compounds and the converse is true for electron withdrawing substituents.

M. Abdallah et al. ${ }^{81}$ studied the inhibition efficiency of five 5-arylazothiazole derivatives for 1018 carbon steel corrosion in $0.5 \mathrm{M} \mathrm{H}_{2} \mathrm{SO}_{4}$ using experimental methods. These compounds differed in the nature of substituents and were designated as compound $1\left(-\mathrm{NO}_{2}\right)$, compound $2(-\mathrm{Br})$, compound $3(-\mathrm{H})$, compound $4\left(-\mathrm{CH}_{3}\right)$ and compound $5\left(-\mathrm{OCH}_{3}\right)$. The results derived through weight loss study showed that, as compared to the non-substituted 5-arylazothiazole derivative (compound 3), compounds 4 and 5 having electron donating substituents showed superior corrosion inhibition efficiency and compounds 1 and 2 having electron withdrawing substituents showed inferior corrosion inhibition efficiency. The weight loss study was further supported by electrochemical studies. The order of inhibition efficiencies derived from electrochemical studies was consistent with the order of weight loss. The analysis showed that the 5-arylazothiazole derivative containing the most electron withdrawing nitro substituent (compound 1) exhibited the lowest inhibition efficiency and the 5-arylazothiazole derivative containing the most electron donating methoxy substituent (compound 5) exhibited the highest inhibition efficiency (compound 1) toward 1018 carbon steel corrosion in $0.5 \mathrm{M} \mathrm{H}_{2} \mathrm{SO}_{4}$.

The effect of the substituents on the corrosion inhibition effectiveness of organic corrosion inhibitors is also investigated in various other reports. ${ }^{15,82}$ Our research group also widely reported the effect of substituent on the corrosion inhibition effectiveness of organic compounds for mild steel in acidic hydrochloric acid solution. Findings from the literature investigation suggest that the inhibition efficiency of organic corrosion inhibitors is greatly dependent upon the nature of substituents. Therefore, it is important to notice that compounds that contain electron donating substituents would be preferred to be used as corrosion inhibitors as compared to compounds that contain electron withdrawing substituents in their molecular structures.

\subsection{Corrosion inhibitors for industrial processes}

Various industrial processes involve the utilization of highly concentrated acidic solutions. ${ }^{83-85}$ One of the most significant and widely known acidic processes is acid pickling which involves the removal of rusts and surface impurities of metal plates, wires and pipelines and metal equipment in various industrial sectors including heat exchange, heat transfer, cooling systems and boilers. Acidic solutions of hydrochloric acid, sulfuric acid, phosphoric acid, nitric acid, sulfamic acid, citric acid, and hydrofluoric acid are commonly used in acid pickling and descaling processes to remove surface metal oxide based rusts and scales. ${ }^{86}$ Because of their highly aggressive nature acidic solutions cause corrosion related failure of metallic structures during these processes. In addition, during these processes hydrogen gas is produced which can penetrate the interior of metal structures and can induce hydrogen embrittlement. ${ }^{87}$ 
Therefore, these industrial processes need the addition of some suitable chemical species called corrosion inhibitors. It is important to mention that most of the effective acid pickling based corrosion inhibitors are organic, especially heterocyclic compounds. ${ }^{87}$ The addition of corrosion inhibitors not only avoids metallic corrosion but can also extend the service duration of metallic equipment and diminish the amount of acid used.

Organic compounds, especially organic amines, quaternary ammonium salt, urea and thiourea derivatives, rosin amine, acetylenic compounds, alkaloids, Mooney alkali and so on, are widely used as corrosion inhibitors for pickling in sulfuric acid solution. ${ }^{8-90}$ On the other hand, acid pickling of various metallic alloys, especially mild steel and carbon steel, in hydrochloric acid mainly employs heterocyclic organic compounds containing $\mathrm{N}, \mathrm{O}, \mathrm{P}$ and $\mathrm{S}$ atoms. ${ }^{91-95}$ Ammonia and thiourea based organic compounds are extensively used as corrosion inhibitors for pickling in hydrochloric acid based solutions. Metal oxides and boiler scales are extremely soluble in nitric acid. Nitric acid solutions are highly oxidizing in nature and therefore a relatively lower number of corrosion inhibitor formulations have been developed for pickling in nitric acid. Nevertheless, a mixture of hydrazine $\left(\mathrm{C}_{8} \mathrm{H}_{7} \mathrm{~N}\right)$ and $\mathrm{Na}_{2} \mathrm{~S}$ or $\mathrm{NH}_{4} \mathrm{SCN}$ and a mixture of thiourea and $\mathrm{Na}_{2} \mathrm{~S}$ are extensively used as corrosion inhibitors for pickling in nitric acid. ${ }^{87}$ The pickling process in phosphoric acid solutions involves the consumption of various heterocyclic compounds including triazole, benzotriazole and urea derivatives, polyvinylpyrrolidone (PVP), sulfonated imidazoline, polyethyleneimine (PEI), etc. ${ }^{96-99}$ along with the inorganic and their mixed-formulations. Organic compounds are also used as corrosion inhibitors for pickling in other acidic solutions. These compounds become effective by adsorbing on the metallic surface using their electron rich centers called adsorption sites. It is important to mention that lower concentrations of acidic solutions are used for the descaling process, whereas highly concentrated acidic solutions are used for the acid pickling process.

Another industrial process that requires the use of highly concentrated acidic solution is oil-well acidification in the petroleum industry. ${ }^{100,101}$ In this process, a highly concentrated acidic solution of hydrochloric acid (mostly 15-28\%) is injected into the well through a metallic pipeline to enhance the flow of oil. Tubing of these highly acidic solutions causes extensive corrosion of the metallic surface during the acidization process. Therefore, some external additives known as corrosion inhibitors are added into the acidizing solution. A literature study showed that most of the previously used inhibitors for the acidization process are heterocyclic compounds containing heteroatoms, especially $\mathrm{N}$ and $\mathrm{O}$. Obviously, these compounds become effective by adsorbing on the metallic surface using their electron rich centers called adsorption centers. This type of adsorption results in the formation of a protective film which isolates the metal surface from aggressive solutions and protects from corrosive damage.

Most of the previously used industrially useful corrosion inhibitors are not environment-friendly because of their toxic nature and synthesis using toxic chemicals and solvents. However, because of the increasing ecological awareness and strict environmental regulations, the use of environment-friendly compounds as corrosion inhibitors derived through environment-friendly synthetic approaches and natural resources would be preferred. In view of this, compounds derived from amino acids are used as corrosion inhibitors for pickling, descaling and acidization processes. ${ }^{102,103}$ Organic compounds (especially heterocyclic ones) derived from one-step multicomponent reactions (MCRs) with and without MW and US irradiations can be used as environment-friendly corrosion inhibitors for these industrial processes. ${ }^{104-106}$

\section{Environment-friendly corrosion inhibitors: literature survey}

\subsection{Biopolymers as environment-friendly corrosion inhibitors}

Biopolymers are natural polymers produced by the cells of animals and plants. Because of their natural (animal and plant) origin, biopolymers are considered as environment-friendly alternatives to be used for different biological and industrial applications. Moreover, unlike synthetic polymers, biopolymers are biodegradable and non-bioaccumulative. Some of the common biopolymers are polysaccharides (starch, cellulose, chitosan, etc.), polypeptides, nucleic acids (RNA \& DNA), natural rubber, lignin, etc. Because of the increasing ecological awareness and environmental regulations, the use of environment-friendly biopolymers would be preferred. In view of this, various reports have been published describing the anticorrosive effect of biopolymers. It is important to mention that almost all kinds of biopolymers are evaluated as corrosion inhibitors; however, in the present study we described the corrosion inhibition effect of carbohydrate based polymers, especially chitosan and cellulose and their derivatives as they are the most frequently used biopolymer based corrosion inhibitors.

Chitosan is a linear polysaccharide of randomly distributed $\mathrm{N}$-acetyl-D-glucosamine and D-glucosamine connected together by a $\beta$-1,4-glycosidic linkage. ${ }^{107-109} \mathrm{~N}$-Acetyl-D-glucosamine and D-glucosamine are called acetylated and deacetylated units, respectively. ${ }^{107-109}$ Generally, the synthesis of chitosan is achieved by deacetylation of chitin as shown in Fig. 7. Chitosan possesses numerous industrial and biological applications and commercially fashioned by the partial deacetylation of chitin which is a structural constituent of the exoskeleton of crustacea (such as shrimps and crabs) and the cell walls of fungi. ${ }^{110-112}$ Commercially useful chitosan acquires a degree of deacetylation (\%DD) of 60-100 and a molecular weight of 3800-20000 Da. ${ }^{113,114}$ Polar substituents such as $-\mathrm{CH}_{2} \mathrm{OH}$ (hydroxymethyl), $-\mathrm{NHCOCH}_{3}$ (acetyl), $-\mathrm{OH}$ (hydryl), $-\mathrm{NH}_{2}$ (amine) and -O- (ether) present in the molecular structure of chitosan can effectively form bonding with the metallic surface. The anticorrosive effect of chitosan for metals and alloys is widely reported. ${ }^{115-118}$ Because of their natural origin, chitosan based corrosion inhibitors are considered as environment-friendly. ${ }^{119-121}$ Generally, chitosan modified with various organic compounds exhibits a higher corrosion inhibition efficiency than pure chitosan. 


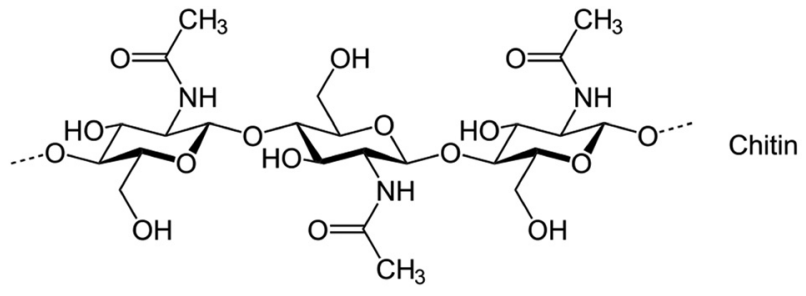

Chitin-Deacetylase

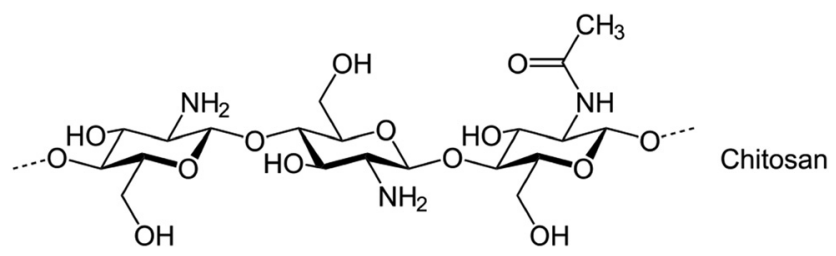

Fig. 7 Schematic illustration of the synthesis of chitosan from chitin.

Umoren et al. ${ }^{122}$ reported the corrosion inhibition effect of chitosan for $\mathrm{MS}$ in $\mathrm{HCl}$ medium using chemical, surface characterization and electrochemical methods. Studies revealed that $\mathrm{CH}$ showed reasonably good efficiencies of $96 \%$ and $93 \%$ at $60{ }^{\circ} \mathrm{C}$ and $70{ }^{\circ} \mathrm{C}$, respectively. Adsorption of $\mathrm{CH}$ followed the Langmuir adsorption isotherm model. Electrochemically it was derived that $\mathrm{CH}$ behaved as an interface- and mixed-type inhibitor for MS acidic corrosion. The anticorrosive effect of $\mathrm{CH}$ for $\mathrm{MS}$ in $1 \mathrm{M} \mathrm{HCl}$ has also been reported elsewhere. ${ }^{123}$ Generally, chitosan acts as a mixed-type corrosion inhibitor by retarding the anodic as well as cathodic half-cell reactions. Recently, our research team described the influence of the inhibition of $\mathrm{CH}$ for $\mathrm{MS}$ corrosion in sulfamic acid medium. ${ }^{124}$ Numerous experimental methods were employed to determine the inhibition efficiency of $\mathrm{CH}$ with and without potassium iodide, KI ( $5 \mathrm{ppm})$. The authors observed that at a 200 ppm concentration $\mathrm{CH}$ manifests $90 \%$ and $73.8 \%$ inhibition efficiencies with and without KI, respectively. ${ }^{124}$ In all the experimental conditions $\mathrm{CH}$ behaves as a mixed-type inhibitor. The adsorption mechanism of $\mathrm{CH}$ on the MS surface was studied by means of SEM and AFM methods. The outcomes of this study showed that the presence of KI significantly improved the corrosion inhibition effectiveness of $\mathrm{CH}$. An increase in the inhibition efficiency of organic corrosion inhibitors by the addition of other chemical species, especially salts (e.g. KI \& $\mathrm{ZnCl}_{2}$ ), is known as synergism. Synergism or the synergistic effect is widely investigated in the field of corrosion inhibition using organic compounds. $\mathrm{CH}$ is also used as a corrosion inhibitor for copper in acidic ${ }^{125}$ and $\mathrm{NaCl}^{126,127}$ electrolytes. Harmami and coworkers ${ }^{128}$ demonstrated the inhibition effect of water soluble chitosan (WSC) derived from shrimp and mussel shells for tinplate in $2 \% \mathrm{NaCl}$ medium. Protection efficiency was determined at different concentrations ranging from 10 to $1500 \mathrm{mg} \mathrm{L}^{-1}$. The weight loss and PDP methods revealed that WSC derived from shrimp shell waste showed the highest efficiencies of $72.73 \%$ and $91.41 \%$, respectively, whereas
WSC derived from mussel shells showed the highest efficiency of $54.55 \%$ at a $1300 \mathrm{mg} \mathrm{L}^{-1}$ concentration. WSC derived from shrimp and mussel shell waste acted as mixed-type inhibitors (PDP analyses).

Although chitosan shows reasonably good anticorrosive properties in salt solutions and acidic electrolytes, its anticorrosive effect and solubility in aqueous electrolytes can be further enhanced by its functionalization using several species. ${ }^{129-137}$ It is important to mention that this type of functionalization not only increases chitosan's solubility in polar electrolytes but also enhances its corrosion inhibition effectiveness by increasing the number of donor (active) sites responsible for interaction/ adsorption with the metallic surface. Generally, this type of functionalization also increases the molecular size which results in a higher protection efficiency of chitosan derivatives as compared to chitosan itself. An inhibitor molecule with a larger molecular size acts as a better corrosion inhibitor as compared to the molecule with a smaller molecular size. Table 1 presents the functionalization of chitosan and its derivatives and their use in corrosion inhibition.

Recently, various reports dealing with the anticorrosive effect of Schiff bases (SBs) derived from aromatic aldehydes and chitosan have been published. ${ }^{133}$ SBs show remarkably high solubility and protection efficiency in polar electrolytes as compared to pure chitosan. The increase in the protection effectiveness on adding organic moieties in the molecular structure of chitosan is attributed to the increased number of active centers and enhanced solubility. Haque et al. ${ }^{138}$ synthesized three chitosan based SBs (CSBs) from benzaldehyde (CSB-1), 4-(dimethylamino)benzaldehyde (CSB-2) and 4-hydroxy-3-methoxybenzaldehyde (CSB-3) and they were evaluated for their ability to prevent metallic corrosion in $1 \mathrm{M} \mathrm{HCl}$. Among the tested CSBs, CSB-3 showed the highest protection efficiency of $90.65 \%$ at a $50 \mathrm{ppm}$ concentration. SEM, EDX and FT-IR analyses were conducted to demonstrate the adsorption nature of corrosion protection. Electrochemical studies validated the mixed and interfacetype nature of the tested CSBs. DFT and MD simulation studies indicated that the CSBs interact with the metal surface in the donor-acceptor mode and acquire planar orientations on the $\mathrm{Fe}(100)$ surface. CSBs are also reported as anticorrosive materials in other studies. ${ }^{139,140}$ Most of the investigated SBs behave as mixed-type corrosion inhibitors as they adversely affect the anodic as well as cathodic Tafel reactions. Through EIS studies, it can be observed that SBs act as interface-type corrosion inhibitors as they become effective by adsorbing at the interface of metal and electrolyte.

Currently, cross-linking of chitosan with organic compounds and their relevance as corrosion inhibitors is gaining particular attention. Cross-linking of chitosan results in the joining of two or more polymeric chains (of chitosan) through an organic linker. This type of cross-linking increases the solubility as well as protection efficiency of chitosan derivatives. ${ }^{141,142}$ Recently, Chauhan and coworkers ${ }^{143}$ cross-linked chitosan with PEG (Cht-PEG) and evaluated its ability to act as a corrosion inhibitor for mild steel in $1 \mathrm{M}$ sulfamic acid. Cht-PEG showed the highest protection of $93.9 \%$ at a $200 \mathrm{mg} \mathrm{L}^{-1}$ concentration. The Cht-PEG 
Table 1 Chemical name, abbreviation, nature of adsorption, metal and electrolyte system, method of corrosion measurements, highest inhibition efficiency and optimum concentration of some chitosan derivatives evaluated as corrosion inhibitors

\begin{tabular}{|c|c|c|c|c|c|c|}
\hline $\begin{array}{l}\text { S. } \\
\text { no. }\end{array}$ & $\begin{array}{l}\text { Moiety attached from chitosan \& } \\
\text { abbreviation }\end{array}$ & Nature of adsorption & Electrolyte and metal & $\begin{array}{l}\text { Method of corrosion } \\
\text { monitoring }\end{array}$ & IE\% and conc. & Ref. \\
\hline 1 & $\begin{array}{l}\text { Chitosan-cinnamaldehyde } \\
\text { (Cinn-Cht) }\end{array}$ & $\begin{array}{l}\text { Langmuir isotherm \& } \\
\text { mixed-type inhibitor }\end{array}$ & $15 \% \mathrm{HCl} /$ carbon steel & $\begin{array}{l}\text { WL, EIS, PDP, SEM, } \\
\text { DFT and MCS }\end{array}$ & $\begin{array}{l}87.72 \% \text { at } 600 \mathrm{ppm} \mathrm{\&} \\
92.67 \% \text { at } 600 \mathrm{ppm}+ \\
10 \mathrm{mM} \mathrm{KI}\end{array}$ & 134 \\
\hline 2 & $\begin{array}{l}\text { Carboxymethyl-chitosan- } \\
\text { benzaldehyde (CMChi-B) \& } \\
\text { carboxymethyl-chitosan- } \\
\text { urea-glutaric acid (CMChi-UGLU) }\end{array}$ & - & $\begin{array}{l}2 \% \mathrm{NaCl} \text { and } 1-3 \mathrm{M} \\
\mathrm{HCl} / \mathrm{steel}\end{array}$ & $\begin{array}{l}\text { Fluidization } \\
\text { techniques }\end{array}$ & $\begin{array}{l}\text { CMChi-B }(80.82 \%)> \\
\text { CMChi-UGLU }(80.62 \%)\end{array}$ & 133 \\
\hline 3 & $\begin{array}{l}\text { CH-Benzaldehyde (CSB-1), CH-4 } \\
\text { (dimethylamino)benzaldehyde } \\
\text { (CSB-2) \& 4-hydroxy-3-methoxy } \\
\text { benzaldehyde (CSB-3) }\end{array}$ & $\begin{array}{l}\text { Langmuir isotherm \& } \\
\text { slight cathodic-type } \\
\text { inhibitor }\end{array}$ & $1 \mathrm{M} \mathrm{HCl} / \mathrm{mild}$ steel & $\begin{array}{l}\text { WL, EIS, PDP, SEM, } \\
\text { EDX, FT-IR, DFT } \\
\text { and MDS }\end{array}$ & $\begin{array}{l}\text { CSB-3 }(91.43 \%)>\text { CSB-2 } \\
(89.87 \%) \text { CSB-1 }(88.63 \%) \\
\text { at } 100 \mathrm{ppm}\end{array}$ & 138 \\
\hline 4 & Chitosan-vanillin (Van-Cht) & $\begin{array}{l}\text { Langmuir isotherm \& } \\
\text { mixed-type inhibitor }\end{array}$ & $15 \% \mathrm{HCl} /$ carbon steel & $\begin{array}{l}\text { WL, EIS, EFM, PDP, } \\
\text { SEM, FT-IR and DFT }\end{array}$ & $92.72 \%$ at $500 \mathrm{mg} \mathrm{L}^{-1}$ & 139 \\
\hline 5 & Chitosan-salicylaldehyde (CHSA) & $\begin{array}{l}\text { Temkin adsorption } \\
\text { isotherm/mixed-type } \\
\text { inhibitor }\end{array}$ & $1 \mathrm{M} \mathrm{HCl} / \mathrm{mild}$ steel & $\begin{array}{l}\text { WL, EIS, PDP, EDX } \\
\text { and SEM }\end{array}$ & $70.08 \%$ at $1500 \mathrm{ppm}$ & 140 \\
\hline 6 & $\begin{array}{l}\text { Chitosan-thiosemicarbazide } \\
\text { (TSFCS) \& chitosan- } \\
\text { thiocarbohydrazide (TCFCS) }\end{array}$ & Mixed-type inhibitors & $\begin{array}{l}2 \% \text { Acetic acid/ } \\
304 \text { steel }\end{array}$ & PDP & TCFCS $(92 \%)$ at $60 \mathrm{mg} \mathrm{L}^{-1}$ & 141 \\
\hline 7 & $\begin{array}{l}\text { Chitosan-poly(vinyl butyral) } \\
\text { (PVB-Ch) }\end{array}$ & - & $\begin{array}{l}0.3 \mathrm{M} \text { salt solution/ } \\
\text { carbon steel }\end{array}$ & $\begin{array}{l}\text { EIS, PDP, SEM, EDX } \\
\text { and Raman } \\
\text { spectroscopy }\end{array}$ & - & 142 \\
\hline 8 & $\begin{array}{l}\text { Chitosan-polyethylene glycol } \\
\text { (Cht-PEG) }\end{array}$ & $\begin{array}{l}\text { Langmuir isotherm \& } \\
\text { slight cathodic-type } \\
\text { inhibitor }\end{array}$ & $\begin{array}{l}1 \mathrm{M} \text { sulfamic acid/ } \\
\text { mild steel }\end{array}$ & $\begin{array}{l}\text { WL, EIS, PDP, SEM, } \\
\text { FT-IR and DFT }\end{array}$ & $93.9 \%$ at $200 \mathrm{ppm}$ & 143 \\
\hline 9 & $\begin{array}{l}\text { Chitosan-polyethylene glycol } \\
\text { (CS-PEG) }\end{array}$ & $\begin{array}{l}\text { Langmuir isotherm \& } \\
\text { slight cathodic-type } \\
\text { inhibitor }\end{array}$ & $1 \mathrm{M} \mathrm{HCl} /$ mild steel & $\begin{array}{l}\text { WL, EIS, PDP, AFM } \\
\text { and DFT }\end{array}$ & $93.9 \%$ at $200 \mathrm{mg} \mathrm{L}^{-1}$ & 145 \\
\hline 10 & Chitosan-polyaniline (PANI/CTS) & Mixed-type inhibitor & $0.5 \mathrm{M} \mathrm{HCl} / \mathrm{Q} 235$ steel & $\begin{array}{l}\text { EIS, PDP, SEM and } \\
\text { DFT }\end{array}$ & $79.02 \%$ at $200 \mathrm{ppm}$ & 146 \\
\hline 11 & $\begin{array}{l}\text { Chitosan-methyl acrylate- } \\
\text { ethylene diamine (CS-MAA-EN) \& } \\
\text { chitosan-methyl acrylate- } \\
\text { triethylene tetramine (CS-MAA-TN) }\end{array}$ & - & $5 \% \mathrm{HCl} /$ carbon steel & $\begin{array}{l}\text { WL, EIS, PDP and } \\
\text { SEM }\end{array}$ & $\begin{array}{l}\text { CS-MAA-EN }(88.06 \%)> \\
\text { CS }(84.22 \%)>\text { CS-MAA-TN } \\
(69.46 \%) \text { at } 0.3 \%\end{array}$ & 135 \\
\hline 12 & $\begin{array}{l}\text { Chitosan-polyaspartic acid } \\
\text { (PASP/CS) }\end{array}$ & Anodic-type inhibitor & $\begin{array}{l}3.5 \% \mathrm{NaCl} / \\
\text { carbon steel }\end{array}$ & $\begin{array}{l}\text { WL, EIS, PDP and } \\
\text { SEM }\end{array}$ & $87.56 \%$ at $20 \mathrm{ppm}$ & 136 \\
\hline 13 & Carboxymethyl chitosan (CMC) & $\begin{array}{l}\text { Langmuir adsorption } \\
\text { isotherm/mixed-type } \\
\text { inhibitor }\end{array}$ & $\begin{array}{l}3.5 \% \mathrm{NaCl} / 1020 \\
\text { carbon steel }\end{array}$ & PDP, EIS & $85.57 \%$ at $80 \mathrm{ppm}$ & 137 \\
\hline
\end{tabular}

adsorption obeyed the Langmuir adsorption isotherm model. The polarization study validated the mixed and slightly cathodic dominance behavior of Cht-PEG. Cht-PEG interacts with the MS surface using the donor-acceptor mechanism. Recently, our research team reported the cross-linking of chitosan with thiocarbohydrazide (TC-Cht) and tested it as an anticorrosive material for stainless steel in $3.5 \% \mathrm{NaCl}$ medium. ${ }^{144}$ TC-Cht showed more than $94 \%$ efficiency at a $500 \mathrm{mg} \mathrm{L}^{-1}$ concentration. Similar to Cht-PEG, TC-Cht adsorption obeyed the Langmuir isotherm model and exhibited slightly cathodic behavior. SEM and EDX studies were performed to demonstrate the adsorption nature of corrosion protection.

The above chitosan based composite materials are also used extensively as corrosion inhibitors for different metals and alloys in various electrolytes. It is important to mention that these formulations exhibit superior anticorrosive properties to pure chitosan. Kong et al. synthesized a chitosan-polyaniline (PANI/ CTS) and tested its anticorrosive effect for Q235 steel in acidic medium. ${ }^{146}$ Electrochemical studies demonstrate that PANI/CTS manifests a mixed-type nature. Interactions of PANI/CTS with the Q235 steel surface take place through the donor-acceptor mode.
SEM studies suggested that PANI/CTS adsorbs on the Q235 steel surface and improves the surface morphology of the inhibited metal specimen. Fig. 8 shows the SEM images of the Q235 steel surface after $2 \mathrm{~h}$ corrosion in $0.5 \mathrm{M} \mathrm{HCl}$. It can be clearly seen that PANI/CTS remarkably smoothened the surface morphology of Q235 steel. This observation suggests that PANI/CTS forms an inhibitive film through adsorption on the Q235 steel surface. Other chitosan based composites such as chitosan-Zn nanoparticles, ${ }^{147-150}$ chitosan-Ag nanoparticles, ${ }^{151,152}$ chitosan-Cu, Ni, Au, and $\mathrm{F}^{153-155}$ chitosan/TiO ${ }_{2},{ }^{156-158}$ chitosan-hydroxyapatite, ${ }^{159-163}$ chitosanpolyamines, ${ }^{135}$ chitosan-drug, ${ }^{164}$ chitosan-polymer, ${ }^{142,146,165,166}$ chitosan-boron nitrile, ${ }^{167}$ chitosan-nanocomposites, ${ }^{168-170}$ carboxymethyl chitosan grafted poly(2-methyl-1-vinylimidazole), ${ }^{171,172}$ sulfonated chitosan, ${ }^{173,174}$ chitosan-polymer blends, ${ }^{142,175}$ etc. are also widely used as anticorrosive materials. Generally, the above chitosan based formulations showed a higher protection efficiency as compared to pure chitosan. Therefore, it is recommended that in future studies, instead of using pure chitosan, its derivatives would be preferred. Obviously, these compounds become effective by adsorbing on the metallic surface following the Langmuir adsorption isotherm model. Using potentiodynamic 

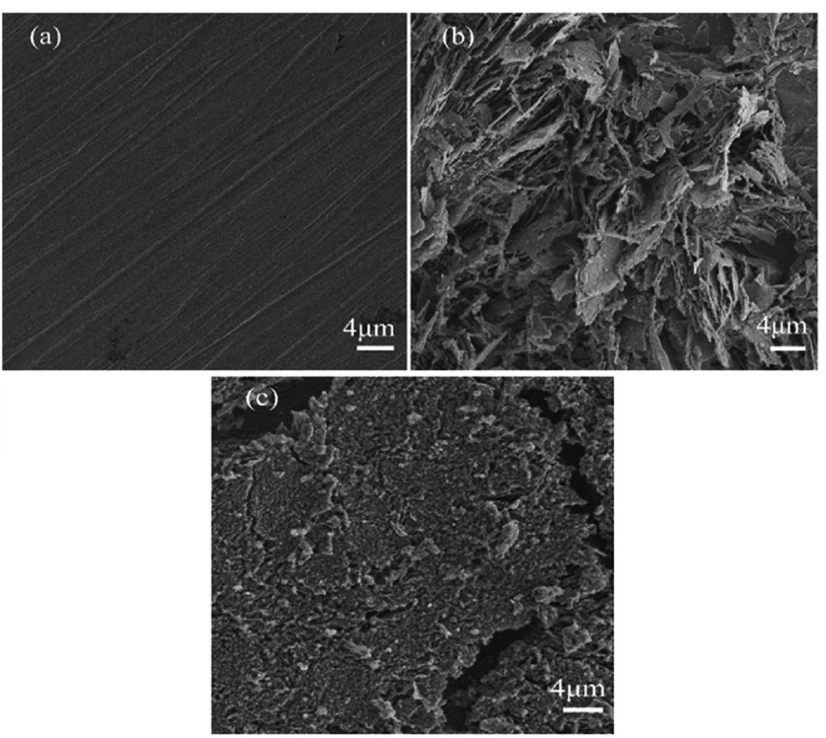

Fig. 8 SEM micrographs of Q235 steel (a) before and (b) after $2 \mathrm{~h}$ corrosion in $0.5 \mathrm{M} \mathrm{HCl}$ without PANI/CTS and (c) after $2 \mathrm{~h}$ corrosion in $0.5 \mathrm{M} \mathrm{HCl}$ with PANI/CTS. ${ }^{146}$

polarization studies, it can be observed that most of the chitosan based formulations act as mixed-type corrosion inhibitors as they become effective by retarding both anodic as well as cathodic Tafel (polarization) reactions.

Cellulose is another biologically and industrially useful carbohydrate based polymer. It is a linear chain polysaccharide composed of D-glucose units joined together by a $\beta \rightarrow 1-4$ glycosidic linkage. ${ }^{176,177}$ Cellulose has the general formula of $\left(\mathrm{C}_{5} \mathrm{H}_{10} \mathrm{O}_{5}\right)_{n}$ and it is a structural component of plant cell walls, algae and oomycetes. Cellulose is one of the most plentiful polymers on the earth and around $90 \%, 40-5 \%$ and $57 \%$ of cellulose is present in cotton, wood and hemp, respectively. ${ }^{178-181}$ Cellulose is widely used for various industrial and biological applications. However, its use as an anticorrosive material is scarce because of its limited solubility in most of the polar electrolytes. However, its derivatives are widely used either as corrosion inhibitors in aqueous electrolytes or as coating phase inhibitors. ${ }^{182}$ Similar to other polysaccharides, cellulose and its derivatives can be regarded as environment-friendly alternatives to be used as corrosion inhibitors. The environment-friendly nature of cellulose and its derivatives is attributed to their biological origin and/or properties of biodegradation and nonbioaccumulation. Derivatization of cellulose has been widely reported; however, carboxymethyl cellulose (CMC) and hydroxymethyl cellulose (HEC) are most frequently utilized as corrosion inhibitors. Table 2 presents a summary of cellulose derivatives used as corrosion inhibitors. ${ }^{183-199}$ Umoren et al. ${ }^{183}$ reported the inhibition effect of CMC for MS corrosion in $2 \mathrm{M} \mathrm{H}_{2} \mathrm{SO}_{4}$ using weight loss (WL) and hydrogen evolution (HE) methods. The results showed that the adsorption of CMC obeyed the Langmuir adsorption isotherm model. The protection efficiency of CMC was measured at different temperatures in the absence and presence of $\mathrm{KCl}, \mathrm{KBr}$ and $\mathrm{KI}(5 \mathrm{mM})$. Studies showed that significant improvement in the inhibition effectiveness was observed in the presence of halide salts, except in the case of $\mathrm{KCl}$. The inhibition efficiency of CMC with halide salts followed the order: KI > $\mathrm{KBr}>\mathrm{KCl}$. CMC $\left(0.5 \mathrm{~g} \mathrm{~L}^{-1}\right), \mathrm{CMC}+\mathrm{KCl}(5 \mathrm{mM}), \mathrm{CMC}+\mathrm{KBr}$ (5 $\mathrm{mM})$ and $\mathrm{CMC}+\mathrm{KI}(5 \mathrm{mM})$ showed protection effectiveness of $56 \%, 48 \%, 63 \%$ and $85 \%$, respectively.

The same group of authors reported the synthesis, characterization and corrosion inhibition effectiveness of the CMC and $\mathrm{Ag}$ nanoparticle (AgNP) composite (CMC/AgNPs) for St37 steel in $15 \% \mathrm{H}_{2} \mathrm{SO}_{4}$ using chemical, electrochemical and surface morphological measurements. ${ }^{184}$ The results showed that CMC/ AgNPs inhibited corrosion by adsorption and its adsorption was reinforced by SEM, EDX, AFM and FT-IR methods. The SEM study showed that the surface morphology of the metal is improved significantly in the presence of CMC/AgNPs which validated the adsorption mechanism of corrosion inhibitors. This observation was further supported by the change in elemental composition in the EDX spectra of St37 steel recorded with and without CMC/AgNPs after $25 \mathrm{~h}$ immersion. The SEM and EDX spectra of the St37 surface after $25 \mathrm{~h}$ immersion in $15 \% \mathrm{H}_{2} \mathrm{SO}_{4}$ with and without CMC/AgNPs are shown in Fig. 9. The corrosion inhibition properties of cellulose derivatives are also extensively reported in other studies for carbon and mild steel in acidic ${ }^{4,6,13,14}$ and $\mathrm{NaCl}^{3,14}$ electrolytes. They are also used as corrosion inhibitors for aluminum ${ }^{7,8,11,12,15,18}$ and copper. ${ }^{5,10,16}$ The synergistic effect of halide ions on the anticorrosive effect of cellulose derivatives for aluminum is also studied widely. ${ }^{8,11}$

Starch, consisting of linear amylose and branched-chain amylopectin, is also used as an effective corrosion inhibitor for metals and alloys. However, because of its limited solubility, its application in corrosion inhibition is limited. Therefore, chemically and physically modified starch is widely employed as a corrosion inhibitor for metals. Brindha et $a l^{200}$ demonstrated the anticorrosive properties of starch modified with 2,6-diphenyl3-methylpiperidin-4-one (DPMP) for mild steel in acidic medium. Several chemical and electrochemical methods were employed and it was observed that the protection efficiency of modified starch was dependent on immersion time and temperature. The protection effectiveness of starch modified with sodium dodecyl sulfate (DS) and cetyltrimethylammonium bromide (CMAB) was reported using chemical and electrochemical techniques. ${ }^{201}$ Later on, several other studies dealing with the anticorrosive effect of starch, ${ }^{202-204}$ pectin, ${ }^{205-210}$ dextrin \& cyclodextrin, ${ }^{13,211-215}$ pectate $^{216,217}$ alginates ${ }^{218,219}$ and exudate gums ${ }^{220-225}$ are reported for metals and alloys in different electrolytes. The synergistic effect of halide ions is also reported for different classes of biopolymers. $^{226-229}$ Similar to chitosan, cellulose and their derivatives, these polymeric carbohydrates also behave as mixedtype corrosion inhibitors. They become effective by retarding the anodic and cathodic Tafel polarization reactions.

\subsection{Plant extracts as environment-friendly corrosion inhibitors}

Recently, the use of plant based materials is gaining particular attention because of their environmentally benign nature. Because of the natural and biological origin, plant based materials including 
Table 2 Chemical name, abbreviation, nature of adsorption, metal and electrolyte system, method of corrosion measurements, highest inhibition efficiency and optimum concentration of some cellulose derivatives evaluated as corrosion inhibitors

\begin{tabular}{|c|c|c|c|c|c|c|}
\hline $\begin{array}{l}\text { S. } \\
\text { no. }\end{array}$ & $\begin{array}{l}\text { Moiety attached from chitosan } \\
\text { \& abbreviation }\end{array}$ & Nature of adsorption & Electrolyte and metal & $\begin{array}{l}\text { Method of corrosion } \\
\text { monitoring }\end{array}$ & IE\% and conc. & Ref. \\
\hline 1 & $\begin{array}{l}\text { Carboxymethyl cellulose } \\
\text { (CMC) }\end{array}$ & $\begin{array}{l}\text { Langmuir adsorption } \\
\text { isotherm }\end{array}$ & $2 \mathrm{M} \mathrm{H}_{2} \mathrm{SO}_{4} /$ mild steel & $\begin{array}{l}\text { WL and hydrogen } \\
\text { evolution }\end{array}$ & $\mathrm{CMC}\left(65 \%\right.$ at $\left.0.5 \mathrm{~g} \mathrm{~L}^{-1}\right)$ & 183 \\
\hline 2 & Hydroxyethyl cellulose (HEC) & $\begin{array}{l}\text { Langmuir isotherm \& } \\
\text { mixed-type inhibitor }\end{array}$ & $3.5 \mathrm{NaCl} / 1018 \mathrm{c}$-steel & $\begin{array}{l}\text { PDP, EIS, EFM, SEM, } \\
\text { EDX and DFT }\end{array}$ & $95.5 \%$ at $0.5 \mathrm{mM}$ & 185 \\
\hline 3 & Hydroxyethyl cellulose (HEC) & $\begin{array}{l}\text { Freundlich isotherm \& } \\
\text { mixed-type inhibitor }\end{array}$ & $0.5 \mathrm{M} \mathrm{H}_{2} \mathrm{SO}_{4} /$ mild steel & $\begin{array}{l}\text { WL, EIS, PDP, DFT and } \\
\text { MDS }\end{array}$ & $\begin{array}{l}70.35 \% \text { at } 2000 \mathrm{mg} \mathrm{L}^{-1} \\
(333 \mathrm{~K})\end{array}$ & 186 \\
\hline 4 & $\begin{array}{l}\text { Hydroxyethyl cellulose (HEC) } \\
2017\end{array}$ & $\begin{array}{l}\text { Langmuir isotherm \& } \\
\text { mixed-type inhibitor }\end{array}$ & $\begin{array}{l}1 \mathrm{M} \mathrm{HCl} / \mathrm{A} 1020 \\
\text { carbon } \\
\text { steel }\end{array}$ & $\begin{array}{l}\text { WL, PDP, EIS, SEM, } \\
\text { EDX, AFM and DFT }\end{array}$ & $91.62 \%$ at $500 \mathrm{ppm}$ & 187 \\
\hline 5 & $\begin{array}{l}\text { Ethyl hydroxyethyl cellulose } \\
\text { (EHEC) }\end{array}$ & $\begin{array}{l}\text { Langmuir isotherm \& } \\
\text { slightly cathodic-type } \\
\text { inhibitor }\end{array}$ & $1 \mathrm{M} \mathrm{H}_{2} \mathrm{SO}_{4} /$ mild steel & WL, EIS, PDP and DFT & $\begin{array}{l}68.19 \%(\text { EHEC) and } 91.05 \% \\
\left(\text { EHEC + KI) at } 2.5 \mathrm{~g} \mathrm{~L}^{-1}\right.\end{array}$ & 188 \\
\hline 6 & Hydroxyethyl cellulose (HEC) & $\begin{array}{l}\text { Langmuir isotherm \& } \\
\text { mixed-type inhibitor }\end{array}$ & $\begin{array}{l}2 \% \mathrm{NH}_{4} \mathrm{Cl} \text {, zinc- } \\
\text { carbon battery }\end{array}$ & $\begin{array}{l}\text { PDP, EIS, SEM and } \\
\text { FT-IR }\end{array}$ & $92.07 \%$ at $300 \mathrm{ppm}$ & 189 \\
\hline 7 & Hydroxypropyl cellulose (HPC) & $\begin{array}{l}\text { Langmuir isotherm \& } \\
\text { mixed-type inhibitor }\end{array}$ & $\begin{array}{l}0.5 \mathrm{M} \mathrm{HCl} \text { and } 2 \mathrm{M} \\
\mathrm{H}_{2} \mathrm{SO}_{4} / \text { aluminum }\end{array}$ & WL, PDP and DFT & $\begin{array}{l}92.54 \%\left(\mathrm{H}_{2} \mathrm{SO}_{4}\right) \& 80.33 \% \\
(\mathrm{HCl}) \text { at } 5 \mathrm{~g} \mathrm{~L}^{-1}\end{array}$ & 190 \\
\hline 8 & $\begin{array}{l}\text { Hydroxyethyl cellulose (HEC) \& } \\
\text { hydroxypropyl methylcellulose } \\
\text { (HPMC) }\end{array}$ & $\begin{array}{l}\text { Slightly cathodic-type } \\
\text { inhibitors }\end{array}$ & $1 \mathrm{M} \mathrm{HCl} /$ aluminum & WL, PDP, EIS and DFT & $\begin{array}{l}\text { HEC }(83.25 \%) \text { and HPMC } \\
(84.68 \%) \text { at } 2000 \mathrm{mg} \mathrm{L}^{-1} \\
(1 \text { day })\end{array}$ & 191 \\
\hline 9 & Hydroxyethyl cellulose (HEC) & $\begin{array}{l}\text { Langmuir isotherm \& } \\
\text { mixed-type inhibitor }\end{array}$ & $\begin{array}{l}0.5 \mathrm{M} \mathrm{H}_{2} \mathrm{SO}_{4} / \text { mild } \\
\text { steel \& aluminum }\end{array}$ & $\begin{array}{l}\text { WL, EIS, PDP, DFT and } \\
\text { MDS }\end{array}$ & $\begin{array}{l}93.61 \%(\text { mild steel) } 64.18 \% \\
\text { (Al) at } 2000 \mathrm{mg} \mathrm{L}^{-1}\end{array}$ & 192 \\
\hline 10 & Cellulose acetate & - & $\begin{array}{l}0.5,1,2 \& 3 \mathrm{M} \\
\mathrm{HCl} / \text { aluminum }\end{array}$ & WL and SEM & $55.71 \%$ & 193 \\
\hline 11 & $\begin{array}{l}\text { Sodium carboxymethyl } \\
\text { cellulose (Na-CMC) } 2020\end{array}$ & $\begin{array}{l}\text { Freundlich adsorption } \\
\text { isotherm }\end{array}$ & $1 \mathrm{M} \mathrm{HCl} /$ aluminum & WL & $86.0 \%$ at $1 \mathrm{~g} \mathrm{~L}^{-1}\left(\right.$ at $\left.35^{\circ} \mathrm{C}\right)$ & 194 \\
\hline 12 & Hydroxyethyl cellulose (HEC) & & $\begin{array}{l}0.5 \mathrm{M} \mathrm{HCl} / \text { mild } \\
\text { steel \& aluminum }\end{array}$ & WL & $67.94 \%$ at $2.5 \times 10^{-3} \mathrm{M}$ & 195 \\
\hline 13 & $\begin{array}{l}\text { Carboxymethyl cellulose/AgNPs } \\
\text { composite (CMC/AgNPs) }\end{array}$ & $\begin{array}{l}\text { Langmuir isotherm \& } \\
\text { mixed-type inhibitor }\end{array}$ & $15 \% \mathrm{H}_{2} \mathrm{SO}_{4} / \mathrm{St} 37$ steel & $\begin{array}{l}\text { WL, EIS, PDP, SEM, } \\
\text { EDX, AFM and FT-IR }\end{array}$ & $\begin{array}{l}96.37 \% \text { at } 1000 \mathrm{ppm} \\
\left(\text { at } 60{ }^{\circ} \mathrm{C}\right)\end{array}$ & 184 \\
\hline 14 & $\begin{array}{l}\text { Chitosan (CH) and carbox- } \\
\text { ymethyl cellulose (CMC) }\end{array}$ & $\begin{array}{l}\text { Langmuir isotherm \& } \\
\text { mixed-type inhibitors }\end{array}$ & $\begin{array}{l}3.5 \% \mathrm{NaCl}+\mathrm{CO}_{2} / \mathrm{API} \\
5 \mathrm{~L} \text { X60 pipeline steel }\end{array}$ & EIS, PDP and SEM & $\begin{array}{l}88 \% \text { (Commercial inh.), } 45 \% \\
\text { (CH) and } 39 \%(\mathrm{CMC}) \text { at } \\
100 \mathrm{ppm}\end{array}$ & 196 \\
\hline 15 & Hydroxyethyl cellulose (HEC) & Mixed-type inhibitor & $\begin{array}{l}1 \mathrm{M} \mathrm{HCl} \text { and } 0.5 \mathrm{M} \\
\mathrm{H}_{2} \mathrm{SO}_{4} / \text { copper }\end{array}$ & $\begin{array}{l}\text { WL, EIS, PDP, DFT and } \\
\text { MDS }\end{array}$ & $95 \%$ at $2000 \mathrm{mg} \mathrm{L}^{-1}$ & 197 \\
\hline 16 & $\begin{array}{l}\text { Sodium carboxymethyl } \\
\text { cellulose (Na-CMC) }\end{array}$ & $\begin{array}{l}\text { Langmuir isotherm \& } \\
\text { slightly cathodic-type } \\
\text { inhibitor }\end{array}$ & $\begin{array}{l}\text { Simulated water } \\
(\mathrm{NaCl}) / \text { copper }\end{array}$ & $\begin{array}{l}\text { PDP, EIS, AFM, FT-IR, } \\
\text { DFT and MDS }\end{array}$ & $83.34 \%$ at $5 \mathrm{mg} \mathrm{L}^{-1}\left(\right.$ at $\left.20^{\circ} \mathrm{C}\right)$ & 198 \\
\hline 17 & NEC, NMCC \& NCMC & Mixed-type inhibitors & $3.5 \% \mathrm{NaCl} /$ copper & PDP, EIS, SEM and EDX & $\begin{array}{l}94.7 \%(\mathrm{NEC}), 33.2 \%(\mathrm{NMCC}) \& \\
83.4 \% \text { (NCMC) at } 100 \mathrm{ppm}\end{array}$ & 199 \\
\hline
\end{tabular}

plant extracts are environment-friendly alternatives to be used as metallic corrosion inhibitors for different biological and industrial applications. ${ }^{230-234}$ Generally, each plant extract contains several complex phytochemicals containing several electron rich centers that can act as adsorption centers during metal-inhibitor interactions. $^{230,235-237}$ The electron rich centers include polar functional groups such as hydroxyl $(-\mathrm{OH})$, amino $\left(-\mathrm{NH}_{2}\right)$, ester $\left(-\mathrm{COOC}_{2} \mathrm{H}_{5}\right)$, amide $\left(-\mathrm{CONH}_{2}\right)$, acid chloride $(-\mathrm{COCl})$, dimethyl amino $\left(-\mathrm{NMe}_{2}\right)$, methoxy (-OMe), ether $(-\mathrm{O}-)$, etc. and multiple bonds such as $>\mathrm{C}=\mathrm{C}<,>\mathrm{C}=\mathrm{N}-,>\mathrm{C}=\mathrm{O},-\mathrm{N}=\mathrm{O},-\mathrm{C} \equiv \mathrm{C}-$, $-\mathrm{C} \equiv \mathrm{N},-\mathrm{N}=\mathrm{N}-$, etc.

Although most of the phytochemicals are complex molecules, they are readily soluble in polar electrolytes because of their association with high peripheral functionalities in the form of polar functional groups. Plant extracts are extensively used as environment-friendly corrosion inhibitors for different metals and alloys in different electrolytic systems. The protection efficiency of extracts that have a relatively lower protection efficiency against metallic corrosion can be further enhanced by using inorganic salts such as KI that affect inhibition protectiveness through synergism. ${ }^{238-240}$ Because of their huge availability at the cost-effective and commercial level, the development and consumption of plant extracts are increasing day by day. Extracts of several parts of plants such as leaves, barks, fruits, peels, flowers, etc. are widely used as corrosion inhibitors. ${ }^{241}$ Generally, extracts of plants are prepared in a biphasic system consisting of an organic and an aqueous phase. A schematic illustration of the preparation of extracts is shown in Fig. 10. Before application, the prepared plant extracts should be stored in a refrigerator at low temperature. Table 1 presents a summary of some major works on extracts as corrosion inhibitors.

Among the different parts of plants, the extracts of leaves are most commonly tested as they showed the highest protection efficiency. In most of the plants, the synthesis of phytochemicals mostly takes place in leaves and therefore leaves are the part of plants that are richest in phytochemicals.

Similar to organic corrosion inhibitors, phytochemicals are generally rich in electron donor sites called active or adsorption sites. These electron rich sites of phytochemicals include polar functional groups and multiple bonds. Using these electron rich sites, phytochemicals form strong bonding with the metallic surface, especially through coordination bonding, and behave as 

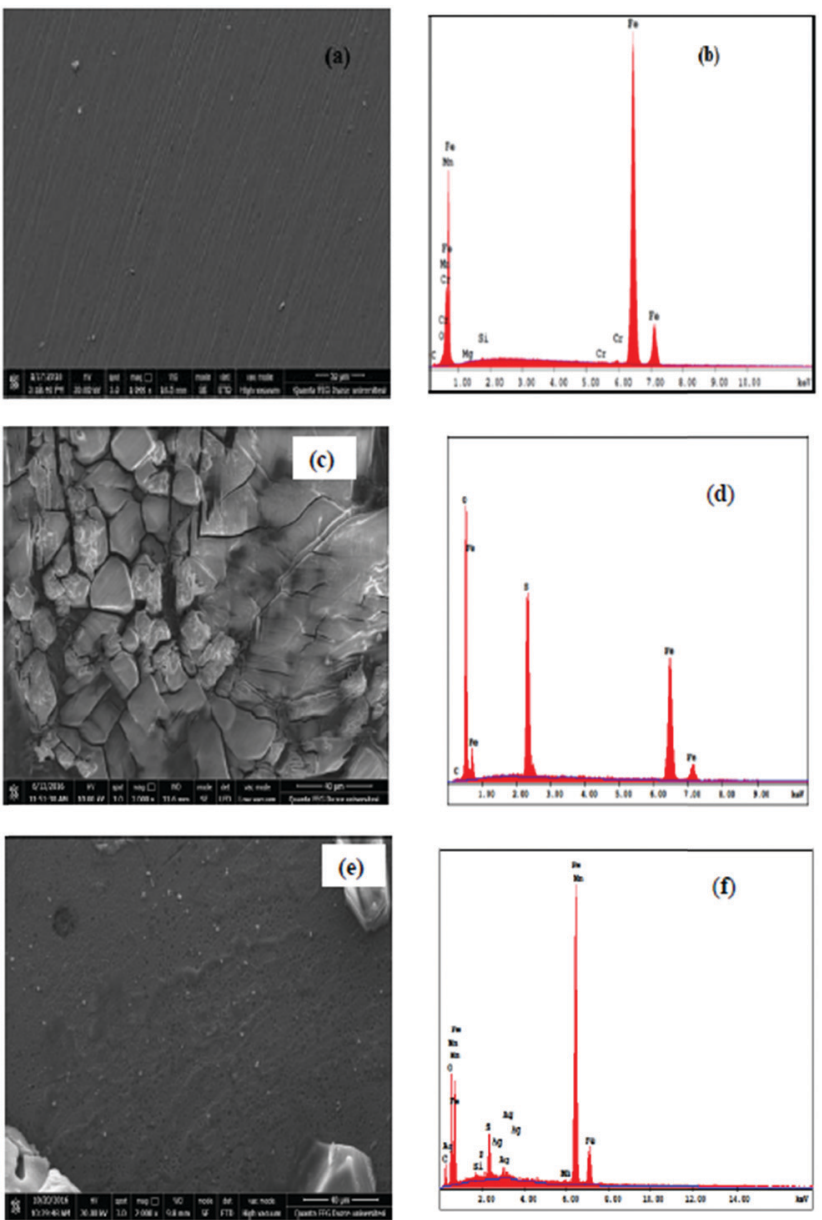

Fig. 9 SEM and EDX spectra of (a and b) abraded St37 surface, (c and d) corroded St37 surface in $15 \% \mathrm{H}_{2} \mathrm{SO}_{4}$ without CMC/AgNPs for $25 \mathrm{~h}$ at $25^{\circ} \mathrm{C}$ and (e and f) corroded St37 surface in $15 \% \mathrm{H}_{2} \mathrm{SO}_{4}$ with $1000 \mathrm{ppm}$ of $\mathrm{CMC} /$ AgNPs for $25 \mathrm{~h}$ at $25{ }^{\circ} \mathrm{C}$. The morphology of the St37 steel surface is significantly improved in the presence of CMC/AgNPs. ${ }^{184}$

strong ligands. Table 3 presents a collection of major leaf extracts evaluated as corrosion inhibitors. Mehdipour et al. ${ }^{242}$ reported the corrosion inhibition effect of aloe vera leaf extract as an effective corrosion inhibitor for stainless steel in sulfuric acid medium using electrochemical impedance spectroscopy (EIS), potentiodynamic polarization and scanning electron microscopy (SEM). The polarization study revealed that the extract retards both anodic and cathodic reactions and behaves as a mixed-type corrosion inhibitor. However, the authors observed slight anodic predominance. EIS studies showed that the extract becomes effective by controlling the charge transfer process. This finding suggested that the extract acted as an interface-type corrosion inhibitor as it becomes effective by adsorbing at the interface of the metal and electrolyte. The SEM analysis showed that, in the absence of the extract, the metallic surface was extremely damaged because of the unrestricted acidic attack. However, in the presence of the extract, the metallic surface became smooth and was protected significantly. This observation suggested that the phytochemicals present in the extract adsorbed and formed a corrosion protective film over the metallic surface. A similar finding has also been reported using plant extracts as corrosion inhibitors for metals and alloys in various electrolytes (Table 3).

\subsection{Chemical medicines as environment-friendly alternatives}

Chemical medicines or drugs represent another class of environment-friendly alternatives to the traditional toxic corrosion inhibitors. Several reports dealing with the inhibition effect of drugs have been published. ${ }^{318-321}$ Chemical medicines are ideal environment-friendly alternatives as they are derived from biological and natural resources. Further, most of the drugs are bio-tolerable, bio-compatible and non-bioaccumulative in nature and therefore they offer environmentally sustainable alternatives. ${ }^{322,323}$ Generally, drugs are complex molecules with several electron rich centers in the way of polar functional groups and multiple bonds through which they acquire a high anticorrosion ability. Because of their macromolecular nature, most of the drugs provide a large surface coverage and a high protection efficiency. Possessing numerous polar functional groups along with enhanced protection efficiency, they synergize the solubility of drug molecules in polar electrolytes. In view of their high efficiency, high solubility in polar electrolytes and environmental sustainability, numerous classes of drug molecules are evaluated as effective corrosion inhibitors for numerous metals and alloys in versatile electrolytes. Although the use of chemical medicines is an environmentally sustainable alternative method of corrosion inhibition, most of the drug molecules are highly expensive. Their high cost is associated with their multistep synthesis and ultra-purification processes. In view of this, corrosion scientists have started to use expired drugs as corrosion inhibitors. ${ }^{324,325}$ Most of the expired drugs are thrown out as they are useless after their expiry. Although the application of such drugs in the biological system is not possible, they can be effectively used in industries for various applications. One of the greatest uses of expired drugs is in metallic corrosion inhibition. The use of expired drugs as corrosion inhibitors represents an environment-friendly and cost-effective approach. ${ }^{325}$ Because of this, several articles and research papers have been published on expired drugs as corrosion inhibitors. ${ }^{326,327}$ Various new and expired drugs are tested as effective corrosion inhibitors for different metals and alloys in various electrolytes. A summary of some major reports on the anticorrosive effect of drug molecules is provided in Table 4. Most of the drug molecules contain highly complex structures that enable them to be effective species to act as good corrosion inhibitors. They become effective by adsorbing on the metallic surface. The adsorption of drug molecules on the metallic surface mostly followed the Langmuir adsorption isotherm model. Using potentiodynamic polarization and electrochemical impedance spectroscopy (EIS), it can be observed that drug molecules mostly behaved as mixed- and interface-type corrosion inhibitors. The adsorption of drug molecules on the metallic surface is mainly supported by SEM, AFM and FT-IR spectroscopy studies.

\subsection{Ionic liquids as environment-friendly corrosion inhibitors}

Ionic liquids are salts in a liquid (molten) state. ${ }^{358}$ Ionic liquids are composed of organic cations and inorganic anions and they 


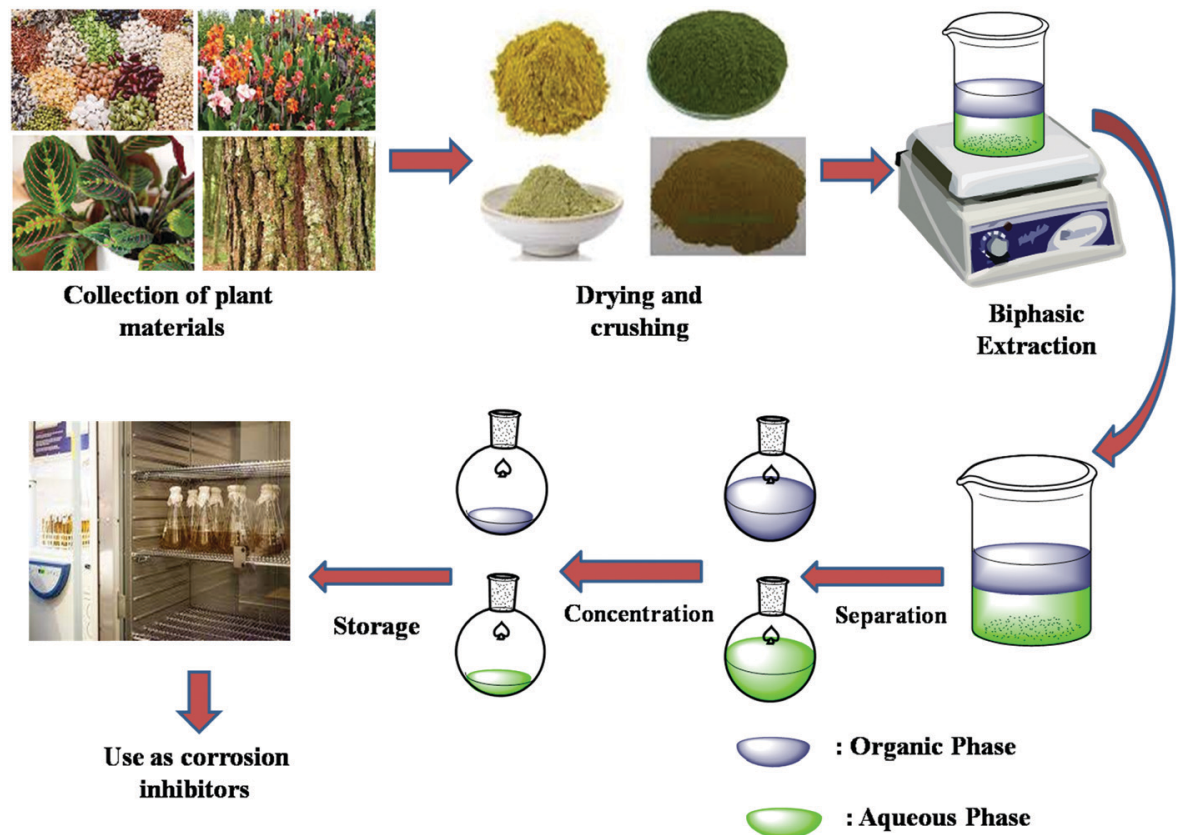

Fig. 10 Schematic illustration of the collection, drying, crushing, separation, extraction, concentration and storage of plant extracts.

are liquid at or below $100{ }^{\circ} \mathrm{C} .{ }^{359,360}$ Ionic liquids are also called ionic glasses, ionic melts, liquid fluids, ionic electrolytes or fused salts. Ethylammonium nitrate (MP: $12{ }^{\circ} \mathrm{C}$ ) was the first reported ionic liquid (in 1914). ${ }^{361,362}$ After that, several classes of ionic liquids have been developed and used for industrial and biological applications. ${ }^{363-366}$ Ionic liquids are characterized by their ability to dissolve a wide range of organic and inorganic compounds. Because of their association with several environment-friendly properties including low toxicity, low melting point, high polarity, low vapor pressure and high resistivity for thermal and chemical treatment, ionic liquids are ideal environmentally benign alternatives to the traditional corrosion inhibitors. ${ }^{57,367,368}$ Unlike traditional organic compounds, ionic liquids are readily soluble in polar electrolytes and manifest reasonably high protection effectiveness. Ionic liquids are rightly called designer corrosion inhibitors as their inhibition effect can be suitably tailored using a proper combination of cations and anions. ${ }^{9,57}$ The chemical structures of major cations and anions are presented in Fig. 11. Ionic liquids can be classified as neutral, basic, acidic, functionalized or supported type. ${ }^{369-371}$

The literature study showed that several classes of ionic liquids are used as effective corrosion inhibitors for different metals and alloys. ${ }^{57,367,372-374}$ Imidazolium based ionic liquids are most frequently used as corrosion inhibitors. ${ }^{368,375-377}$ Likhanova et $a l .{ }^{378}$ proposed that the cationic and anionic moieties of ILs differently adsorb on cathodic and anodic active sites and inhibit the corrosion. The cationic part of ionic liquids mainly adsorbs on cathodic sites and anionic moieties mainly adsorb at anodic sites. While studying the corrosion inhibition effect of three imidazolium based liquids for mild steel corrosion in $1 \mathrm{M} \mathrm{HCl}$, the authors observed that the inhibition effect was largely dependent on the nature of anions present in the investigated ionic liquids. ${ }^{379}$ Imidazolium based ionic liquids interact with the metal surface through donor-acceptor interactions and acquire planar orientations. The polarization study showed that the tested ionic liquids behaved as mixed-type corrosion inhibitors, i.e. the tested ionic liquids adversely affect the rate of cathodic and anodic Tafel reactions. Polarization curves for mild steel corrosion in $1 \mathrm{M} \mathrm{HCl}$ with and without the evaluated ionic liquids are shown in Fig. 12. The observation of Fig. 12 shows that the shapes of both anodic and cathodic curves are affected by the presence of ionic liquids which validated the finding that ionic liquids adversely affect the rate of corrosion reactions. The adsorption mechanism was reinforced using SEM and AFM studies. SEM and AFM micrographs of the mild steel surface corroded in $1 \mathrm{M} \mathrm{HCl}$ for $3 \mathrm{~h}$ are shown in Fig. 13. It can be seen from the SEM and AFM images of the black specimen that the surface of the specimen is highly corroded because of free acid attack. However, in the presence of ionic liquids, the surface morphologies of the metallic specimens are greatly improved because of their anticorrosive effect. The order of metallic surface smoothness is consistent with the order of corrosion inhibition effect of ionic liquids. The average surface roughness of non-protected metallic surface was $372 \mathrm{~nm}$. The average surface roughness in the presence of $[\mathrm{bmim}][\mathrm{Cl}]$, [bmim] $\left[\mathrm{CF}_{3} \mathrm{SO}_{3}\right]$ and [bmim] $[\mathrm{Ac}]$ 187, 134 and $114 \mathrm{~nm}$, respectively.

Table 5 presents a summary of some major reports published on the anticorrosive effect of imidazolium based ionic liquids. ${ }^{380-401}$ Several experimental and computational methods are employed to demonstrate the anticorrosive effect of imidazolium ionic liquids. It can be observed that most of the ionic liquids become effective against metallic corrosion by adsorbing on the metallic surface. Adsorption of imidazolium ionic liquids mostly follows the Langmuir adsorption isotherm; however, other adsorption isotherm mechanisms have also been reported. Adsorption of ionic 
Table 3 Chemical name and metal and electrolyte system of some plant extracts evaluated as corrosion inhibitors

\begin{tabular}{|c|c|c|c|c|c|}
\hline Plant name & System & Ref. & Plant name & System & Ref. \\
\hline \multicolumn{6}{|l|}{ Leaf extracts as corrosion inhibitors in $\mathrm{H}_{2} \mathrm{SO}_{4}$} \\
\hline Aloe vera & $\mathrm{Fe} / 1 \mathrm{M} \mathrm{H}_{2} \mathrm{SO}_{4}$ & 242 & Spondias cytherea & $\mathrm{Fe} / 5 \mathrm{M} \mathrm{H}_{2} \mathrm{SO}_{4}$ & 243 \\
\hline Citrus aurantium & $\mathrm{Fe} / 1 \mathrm{M} \mathrm{H}_{2} \mathrm{SO}_{4}$ & 244 & Combretum bracteosum & $\mathrm{Fe} / 2 \& 5 \mathrm{M} \mathrm{H}_{2} \mathrm{SO}_{4}$ & 245 \\
\hline Sida acuta (leaf and stem) & $\mathrm{Fe} / 1 \mathrm{M} \mathrm{H}_{2} \mathrm{SO}_{4}$ & 246 & Hyptis suaveolens & $\mathrm{Fe} / 1 \mathrm{M} \mathrm{H}_{2} \mathrm{SO}_{4}$ & 247 \\
\hline African parquetina & $\mathrm{Fe} / 2 \mathrm{M} \mathrm{H}_{2} \mathrm{SO}_{4}$ & 248 & Polyalthia longifolia & $\mathrm{Fe} / 1 \mathrm{M} \mathrm{H}_{2} \mathrm{SO}_{4}$ & 249 \\
\hline Emblica leaves & $\mathrm{Fe} / 2 \mathrm{M} \mathrm{H}_{2} \mathrm{SO}_{4}$ & 250 & Buddleia perfoliata & $\mathrm{Fe} / 0.5 \mathrm{M} \mathrm{H}_{2} \mathrm{SO}_{4}$ & 251 \\
\hline Cassia tora & $\mathrm{Fe} / 0.5 \mathrm{M} \mathrm{H}_{2} \mathrm{SO}_{4}$ & 252 & Bambusa glaucescens & $\mathrm{Fe} / 2 \mathrm{M} \mathrm{H}_{2} \mathrm{SO}_{4}$ & 253 \\
\hline Nicotiana tabacum & $\mathrm{Fe} / 2 \mathrm{M} \mathrm{H}_{2} \mathrm{SO}_{4}$ & 254 & Vernonia amygdalina & $\mathrm{Fe} / 1.5 \mathrm{M} \mathrm{H}_{2} \mathrm{SO}_{4}$ & 255 \\
\hline Mango (Mangifera indica) & $\mathrm{Fe} / 1 \mathrm{M} \mathrm{H}_{2} \mathrm{SO}_{4}$ & 256 & Cassava (Manihot esculenta) & $\mathrm{Fe} / 0.5 \mathrm{M} \mathrm{H}_{2} \mathrm{SO}_{4}$ & 257 \\
\hline Achyranthes aspera & $\mathrm{Fe} / 0.5 \mathrm{M} \mathrm{H}_{2} \mathrm{SO}_{4}$ & 258 & Oxystelma esculentum & $\mathrm{Fe} / 0.5 \mathrm{M} \mathrm{H}_{2} \mathrm{SO}_{4}$ & 259 \\
\hline African breadfruit & $\mathrm{Fe} / 1 \mathrm{M} \mathrm{H}_{2} \mathrm{SO}_{4}$ & 260 & Stachytarpheta indica & $\mathrm{Fe} / 1 \mathrm{M} \mathrm{H}_{2} \mathrm{SO}_{4}$ & 261 \\
\hline Jatropha curcas & $\begin{array}{l}\mathrm{Fe} / 0.5 \mathrm{M} \mathrm{H}_{2} \mathrm{SO}_{4} \\
\text { and } 0.5 \mathrm{M} \mathrm{NaCl}\end{array}$ & 262 & Sida acuta & $\mathrm{Fe} / 1 \mathrm{M} \mathrm{H}_{2} \mathrm{SO}_{4}$ & 263 \\
\hline $\begin{array}{l}\text { Wrightiatinctoria, Clerodendrumphlomidis, } \\
\text { Ipomoeatriloba } \\
\text { Leaf extracts as corrosion inhibitors in } \mathrm{HCl}\end{array}$ & $\mathrm{Fe} / 0.5 \mathrm{M} \mathrm{H}_{2} \mathrm{SO}_{4}$ & 264 & $\begin{array}{l}\text { Nauclea latifolia } \\
\text { (leaf, bark, root) }\end{array}$ & $\mathrm{Fe} / 1 \mathrm{M} \mathrm{H}_{2} \mathrm{SO}_{4}$ & 265 \\
\hline Olea europaea & $\mathrm{Fe} / 2 \mathrm{M} \mathrm{HCl}$ & 266 & Azadirachta excelsa & $\mathrm{Fe} / 1 \mathrm{M} \mathrm{HCl}$ & 267 \\
\hline Tabernaemontana divaricata & $\mathrm{Fe} / 1 \mathrm{M} \mathrm{HCl}$ & 268 & Boscia senegalensis & $\mathrm{Fe} / 1 \mathrm{M} \mathrm{HCl}$ & 269 \\
\hline Phyllanthus amarus & $\mathrm{Fe} / 1 \mathrm{M} \mathrm{HCl}$ & 270 & Acalypha indica & $\mathrm{Fe} / 1 \mathrm{M} \mathrm{HCl}$ & 271 \\
\hline Eleusine aegyptiaca and Croton rottlerin & $\mathrm{Fe} / 1 \mathrm{M} \mathrm{HCl}$ & 272 & Phoenix dactylifera & $\mathrm{Fe} / 1 \mathrm{M} \mathrm{HCl}$ & 273 \\
\hline Pimenta dioica & $\begin{array}{l}\mathrm{Fe} / 0.5 \mathrm{M} \text { and } \\
1.0 \mathrm{M} \mathrm{HCl}\end{array}$ & 274 & Ruta graveolens & $\mathrm{Fe} / 1 \mathrm{M} \mathrm{HCl}$ & 275 \\
\hline Thyme & $\mathrm{Fe} / 2 \mathrm{M} \mathrm{HCl}$ & 276 & Annona muricata $L$. & $\mathrm{Fe} / 1 \mathrm{M} \mathrm{HCl}$ & 277 \\
\hline (Guatteria ouregou and Simira tinctoria) & $\mathrm{Fe} / 1 \mathrm{M} \mathrm{HCl}$ & 278 & Michelia alba & $\mathrm{Fe} / \mathrm{mild}$ steel $1 \mathrm{M} \mathrm{HCl}$ & 279 \\
\hline Morusalba pendula & $\mathrm{Fe} / 1 \mathrm{M} \mathrm{HCl}$ & 280 & Anthocleista djalonensis & $\mathrm{Fe} / 1 \mathrm{M} \mathrm{HCl}$ & 281,282 \\
\hline Ficus hispida & $\mathrm{Fe} / 1 \mathrm{M} \mathrm{HCl}$ & 283 & Morinda tinctoria & $\mathrm{Fe} / 1 \mathrm{M} \mathrm{HCl}$ & 282 \\
\hline Solanam xanthocarpum & $\mathrm{Fe} / 1 \mathrm{M} \mathrm{HCl}$ & 284 & Vitex negundo & $\mathrm{Fe} / 1 \mathrm{M} \mathrm{HCl}$ & 285 \\
\hline Gliricidia sepium & $\mathrm{Fe} / 1 \mathrm{M} \mathrm{HCl}$ & 286 & Gymnema sylvestre & $\mathrm{Fe} / 1 \mathrm{M} \mathrm{HCl}$ & 287 \\
\hline Rosmarinus officinalis $L$. & $\mathrm{Fe} / 0.1 \mathrm{M} \mathrm{HCl}$ & 288 & Argemone mexicana & $\mathrm{Fe} / 1 \mathrm{M} \mathrm{HCl}$ & 289 \\
\hline Eichhornia crassipes & $\mathrm{Fe} / 5 \mathrm{M} \mathrm{HCl}$ & 290 & Acalypha torta & $\mathrm{Fe} / 1 \mathrm{M} \mathrm{HCl}$ & 291 \\
\hline Murraya koenigii (curry leaves) & $\mathrm{Fe} / 1 \mathrm{M} \mathrm{HCl}$ & 292 & Podranea ricasoliana & $\mathrm{Fe} / 1 \mathrm{M} \mathrm{HCl}$ & 293 \\
\hline Petroselinum crispum (parsley), & $\mathrm{Fe} / 1 \mathrm{M} \mathrm{HCl}$ & 99 & Passiflora foetida & $\mathrm{Fe} / 1 \mathrm{M} \mathrm{HCl}$ & 294 \\
\hline \multicolumn{6}{|l|}{ Eruca sativa (Arugula), Anethum graveolens } \\
\hline Emblica officinalis & $\mathrm{Fe} / 1 \mathrm{M} \mathrm{HCl}$ & 295 & Funtumia elastica & $\mathrm{Fe} / 1 \mathrm{M} \mathrm{HCl}$ & 296 \\
\hline Pterocarpus soyauxii & $\mathrm{Fe} / 1-2.5 \mathrm{M} \mathrm{HCl}$ & 297 & Tithonia diversifolia & $\mathrm{Fe} / 1 \mathrm{M} \mathrm{HCl}$ & 298 \\
\hline Plumeria alba, Blighia sapida, Secamone afezeli & $\mathrm{Fe} / 1$ and $2 \mathrm{M} \mathrm{HCl}$ & 299 & Gnetum africana & $\mathrm{Fe} / 1 \mathrm{M} \mathrm{HCl}$ & 300 \\
\hline Emblica officinalis & $\mathrm{Fe} / 1 \mathrm{M} \mathrm{HCl}$ & 301 & Lactuca sativa, etc. & $\mathrm{Fe} / 1 \mathrm{M} \mathrm{HCl}$ & 302 \\
\hline Sesbania sesban & $\mathrm{Fe} / 1 \mathrm{M} \mathrm{HCl}$ & 303 & Bryophyllum pinnatum & $\mathrm{Fe} / 0.5 \mathrm{M} \mathrm{HCl}$ & 304 \\
\hline Sansevieria trifasciata & $\begin{array}{l}\mathrm{Al} / 2 \mathrm{M} \mathrm{HCl} \mathrm{\&} \\
2 \mathrm{M} \mathrm{KOH}\end{array}$ & 305 & Piper longum & $\mathrm{Al} / 1 \mathrm{M} \mathrm{NaOH}$ & 306 \\
\hline Gossypium hirsutum (leaf and seed) & $\mathrm{Al} / 2 \mathrm{M} \mathrm{NaOH}$ & 307 & Nicotiana tabacum & AA3003Al/0.1 M HCl & 308 \\
\hline Phyllanthus amarus & $\mathrm{Al} / 2 \mathrm{M} \mathrm{NaOH}$ & 309 & Cannabis sativa (CS) & $\mathrm{Al} / 1 \mathrm{M} \mathrm{NaOH}$ & 310 \\
\hline Jasminum nudiflorum Lindl. & $\mathrm{Al} / 1 \mathrm{M} \mathrm{HCl}$ & 311 & Vernonia amygdalina & $\mathrm{Al} / 1 \mathrm{M} \mathrm{HCl}$ & 312 \\
\hline Raphia hookeri & $\mathrm{Al} / 0.02-2 \mathrm{M} \mathrm{HCl}$ & 223 & Tender arecanut & $\mathrm{Al} / 0.5 \mathrm{M} \mathrm{HCl}$ & 313 \\
\hline Thymus algeriensis & $\mathrm{Al} / 1 \mathrm{M} \mathrm{HCl}$ & 314 & Breadfruit & $\mathrm{Al} / 0.5 \mathrm{M} \mathrm{H}_{2} \mathrm{SO}_{4}$ & 260 \\
\hline Cocos nucifera & $\mathrm{Al} / 0.5 \mathrm{M} \mathrm{HCl}$ & 315 & Maesobatrya barteri & $\mathrm{Al} / 0.5 \mathrm{M}$ and $2 \mathrm{M} \mathrm{HCl}$ & 316 \\
\hline Morinda tinctoria & $\mathrm{Al} / 0.5 \mathrm{M} \mathrm{HCl}$ & 317 & & & \\
\hline
\end{tabular}

liquids results in an increase in the value of charge transfer resistance that occurs in the form of an effective anticorrosive barrier. Most of the evaluated ionic liquids behave as interfacetype corrosion inhibitors. Imidazolium based ionic liquids containing hydrophobic alkyl chain(s) exhibit a reasonably good anticorrosive effect relative to those without hydrophobic chain(s). In this case, it can be expected that the polar and electron rich hydrophilic imidazole ring interacts with the metal surface and forms a protective film, whereas hydrophobic alkyl chains float and prevent the water from coming into contact with the metal surface. Therefore, an increase in the length of the hydrophobic chain is expected to increase the inhibition effect of ionic liquids. Nevertheless, an increase in hydrophobicity can adversely affect the solubility of such ionic liquids in polar electrolytes. Therefore, a proper combination of hydrophilicity and hydrophobicity is highly essential while designing effective corrosion inhibitors. ${ }^{389,402}$ The anticorrosive effect of pyridinium, ${ }^{378,403-405}$ pyrrolidinium, ${ }^{406-408}$ ammonium $^{9,409-412}$ and phosphonium ${ }^{409,413}$ based ionic liquids has also been reported in the literature.

Because of their high solubility and environmentally benign nature ionic liquids are also tested as anticorrosive agents for other metals and alloys. Zhang and Hua ${ }^{414}$ demonstrated three imidazolium based ionic liquids designated as BMIC, HMIC and OMIC for aluminum in $1 \mathrm{M} \mathrm{HCl}$ using chemical and electrochemical methods. BMIC, HMIC and OMIC inhibit Al corrosion by adsorbing on the metallic surface, which followed the Langmuir adsorption isotherm model. The inhibition effect followed the order: BMIC < HMIC < OMIC. All the tested ionic liquids acted as mixed type corrosion inhibitors. In another report, ${ }^{415}$ the anticorrosive effect of an ionic liquid, designated as OPEIB, was evaluated for the $6061 \mathrm{Al}-15$ alloy in $0.5 \mathrm{M} \mathrm{H}_{2} \mathrm{SO}_{4}$ 
Table 4 Chemical structures and names of some major drugs that have been tested as corrosion inhibitors for different systems

Drug name and structure name and structure

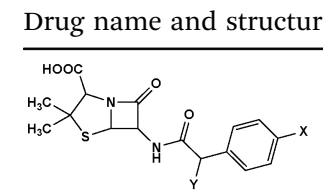

Penicillin $\mathrm{G}(\mathrm{X}, \mathrm{Y}=\mathrm{H})$; ampicillin $(\mathrm{X}=\mathrm{H}$, $\left.\mathrm{Y}=-\mathrm{NH}_{2}\right)$; amoxicillin $(\mathrm{X}=-\mathrm{OH}, \mathrm{Y}=-\mathrm{NH} 2)$

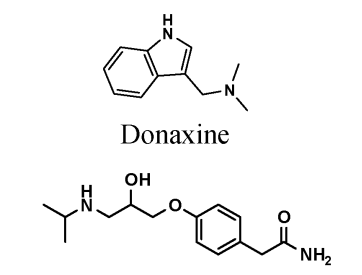

Atenolol

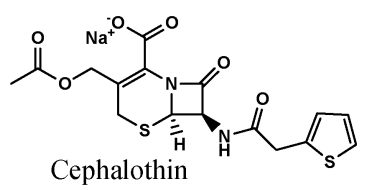

$$
\underbrace{}_{\mathrm{NH}_{2}}
$$

Aminophylline

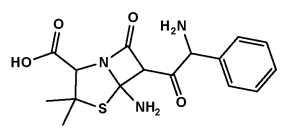

Ampicillin

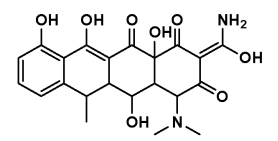

Doxycycline

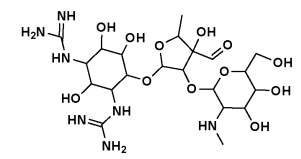

Streptomycin

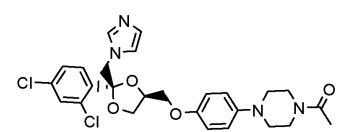

Ketoconazole

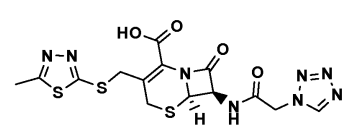

Cefazolin

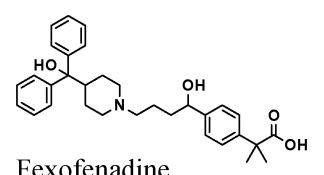

Fexofenadine

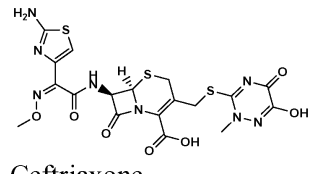

Ceftriaxone
System

$\mathrm{Fe} / 1 \mathrm{M} \mathrm{HCl}$

328

Ref.

$\mathrm{Fe} / 1 \mathrm{M} \mathrm{HCl}$

$\mathrm{Fe} / 1 \mathrm{M} \mathrm{HCl}$

332

330

$\mathrm{Fe} / 1 \mathrm{M} \mathrm{HCl}$

$\mathrm{Fe} / 1 \mathrm{M} \mathrm{HCl}$

$\mathrm{Fe} / 0.1 \mathrm{M} \mathrm{H}_{2} \mathrm{SO}_{4}$

337

$\mathrm{Fe} / 1 \mathrm{M} \mathrm{HCl}$

339

$\mathrm{Fe} / 1 \mathrm{M} \mathrm{HCl}$

$\mathrm{Fe} / 0.1 \mathrm{M} \mathrm{H}_{2} \mathrm{SO}_{4}$

342

$\mathrm{Fe} / 1 \mathrm{M} \mathrm{HCl}$

344

$\mathrm{Fe} / 1 \mathrm{M} \mathrm{HCl}$

346

$\mathrm{Fe} / 1 \mathrm{M} \mathrm{HCl}$

348

341

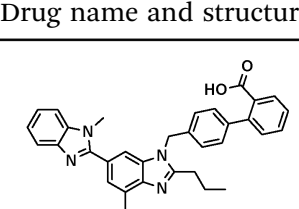

Telmisartan

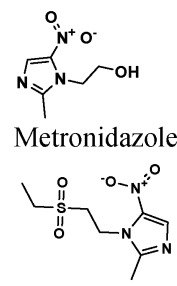

Tinidazole

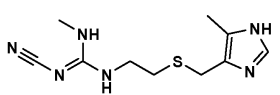

Cimetidine

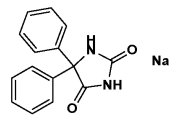

$\mathrm{Fe} / 1 \mathrm{M} \mathrm{HCl}$

324

Phenytoin

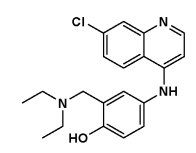

Amodiaquine

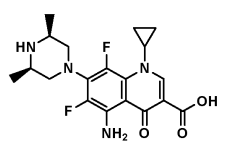

Sparfloxacin

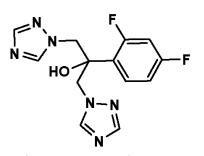

Fluconazole

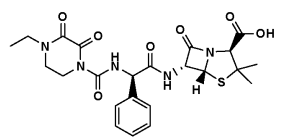

$\mathrm{Fe} / 1 \mathrm{M} \mathrm{HCl}$

343

Piperacillin Sodium<smiles>O=C(O)C1CN(C2CC2)c2cc(N3CCNCC3)c(F)cc2C1=O</smiles>

$\mathrm{Fe} / 1 \mathrm{M} \mathrm{HCl}$

Ciprofloxacin

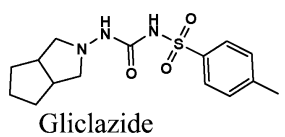

$\mathrm{Fe} / 1 \mathrm{M} \mathrm{HCl}$

347

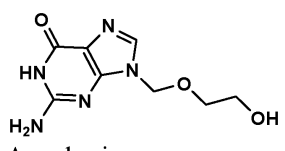

$\mathrm{Fe} / 1 \mathrm{M} \mathrm{HCl}$ 
System

$\mathrm{Fe} / 1 \mathrm{M} \mathrm{HCl}$

350

diethylcarbamazine
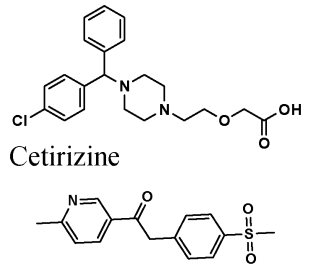

Ketosulfone<smiles>CC(C)(O)[C@@H](N)C(=O)O</smiles>

$\mathrm{Fe} / 1$

d-penicillamine

$\mathrm{Fe} / 1 \mathrm{M} \mathrm{HCl}$

352

$\mathrm{Fe} / 1 \mathrm{M} \mathrm{HCl}$

354
Ref.

Drug name and structure

System

Ref.

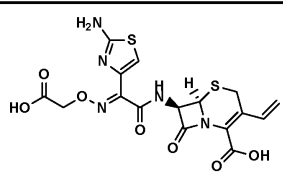

$\mathrm{Fe} / 1 \mathrm{M} \mathrm{HCl}$

Cefixime

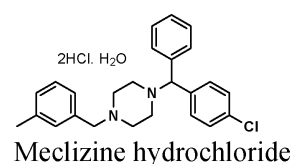

$\mathrm{Fe} / 1 \mathrm{M} \mathrm{HCl}$

353<smiles>CCCC(C)N(C)C(=N)NC(=N)N</smiles>

$\mathrm{Fe} / 1 \mathrm{M} \mathrm{HCl}$<smiles>CN(C)C(=N)NC(=N)N</smiles>

$\mathrm{Fe} / 15 \% \mathrm{HCl}$

\section{Cations}

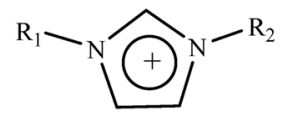

Imidazolium<smiles>[R][N+]1([R])CCCC1</smiles>

Pyrrolidinium<smiles>[R][n+]1ccccc1</smiles>

Pyridinium<smiles>[R][P+]([R3])([R1])[R]</smiles>

Phosphonium<smiles>[R][N+]([R1])([R])[R]</smiles>

Ammonium

Anions<smiles>F[B-](F)(F)F</smiles>

Tetrafluroborate (BF4)<smiles>O=C1O[PH]2(OC1=O)OC(=O)C(=O)O2</smiles>

Bis(oxalato) borate (BOB)<smiles>FP(F)(F)(F)F</smiles>

Hexaflurophosphate $\left(\mathrm{PF}_{6}\right)$<smiles>O=S(=O)(NS(=O)(=O)C(F)(F)F)C(F)(F)F</smiles>

Bis((trifluoromethyl)sulfonyl) amide ( $\left.\mathrm{NTF}_{2} / \mathrm{TFSA}\right)$
Alkyl group: $R_{1,2,3,4}: C_{n} H_{2 n+1}$ 

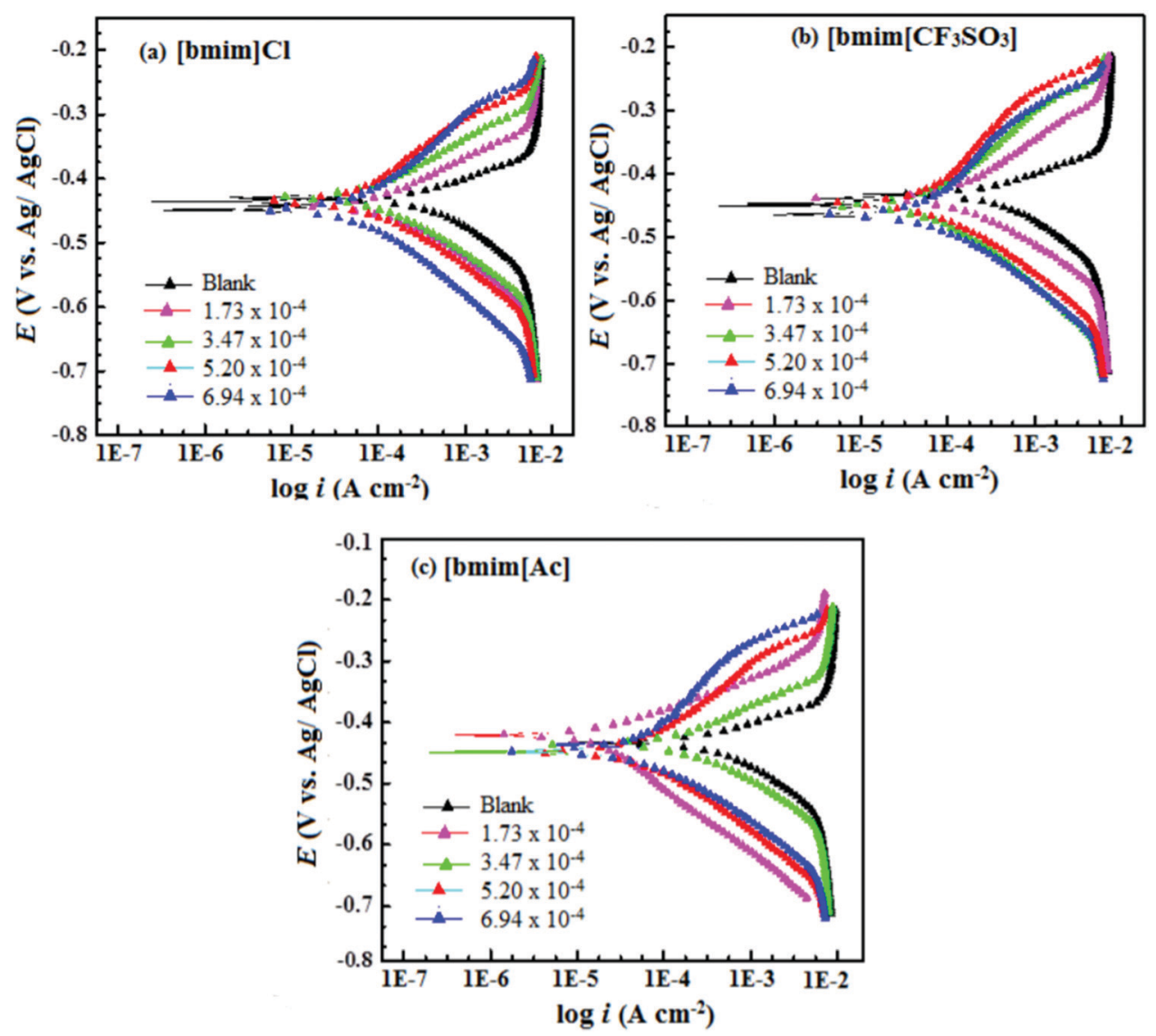

Fig. 12 Potentiodynamic polarization curves for mild steel corrosion in $1 \mathrm{M} \mathrm{HCl}$ in the absence and presence of (a) $[\mathrm{bmim}][\mathrm{Cl}]$, (b) $[\mathrm{bmim}]\left[\mathrm{CF}_{3} \mathrm{SO}_{3}\right]$ and (b) $[\mathrm{bmim}][\mathrm{Ac}]$ at different concentrations. ${ }^{379}$

also widely used as corrosion inhibitors for zinc $^{421,422}$ and copper $^{401,422-424}$ in various electrolytes. In most of the studies, ionic liquids acted as mixed-type corrosion inhibitors and their adsorption followed the Langmuir adsorption isotherm model. Using the EIS technique, it was observed that most of the investigated ionic liquids behaved as interface-type corrosion inhibitors as they become effective by forming a protective film over the metallic surface.

\subsection{Polyethylene glycols as environment-friendly corrosion inhibitors}

Polyethylene glycols (PEGs) represent a special class of industrially and biologically useful compounds. PEGs are connected with several advantages including low flammability, vapor pressure, cost and environmental toxicity. ${ }^{425}$ PEGs are available in different molecular weights varying from 200 to tens of thousands. ${ }^{425,426}$ Low molecular weight PEGs (200-600 D) are in the liquid form at room temperature. PEGs having a molecular weight of 600-800 D are water soluble viscous materials. PEGs having a molecular weight greater than $800 \mathrm{D}$ are in the form of solids. The solubility of PEG polymers decreases with the increase in the molecular weight as PEGs-200-600 D are fully soluble in water, whereas PEG-2000 shows only $60 \%$ solubility (at $20{ }^{\circ} \mathrm{C}$ ) in water. Because of their environment-friendly nature, biocompatibility, high molecular weight and great solubility in polar electrolytes, PEGS are widely used as corrosion inhibitors for metals and alloys. Because of their polymeric nature, PEGs provide massive surface coverage and protection and therefore behave as effective corrosion inhibitors. Although several review articles dealing with the various aspects of PEGs are published, no review on the anticorrosive effect of PEGs has been published yet. ${ }^{425,427-429}$ The literature survey demonstrates that PEGs possess a strong ability to interact with the metallic surface as they form strong coordination bonding with the metallic substrate. ${ }^{430}$ Unlike the traditional corrosion inhibitors, PEGs are nonvolatile, nonflammable and biodegradable which are the requirements for being environmentally benign. ${ }^{431-433}$ PEGs are relatively stable for chemical and thermal treatments and therefore they can be used as effective corrosion inhibitors at high temperature over a wide pH range. ${ }^{434-436}$ PEGs are almost insusceptible to $\mathrm{H}_{2} \mathrm{O}_{2}$ oxidation and reduction via $\mathrm{NaBH}_{4}$. PEGs possess the ability to recover from the medium they use. ${ }^{437,438}$

PEGs are widely employed as corrosion inhibitors in different electrolytes. Ashassi-Sorkhabi and Ghalebsaz-Jeddi ${ }^{439}$ reported the anticorrosive properties of PEGs with molecular weights in the range of $200-10000 \mathrm{~g} \mathrm{~mol}^{-1}$ for carbon steel in $3 \mathrm{~N}$ using chemical and electrochemical methods. It was observed that PEGs exhibited greater than $90 \%$ efficiency at a $10^{-1} \mathrm{M}$ 

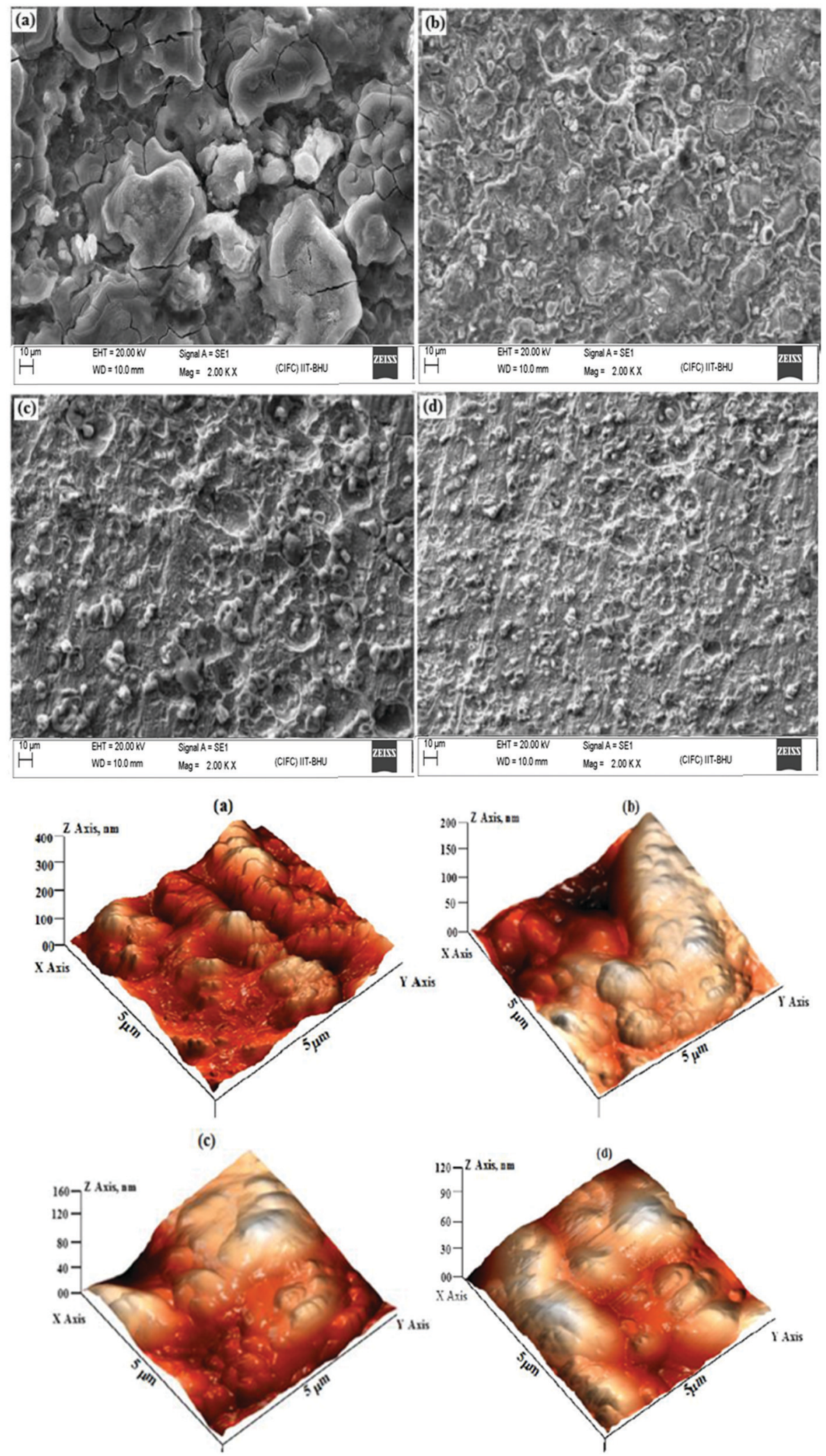

Fig. $13 \mathrm{SEM}$ (above) and AFM (below) micrographs of the mild steel surface in the (a) absence and presence of (b) [bmim] [Cl], (c) [bmim] [CF $\left.\mathrm{SO}_{3}\right]$ and (d) $[\mathrm{bmim}][\mathrm{Ac}]$ at different concentrations. ${ }^{379}$

concentration. The interfacial behavior of PEGs was determined using the EIS method. These authors also reported the anticorrosive effect of PEGs-400-10 $000 \mathrm{~g} \mathrm{~mol}^{-1}$ under the same experimental conditions (carbon steel/3 $\quad \mathrm{N}^{-1} \mathrm{H}_{2} \mathrm{SO}_{4}$ ). ${ }^{440}$ SEM 
Table 5 Chemical structures, abbreviation, nature of adsorption, metal and electrolyte system, method of corrosion measurements, highest inhibition efficiency and optimum concentration of some ionic liquids evaluated as corrosion inhibitors

S. $\quad$ Electrolyte and

no. Chemical structure and abbreviation<smiles>C[n+]1ccn(CCOCCOCCn2cc[n+](C)c2Cl)c1</smiles>

(TSIL)

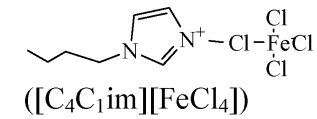<smiles>CCCCn1cc[n+](C)c1</smiles>

[BMIM]Br

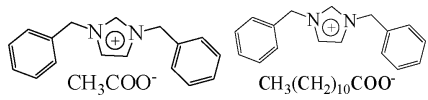

(DBImL)

(DBImA)<smiles>CC1=[N+](C)CCN1C</smiles><smiles>C[n+]1ccn(CCCCP(=O)(O)S(=O)(=O)O)c1</smiles>

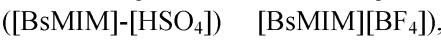<smiles>CCCCCCCCCCCN1C=C[N+](C)([Si]Cl)C1</smiles>

(DMICL)<smiles>CCCCCCCCn1cc[n+](C)c1</smiles>

[Omim]Lpro

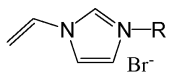

9

$\mathrm{R}=\mathrm{IL} 1: \mathrm{C}_{4} \mathrm{H}_{9} ; \mathrm{IL} 2: \mathrm{C}_{8} \mathrm{H}_{17} ; \mathrm{IL} 3: \mathrm{C}_{12} \mathrm{H}_{25}$;

IL4: $\mathrm{C}_{18} \mathrm{H}_{37} ;$ IL5: $\mathrm{C}_{22} \mathrm{H}_{45}$

F

(N)

$\mathrm{R}=-\mathrm{CH} 3$ (I); -C4H8 (II); -C8H9 (III)

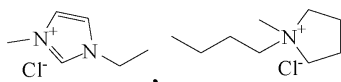

11

$([\mathrm{EMIm}] \mathrm{Cl}) \quad([\mathrm{Py} 1,4] \mathrm{Cl})$

12

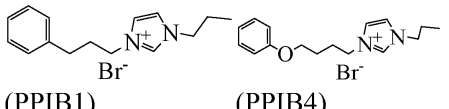

(PPIB1)
Nature of adsorption metal

Langmuir isotherm,
mixed type

steel

Open/A36 mild

steel

Langmuir isotherm, mixed type

Langmuir isotherm, mixed type mild steel

Langmuir adsorption isotherm

\section{-}

Flory-Huggins isotherm, mixed type

Langmuir isotherm, mixed type

$1 \mathrm{M} \mathrm{HCl} / \mathrm{mild}$

steel

$1 \mathrm{M} \mathrm{HCl} \& 1 \mathrm{M}$

$\mathrm{H}_{2} \mathrm{SO}_{4} /$ API

5LX52 steel steel

$\mathrm{NaCl}(3.8 \& 6.8$ $\mathrm{pH}) /$ mild steel

$0.5 \mathrm{M} \mathrm{H}_{2} \mathrm{SO}_{4} /$

mild steel

$1 \mathrm{M} \mathrm{H}_{2} \mathrm{SO}_{4} /$ carbon steel
$1 \mathrm{M} \mathrm{H}_{2} \mathrm{SO}_{4} / 304 \mathrm{~S}$

Mixed type inhibitors

Cast iron/gulf

Langmuir isotherm, mixed type

$1 \mathrm{M} \mathrm{HCl} /$ carbon steel
Method of corrosion

monitoring

IE\% and conc.

Ref.

PDP, EIS \& SEM

DBImL (30\%: $\mathrm{H}_{2} \mathrm{SO}_{4}$; $88 \% \mathrm{HCl}$ )

EIS, PDP, SEM, OM $\quad 86 \%$ MeHImn 4-OHC and FT-IR (4 mM)

OCP, EIS, PDP, SEM，98.2\% (3.8 pH) \& 84.3\%

EDX and XPS $\quad(6.8 \mathrm{pH})$

WL, PDP, EIS, SEM

\& DFT

$76.9 \%$ at $10 \mathrm{mM}$

388

WL, PDP, SEM, EDX \& AFM $90 \%$ at $10^{-4} \mathrm{M}$ (IL4)

WL, OCP, PDP and $R_{\mathrm{p}}=1376([\mathrm{EMIm}]) \&$ EIS $1364([\mathrm{Py} 1,4])$ at $5 \mathrm{mM}$

$1 \mathrm{M} \mathrm{HCl} / \mathrm{mild}$ steel

(MA2)

(MA1)

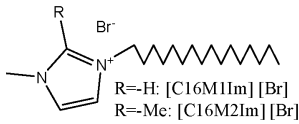

Langmuir isotherm, mixed type
$1 \mathrm{M} \mathrm{HCl} / \mathrm{mild}$ steel
92.3\% (PPIB1) \& 94.2\%

(PPIB4) at $10^{-2}$

WL, PDP \& EIS

WL and DFT

WL, PDP, EIS, SEM,
AFM, EDX \& UV-vis

$66.2 \%\left[\mathrm{C}_{16} \mathrm{M}_{1} \mathrm{Im}\right][\mathrm{Br}] \&$

$71.8 \%\left[\mathrm{C}_{16} \mathrm{M}_{2} \mathrm{Im}\right][\mathrm{Br}]$ at $250 \mathrm{ppm}$ 
S. no. Chemical structure and abbreviation
15

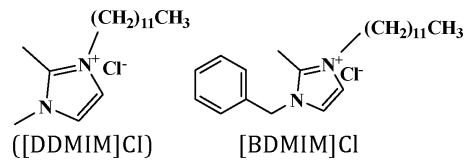

16

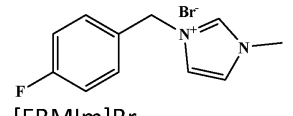

[FBMIm]Br

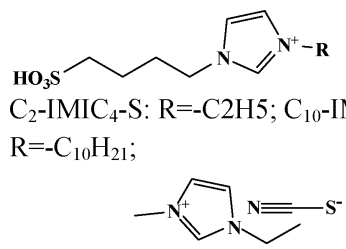

(EMIM) (SCN)-

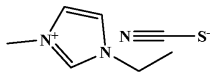

(EMIM) (SCN)-<smiles>C=Cn1cc[n+](CCCN)c1</smiles>

[VAIM][PF6]:[PF6]; [VAIM][BF4]:[BF4]

21<smiles>CCCCn1cc[n+](CC)c1</smiles>

Electrolyte and

Nature of adsorption metal

Langmuir isotherm, mixed type

Langmuir isotherm, mixed type

Langmuir isotherm, mixed type

Langmuir isotherm, mixed type

Langmuir isotherm, mixed type

EI-Awady kineticthermodynamic, mixed type

Langmuir isotherm, mixed type
$15 \% \mathrm{HCl} / \mathrm{N} 80$

steel

$0.5 \mathrm{M} \mathrm{H}_{2} \mathrm{SO}_{4} /$ mild steel

$0.5 \mathrm{M} \mathrm{HCl} /$ carbon steel

$0.5 \mathrm{MH}_{2} \mathrm{SO}_{4} / \mathrm{API}$ 5 L X52

$0.5 \mathrm{M} \mathrm{HCl} \&$ $\mathrm{H}_{2} \mathrm{SO}_{4} /$ API $5 \mathrm{~L}$ $\mathrm{X} 52$

$1 \mathrm{M} \mathrm{HCl} / \mathrm{Q} 235$ carbon steel

$0.01 \mathrm{M} \mathrm{Na}_{2} \mathrm{SO}_{4} /$ copper
Method of corrosion

monitoring

IE\% and conc.

Ref.

STT, WL, EIS, PDP, SEM, AFM, DFT \& MDS

$75.3 \%$ [DDMIM]C \& 98.1\% 395 [BDMIM]Cl at $100 \mathrm{ppm}$

PDP, EIS, SEM, AFM, DFT \& MDS

$98.9 \%$ at $0.01 \mathrm{M}(298 \mathrm{~K})$

396

PDP, EIS, CA, SEM, UV-vis, XPS, DFT $\quad 80.8 \%\left(\mathrm{C} 2-\mathrm{IMIC}_{4}\right.$-S) \& $97.9 \%$ and MDS (C10-IMIC4-SR $\left.=-\mathrm{C}_{10} \mathrm{H}_{21}\right)$ 397

WL, OCP, EIS, PDP, SEM, E-DX, UV, XPS, $93.1 \%$ at $10 \mathrm{ppm}\left(55^{\circ} \mathrm{C}\right) \quad 398$ AFM, DFT \& MDS

WL, EIS, PDP, SEM-EDX, AFM, XPS \& MDS

$69 \%(\mathrm{HCl}) \& 90\left(\mathrm{H}_{2} \mathrm{SO}_{4}\right)$ at $75 \mathrm{ppm}$

WL, PDP, EIS, CA, 90.53\%: [VAIM]PF6) \& 400 SEM, EDX and MDS 54.01 [VA-IM]PF4) $0.8 \mathrm{mM}$

WL, PDP, EIS, CA, SEM,

$91.29 \%$ at $100 \mathrm{ppm}$ 401

analyses revealed that the presence of PEGs enhances the smoothness of the surface and this enhancement was consistent with the molecular weight of PEGs. Umoren et al. extensively studied the corrosion inhibition effect of PEG in correlation with the anticorrosive effect of polyvinyl alcohol (PVA) and natural polymer (gum Arabic; GA). ${ }^{441-444}$ They observed that PEG exhibited a better anticorrosive effect. The adsorption of PEG and GA obeyed the Temkin adsorption isotherm model. The authors observed a synergistic effect in the presence of halide ions and their relative order of effectiveness is as follows: $\mathrm{KI}>\mathrm{KBr}>\mathrm{KCl}$. The corrosion inhibition effect of PEG with halide ions has been reported elsewhere. ${ }^{445}$ The literature survey showed that PEGs are widely used as inhibitors for metals in $\mathrm{H}_{2} \mathrm{SO}_{4}$ medium. ${ }^{446-448}$

PEGs are also used as metallic corrosion inhibitors in $\mathrm{HCl}$ medium. Ashassi-Sorkhabi et al. ${ }^{449}$ manifested the inhibition properties of PEGs (400-10000 $\mathrm{g} \mathrm{mol}^{-1}$ ) for carbon steel in 0.5 M HCl. PEGs behave as mixed-type corrosion inhibitors. An analysis in which the comparative inhibition effect of PEG and ciprofloxacin is evaluated for aluminum in acidic medium showed that PEG showed better protection effectiveness. ${ }^{450}$ The presence of ciprofloxacin synergistically enhanced the protection effect of ciprofloxacin. In another study Awad et al. ${ }^{451}$ demonstrated the anticorrosive properties of PEGs (300-600) for aluminum in the acidic medium of $\mathrm{HCl}$. The results showed that PEGs behaved as mixed-type inhibitors. Recently, the inhibition effect of chitosan modified PEG was reported for mild steel in $1 \mathrm{M}$
HCl. ${ }^{145}$ PEGs are also widely used as corrosion inhibitors in $\mathrm{NaCl}^{452-454}$ and $\mathrm{MOH}$ (metal oxide) ${ }^{455-457}$ solutions.

\subsection{Environment-friendly alternatives derived from MCRs}

The use of organic compounds is one of the most profitable methods of corrosion mitigation. However, most of the synthetic inhibitors are toxic in nature because they are synthesized using toxic chemicals, catalysts and solvents. ${ }^{13,458}$ Nevertheless, corrosion inhibitors synthesized using one-step multicomponent reactions (MCRs) have recently gained particular advancement towards the development of environmentally benign synthesis methods for chemicals to be used for different industrial applications including corrosion inhibition. MCRs possess several advantages that make them environment-friendly. ${ }^{459-462}$ Unlike the synthesis of traditional toxic corrosion inhibitors, MCRs are easy to proceed, profitable, and are associated with high yield and selectivity. In fact, in association with ultrasound (US) and microwave (MW) energy heating, MCRs have emerged as one of the greenest synthetic protocols. ${ }^{462}$ MCRs are characterized by chemical syntheses that employ the reactions between three or more reactants in one step. These types of reactions are generally quick, highly selective and consume less time to complete. Several compounds synthesized using MCRs are evaluated as inhibitors against metallic corrosion inhibitors. The synthetic schemes of MCRs for some classes of corrosion inhibitors are shown in Table 4. A careful observation showed that most of the corrosion inhibitors derived from MCRs are heterocyclic 
compounds, especially those containing $\mathrm{N}$ and $\mathrm{O}$ heteroatoms. It can be observed from the table that nitrogen based heterocyclic compounds such as imidazole, indole, pyridine, etc. are derived using MCRs that offer strong bonding with the metallic surface. On this basis, it can be concluded that MCRs act as a potential medium for the synthesis of heterocyclic compounds that can be used as corrosion inhibitors. Along with MCR syntheses, mechanochemical mixing (MCM $)^{463,464}$ and solid supported syntheses (SSSs) ${ }^{465,466}$ are also regarded as environment-friendly synthetic approaches because of their easy application, costeffective nature and easy and lower number of purification and work-up steps (Table 6).

\subsection{Environment-friendly alternatives derived from US and MW irradiations}

Generally, conventional heating methods offer very slow and non-uniform heating of reaction vessels that allow slow activation of the reactant molecules. ${ }^{503,504}$ Therefore, completion of the reactions carried out using conventional heating methods requires several minutes, hours or even days to complete. In the last three decades, the use of non-conventional heating sources mainly through ultrasound (US) and microwave (MW) irradiations gained significant attention. ${ }^{505,506}$ Chemical reactions using these nonconventional heating methods can proceed within a fraction of a second or minute, which require several hours to complete when using conventional heating methods. The literature study showed that MW and US irradiations cause sudden and instantaneous heating that activates most of the reactant molecules together and the reaction proceeds quickly. ${ }^{507-509}$ The MW and US irradiations are associated with several advantages that are closely related with the principles of green chemistry. Several theories are proposed to describe the activation of reactant molecules using MW and US irradiations. Generally, MW/US irradiation is used to catalyze MCR reactions. ${ }^{510,511}$ In connection with MCRs, US and MW irradiations offer the greenest synthetic protocol. Along with increasing the rates of chemical reactions, US and MW irradiations can also enhance the selectivity of the reactions. ${ }^{512,513}$ Moreover, MW and US irradiations also act as catalysts for chemical transformations. Several biologically and industrially useful compounds, especially heterocyclic compounds, are synthesized using MW and US irradiations. Heterocyclic compounds derived from MW and US irradiations have also been evaluated as inhibitors against metallic corrosion. ${ }^{12}$ Synthetic schemes and chemical structures of some major heterocyclic compounds derived from MW or US irradiation are presented in Table 5. The observation of the table shows that MW/US catalyzed reactions are related with the synthesis of heterocyclic compounds. Although chemical transformations can be catalytically and efficiently catalyzed using MW/US irradiation, their implementation for the synthesis of corrosion inhibitors should be further explored (Table 7).

\subsection{Environment-friendly alternatives derived using green solvents}

Solvents play a significant role in the progress of numerous reactions. ${ }^{521}$ There are several aspects of green chemistry and green synthesis, one of which is the use of environmentally benign and inexpensive solvents. It is well established that polar protic solvents such as alcohol $(\mathrm{ROH})$ and amines $\left(\mathrm{RNH}_{2}\right.$, $\mathrm{R}_{2} \mathrm{NH}$ and $\mathrm{R}_{3} \mathrm{~N}$ ) favor $\mathrm{SN}_{1}$ reactions and polar aprotic solvents such as THF (tetrahydrofuran), DMSO (dimethyl sulfoxide), and DMF (dimethyl formamide) favor $\mathrm{SN}_{2}$ reactions. ${ }^{522,523}$ Nevertheless, most of the traditional solvents used for chemical transformations are toxic and non-environment-friendly in nature. ${ }^{524,525}$ Generally, after their use, they are discharged into the surrounding environment without adequate treatment, thereby causing pollution.

Although "the best solvent is no solvent", there are some environmentally benign alternatives that can be used for the synthesis of organic compounds in the place of traditional toxic and volatile solvents. ${ }^{431}$ One of such solvents is water. Water is regarded as the best alternative to the traditional toxic solvents. Because of its bio-susceptibility, cost-effectivity, unique redox potential, high dielectric constant and huge availability, water represents one of the greenest solvents for chemical transformations. ${ }^{524-526}$ Several chemical transformations have been carried out using water as a solvent. The literature study showed that water has also been used as a medium for the synthesis of compounds used as corrosion inhibitors.

Toxicity of most of the traditional organic solvents is attributed to their high vapor pressure. Therefore, chemical compounds with a lower vapor pressure that exist in a wide liquid range can also be used as environmentally benign solvents for chemical transformations. One such example is ionic liquids. The high polarity, low vapor pressure and high chemical and thermal stability of ionic liquids make them one of the best alternative environment-friendly solvents. ${ }^{521,527}$ Several transformations have been carried out in ionic liquids to be used as effective corrosion inhibitors for metals and alloys. ${ }^{57,528}$ In fact, ionic liquids can themselves be effectively used as corrosion inhibitors for different systems. Because of their ionic nature, most of the ionic liquids are freely soluble in aqueous media and therefore they are mainly used as aqueous phase corrosion inhibitors, ${ }^{529,530}$ although they have also been tested as corrosion inhibitors in the coating phase. The inhibition effectiveness of ionic liquids can be suitably tailored by proper selection of cations and/or anions. In this sense, ionic liquids can be regarded as designer corrosion inhibitors. Imidazolium and pyridinium based ionic liquids are extensively used as corrosion inhibitors; however, other classes of ionic liquids are also used. ${ }^{57}$

Another such alternative is supercritical $\mathrm{CO}_{2}$ that has very low vapor pressure; however, it is not a good solvent for high molecular weight compounds. ${ }^{531,532}$ Therefore, supercritical $\mathrm{CO}_{2}$ is mostly used in combination with other cosolvents (polar and non-polar). $\mathrm{CO}_{2}$ philic (loving) ligands and highly $\mathrm{CO}_{2}$ soluble surfactants can also be used to enhance the solubility of supercritical $\mathrm{CO}_{2} \cdot{ }^{533,534}$ Supercritical $\mathrm{CO}_{2}$ is extensively used for a variety of chemical transformations, as an extraction solvent, and as a solvent in polymer production, purification and processing, powder production and processing and semiconductor processing. 
Table 6 Synthetic schemes for some major corrosion inhibitors derived through MCRs

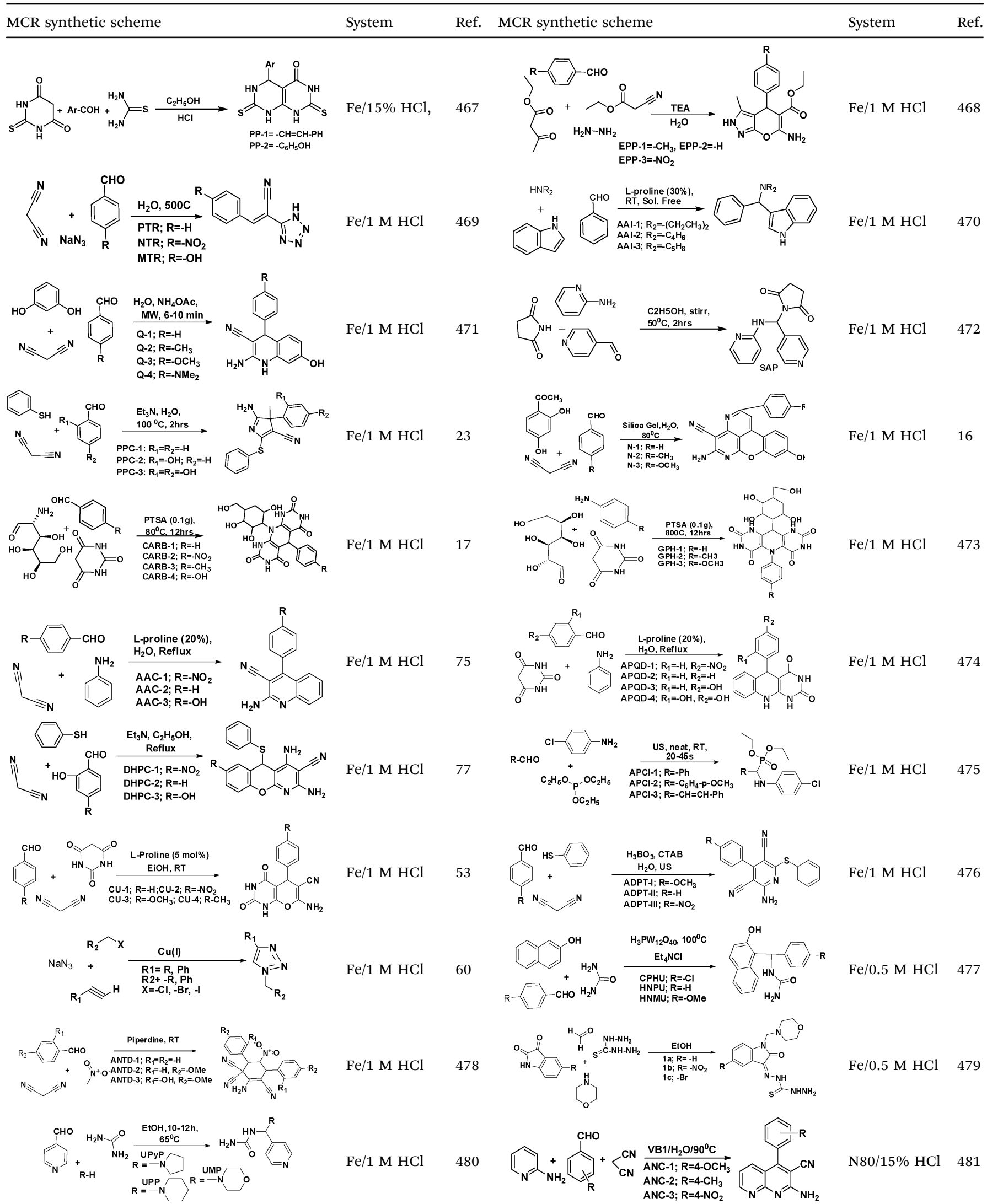


System

Ref. MCR synthetic scheme

System

Ref.

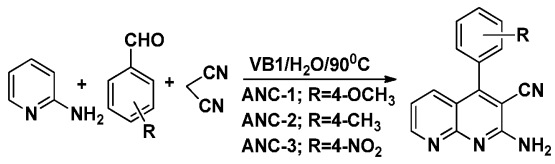

$\mathrm{Fe} / 1 \mathrm{M} \mathrm{HCl}$

482

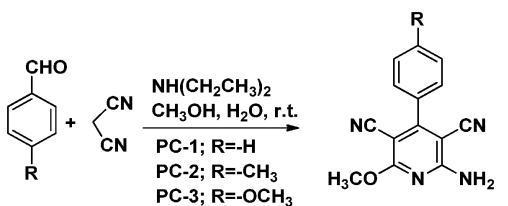

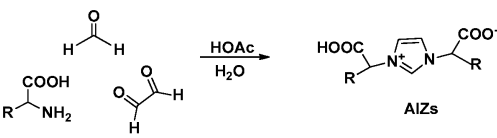

$A \mid Z-1 ; R=-H, \quad A I Z-2 ; R=-C_{3}, \quad A Z Z-3 ; R=-C_{2}-C_{6} H_{3}$

等)

(20\%)

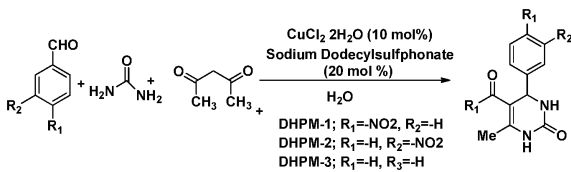

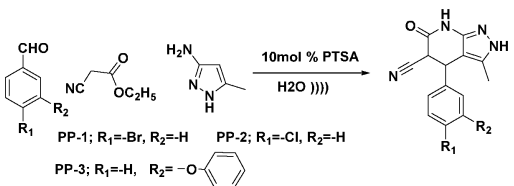
$\mathrm{NH}_{2}$
INH-1, Re-H
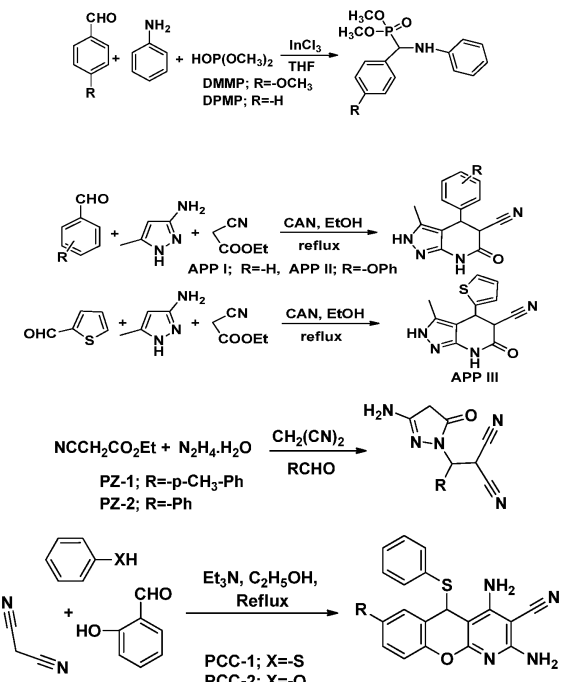

$\mathrm{N} 80 / 15 \% \mathrm{HCl} \quad 501$

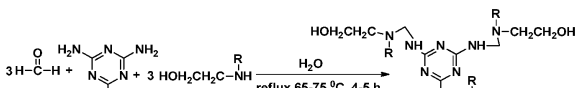

$\mathrm{Fe} / 1 \mathrm{M} \mathrm{HCl} \quad 494$

N80/15\% HCl 496

$\mathrm{Cu} / 0.5 \mathrm{M} \mathrm{HCl} \quad 498$

$\mathrm{N} 80 / 15 \% \mathrm{HCl} \quad 500$

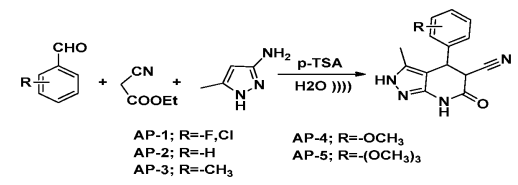

$\mathrm{Fe} / 1 \mathrm{M} \mathrm{HCl} \quad 491$

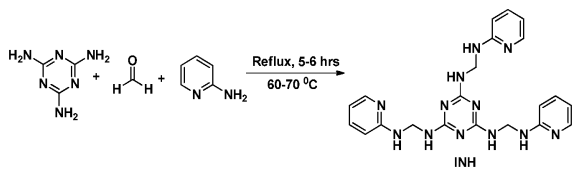

$\mathrm{Fe} / 1 \mathrm{M} \mathrm{HCl}$

493

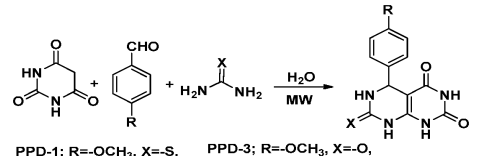

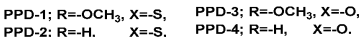

(

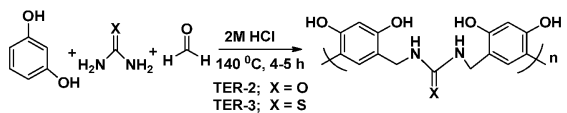

$\mathrm{Fe} / 1 \mathrm{M} \mathrm{HCl} \quad 499$

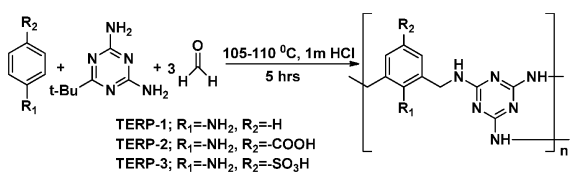


Table 7 Synthetic schemes and chemical structures of some major heterocyclic compounds synthesized using MW or US irradiation and tested as corrosion inhibitors

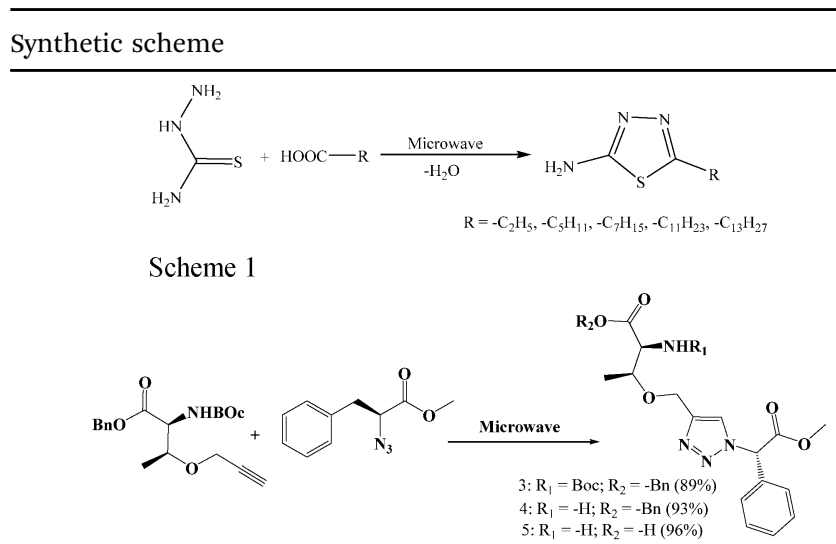

Scheme 2:

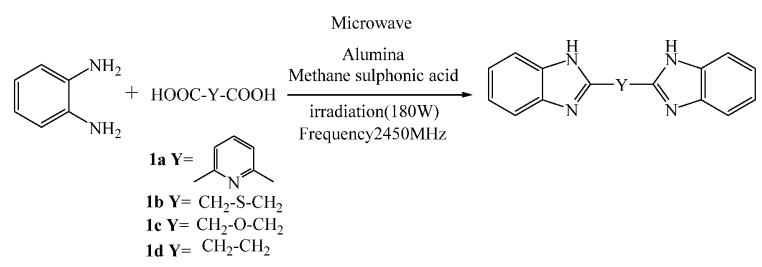

Scheme 3:

$$
\underbrace{}_{\text {Scheme }} \frac{\mathrm{NaH}, \mathrm{THF}}{\mathrm{RBr} \text {, microwave (heat) }}
$$<smiles>CN1C=C[N+](C)(Br)C1</smiles>

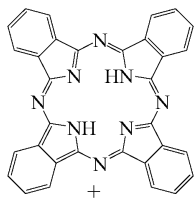

R-COOK

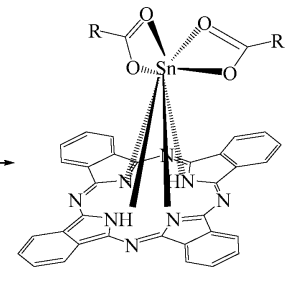

Scheme 5:
System

Ref.

$\mathrm{Fe} / 1 \mathrm{M} \mathrm{H}_{2} \mathrm{SO}_{4}$ 3a: $\mathrm{R}=\left(\mathrm{CH}_{2}\right)_{8} \mathrm{CH}_{3}$
3b: $\mathrm{R}=\left(\mathrm{CH}_{2}\right)_{12} \mathrm{CH}_{3}$

$\mathrm{Fe} / 1 \mathrm{M} \mathrm{HCl}$

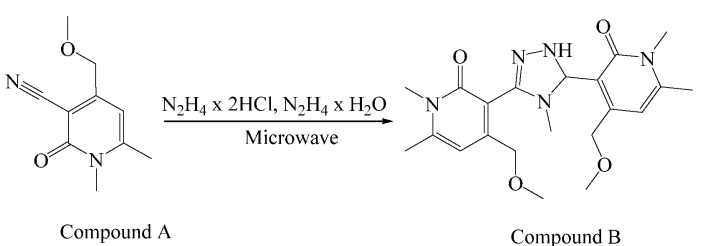

Scheme 6:

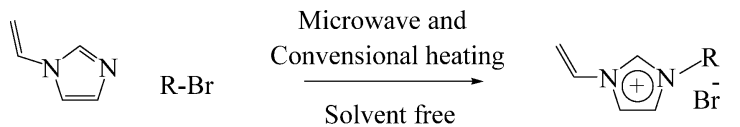

IL1: $\mathrm{R}=-\mathrm{C}_{4} \mathrm{H}_{9} ;$ IL2: $\mathrm{R}=-\mathrm{C}_{8} \mathrm{H}_{17} ;$ IL3: $\mathrm{R}=-\mathrm{C}_{12} \mathrm{H}_{25} ;$ IL4: $\mathrm{R}=-\mathrm{C}_{18} \mathrm{H}_{37}$;

$\mathrm{Fe} / 1 \mathrm{M} \mathrm{H}_{2} \mathrm{SO}_{4}$

60

Scheme 7:

$$
\text { IL5: } \mathrm{R}=-\mathrm{C}_{22} \mathrm{H}_{45}
$$

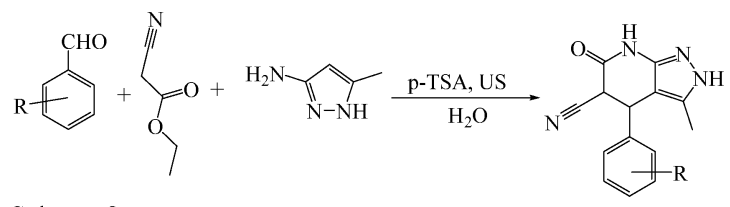

Scheme 8: 
Table 7 (continued)

Synthetic scheme

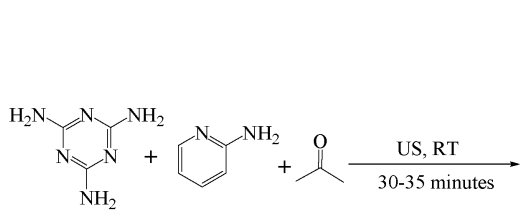

Scheme 9:
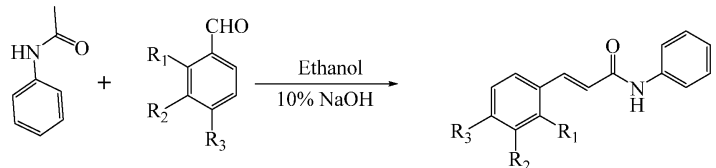

INH-1: $\mathrm{R}_{1}=-\mathrm{OH}, \mathrm{R}_{2}=-\mathrm{H}, \mathrm{R}_{3}=-\mathrm{H}$ INH-2: $\mathrm{R}_{1}=-\mathrm{H}, \mathrm{R}_{2}=-\mathrm{H}, \mathrm{R}_{3}=-\mathrm{N}\left(\mathrm{CH}_{3}\right)_{2}$ INH-3: $\mathrm{R}_{1}=-\mathrm{H}, \mathrm{R}_{2}=-\mathrm{OH}, \mathrm{R}_{3}=-\mathrm{OCH} 3$

Scheme 15:
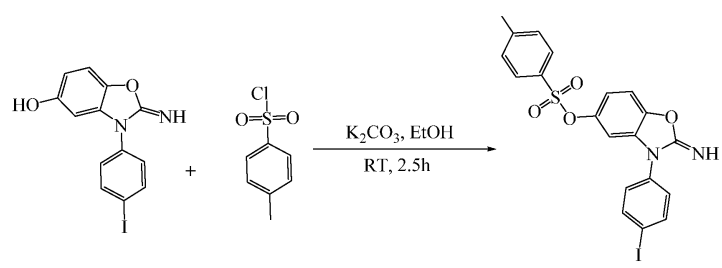

$\mathrm{Fe} / 1 \mathrm{M} \mathrm{HCl}$

Scheme 16:

\section{Summary and outlook}

The present review provides a summary of environmentally sustainable alternatives for traditional toxic corrosion inhibitors. The literature survey shows that several classes of pure and modified natural or bio-polymers have been widely reported as environment-friendly alternatives to traditional toxic corrosion inhibitors. With growing demand for green and sustainable technologies, the implementation of environment-friendly alternatives should be further explored. Among the natural environment-friendly alternatives, plant extracts and chemical medicines (drugs) are frequently used as corrosion inhibitors. Because of their natural and biological origin and property of non-bioaccumulation, they are regarded as environmentfriendly alternatives to traditional toxic corrosion inhibitors. Due to their complex molecular structures that contain numerous electron rich centers including polar functional groups and multiple bonds, the drug molecules and phytochemicals present in plant extracts act as effective metallic corrosion inhibitors. Because of their natural and biological origin they are treated as environmentally sustainable chemicals. However, recently the use of drug molecules has been slightly restricted because of their high cost which promoted the idea of consuming expired drugs as environment-friendly corrosion inhibitors. The use of expired drugs as corrosion inhibitors should be further explored. Currently, compounds derived through multicomponent reactions (MCRs), mechanochemical mixing (MCM), and solid supported syntheses (SSSs) and chemicals derived through microwave (MW) and ultrasound (US) irradiations are widely used as environmentfriendly alternatives to traditional toxic corrosion inhibitors. These synthetic methods provide several advantages over the traditional multistep reactions (MSRs), such as high yields, low reaction times, high selectivity, easy execution and handling, being costeffective and a lower number of purification and work-up steps. The literature study shows that numerous environment-friendly alternatives derived from MCRs and MW/US irradiations are tested as corrosion inhibitors; however, the implementation of such types of chemicals should be further enhanced. Apart from the above, there are numerous solvents that are demonstrated as environment-friendly, and chemicals derived using these solvents as reaction media are also regarded as environmentfriendly. Examples of such types of solvents include water, ILs, polyethylene glycol (PEG) and supercritical $\mathrm{CO}_{2}$. In the literature, numerous chemicals derived from these solvents are widely used as environment-friendly corrosion inhibitors. Carbohydrates, amino acids (AAs) and their derivatives are other representatives of environment-friendly corrosion inhibitors; however, they are not covered herein as several review articles dealing with their anticorrosion behavior have already been published.

\section{Conflicts of interest}

The authors declare that there is no conflict of interest.

\section{References}

1 J. Güttler and J. Reschke, Metal-carbon layers for industrial application in the automotive industry, Surf. Coat. Technol., 1993, 60, 531-535.

$2 \mathrm{~J} . \mathrm{K}$. Saha, Corrosion of constructional steels in marine and industrial environment: Frontier work in atmospheric corrosion, Springer Science \& Business Media, 2012. 
3 G. Koch, Cost of corrosion, Trends in oil and gas corrosion research and technologies, Elsevier, 2017, pp. 3-30.

4 S. A. Umoren, M. M. Solomon and V. S. Saji, Corrosion Inhibitors for Sour Oilfield Environment (H2S Corrosion), Corrosion Inhibitors in the Oil and Gas Industry, 2020, pp. 229-254.

5 C. Verma, H. Lgaz, D. Verma, E. E. Ebenso, I. Bahadur and M. Quraishi, Molecular dynamics and Monte Carlo simulations as powerful tools for study of interfacial adsorption behavior of corrosion inhibitors in aqueous phase: a review, J. Mol. Liq., 2018, 260, 99-120.

6 N. G. Thompson, M. Yunovich and D. Dunmire, Cost of corrosion and corrosion maintenance strategies, Corros. Rev., 2007, 25, 247-262.

7 G. H. Koch, M. P. Brongers, N. G. Thompson, Y. P. Virmani and J. H. Payer, Corrosion cost and preventive strategies in the United States, Federal Highway Administration, United States, 2002.

8 J. De Damborenea, A. Conde and M. Arenas, Corrosion inhibition with rare earth metal compounds in aqueous solutions, Rare Earthbased Corrosion Inhibitors, Elsevier, 2014, pp. 84-116.

9 C. Verma, I. Obot, I. Bahadur, E.-S. M. Sherif and E. E. Ebenso, Choline based ionic liquids as sustainable corrosion inhibitors on mild steel surface in acidic medium: Gravimetric, electrochemical, surface morphology, DFT and Monte Carlo simulation studies, Appl. Surf. Sci., 2018, 457, 134-149.

10 M. T. Alhaffar, S. A. Umoren, I. B. Obot and S. A. Ali, Isoxazolidine derivatives as corrosion inhibitors for low carbon steel in $\mathrm{HCl}$ solution: experimental, theoretical and effect of KI studies, RSC Adv., 2018, 8, 1764-1777.

11 O. Kaczerewska, R. Leiva-Garcia, R. Akid, B. Brycki, I. Kowalczyk and T. Pospieszny, Effectiveness of O-bridged cationic gemini surfactants as corrosion inhibitors for stainless steel in $3 \mathrm{M} \mathrm{HCl}$ : Experimental and theoretical studies, J. Mol. Liq., 2018, 249, 1113-1124.

12 C. Verma, M. Quraishi and E. E. Ebenso, Microwave and ultrasound irradiations for the synthesis of environmentally sustainable corrosion inhibitors: An overview, Sustainable Chem. Pharm., 2018, 10, 134-147.

13 A. Khramov, N. Voevodin, V. Balbyshev and M. Donley, Hybrid organo-ceramic corrosion protection coatings with encapsulated organic corrosion inhibitors, Thin Solid Films, 2004, 447, 549-557.

14 U. Dahlmann and M. Feustel, Corrosion and gas hydrate inhibitors having improved water solubility and increased biodegradability, US Pat., US7323609B2, 2008.

15 C. Verma, L. Olasunkanmi, E. E. Ebenso and M. Quraishi, Substituents effect on corrosion inhibition performance of organic compounds in aggressive ionic solutions: a review, J. Mol. Liq., 2018, 251, 100-118.

16 P. Singh, E. E. Ebenso, L. O. Olasunkanmi, I. Obot and M. Quraishi, Electrochemical, theoretical, and surface morphological studies of corrosion inhibition effect of green naphthyridine derivatives on mild steel in hydrochloric acid, J. Phys. Chem. C, 2016, 120, 3408-3419.

17 C. Verma, L. O. Olasunkanmi, E. E. Ebenso, M. A. Quraishi and I. B. Obot, Adsorption behavior of glucosamine-based, pyrimidine-fused heterocycles as green corrosion inhibitors for mild steel: experimental and theoretical studies, J. Phys. Chem. C, 2016, 120, 11598-11611.

18 A. Mishra, C. Verma, H. Lgaz, V. Srivastava, M. Quraishi and E. E. Ebenso, Synthesis, characterization and corrosion inhibition studies of N-phenyl-benzamides on the acidic corrosion of mild steel: Experimental and computational studies, J. Mol. Liq., 2018, 251, 317-332.

19 V. S. Sastri, Green corrosion inhibitors: theory and practice, John Wiley \& Sons, 2012.

20 E. Ebenso, U. Ekpe, B. Ita, O. Offiong and U. Ibok, Effect of molecular structure on the efficiency of amides and thiosemicarbazones used for corrosion inhibition of mild steel in hydrochloric acid, Mater. Chem. Phys., 1999, 60, 79-90.

21 N. Obi-Egbedi and I. Obot, Xanthione: A new and effective corrosion inhibitor for mild steel in sulphuric acid solution, Arabian J. Chem., 2013, 6, 211-223.

22 V. R. Saliyan and A. V. Adhikari, Quinolin-5-ylmethylene-3$\{[8$-(trifluoromethyl)quinolin-4-yl]thio\}propanohydrazide as an effective inhibitor of mild steel corrosion in $\mathrm{HCl}$ solution, Corros. Sci., 2008, 50, 55-61.

23 C. Verma, E. Ebenso, I. Bahadur, I. Obot and M. Quraishi, 5-(Phenylthio)-3H-pyrrole-4-carbonitriles as effective corrosion inhibitors for mild steel in $1 \mathrm{M} \mathrm{HCl}$ : experimental and theoretical investigation, J. Mol. Liq., 2015, 212, 209-218.

24 M. Goyal, S. Kumar, I. Bahadur, C. Verma and E. E. Ebenso, Organic corrosion inhibitors for industrial cleaning of ferrous and non-ferrous metals in acidic solutions: A review, J. Mol. Liq., 2018, 256, 565-573.

25 A. Maayta and N. Al-Rawashdeh, Inhibition of acidic corrosion of pure aluminum by some organic compounds, Corros. Sci., 2004, 46, 1129-1140.

26 A. El-Etre, Inhibition of aluminum corrosion using Opuntia extract, Corros. Sci., 2003, 45, 2485-2495.

27 S. Refaey, F. Taha and A. Abd El-Malak, Inhibition of stainless steel pitting corrosion in acidic medium by 2-mercaptobenzoxazole, Appl. Surf. Sci., 2004, 236, 175-185.

28 C. Verma, J. Haque, M. Quraishi and E. E. Ebenso, Aqueous phase environmental friendly organic corrosion inhibitors derived from one step multicomponent reactions: a review, J. Mol. Liq., 2019, 275, 18-40.

29 C. Verma, D. K. Verma, E. E. Ebenso and M. A. Quraishi, Sulfur and phosphorus heteroatom-containing compounds as corrosion inhibitors: An overview, Heteroat. Chem., 2018, 29, e21437.

30 C. Verma, E. E. Ebenso and M. Quraishi, Molecular structural aspects of organic corrosion inhibitors: Influence of $-\mathrm{CN}$ and $-\mathrm{NO}_{2}$ substituents on designing of potential corrosion: Inhibitors for aqueous media, J. Mol. Liq., 2020, 113874.

$31 \mathrm{H}$. Wang and J. Zheng, Progress of Research on Environmental-Friendly Corrosion Inhibitors, Corros. Sci. Prot. Technol., 2002, 14, 275-279.

32 M. Bethencourt, F. Botana, J. Calvino, M. Marcos and M. Rodriguez-Chacon, Lanthanide compounds as environmentally-friendly corrosion inhibitors of aluminium alloys: a review, Corros. Sci., 1998, 40, 1803-1819. 
33 S. M. Powell, H. McMurray and D. Worsley, Use of the scanning reference electrode technique for the evaluation of environmentally friendly, nonchromate corrosion inhibitors, Corrosion, 1999, 55, 1040-1051.

34 M. Sun, H. Lin, W. Guo, F. Zhao and J. Li, Bioaccumulation and biodegradation of sulfamethazine in Chlorella pyrenoidosa, J. Ocean Univ. China, 2017, 16, 1167-1174.

35 A. N. Kabra, M.-K. Ji, J. Choi, J. R. Kim, S. P. Govindwar and B.-H. Jeon, Toxicity of atrazine and its bioaccumulation and biodegradation in a green microalga, Chlamydomonas mexicana, Environ. Sci. Pollut. Res., 2014, 21, 12270-12278.

36 J. Greenwood, Organized civil society and democratic legitimacy in the European Union, Brit. J. Polit. Sci., 2007, 333-357.

37 R. Dehousse, Delegation of powers in the European Union: The need for a multi-principals model, West Eur. Poli., 2008, 31, 789-805.

38 W. P. Dinter, Biogeography of the OSPAR Maritime Area. A synopsis and synthesis of biogeographical distribution patterns described for the north-east Atlantic, Federal Agency for Nature Conservation, Bonn, Germany, 2001, vol. 167.

39 L. de La Fayette, The OSPAR convention comes into force: continuity and progress, Int. J. Mar. Coast. Law., 1999, 14, 247-297.

40 P. Heslenfeld and E. L. Enserink, OSPAR Ecological Quality Objectives: the utility of health indicators for the North Sea, ICES J. Mar. Sci., 2008, 65, 1392-1397.

41 A. Castano, M. Cantarino, P. Castillo and J. Tarazona, Correlations between the RTG-2 cytotoxicity test EC50 and in vivo LC50 rainbow trout bioassay, Chemosphere, 1996, 32, 2141-2157.

42 J. Hermens, H. Canton, N. Steyger and R. Wegman, Joint effects of a mixture of 14 chemicals on mortality and inhibition of reproduction of Daphnia magna, Aquat. Toxicol., 1984, 5, 315-322.

43 M. Zhang, D. Aguilera, C. Das, H. Vasquez, P. Zage, V. Gopalakrishnan and J. Wolff, Measuring cytotoxicity: a new perspective on LC50, Anticancer Res., 2007, 27, 35-38.

44 A. Zakari and D. Kubmarawa, Acute toxicity (LD50) studies using Swiss albino mice and brine shrimp lethality (LC50 and LC90) determination of the ethanol extract of stem bark of Echinaceae angustifolia DC, Nat. Prod. Chem. Res., 2016, 4, 2.

45 A. L. Parra, R. S. Yhebra, I. G. Sardiñas and L. I. Buela, Comparative study of the assay of Artemia salina L. and the estimate of the medium lethal dose (LD50 value) in mice, to determine oral acute toxicity of plant extracts, Phytomedicine, 2001, 8, 395-400.

46 M. Chomel, C. Fernandez, A. Bousquet-Mélou, C. Gers, Y. Monnier, M. Santonja, T. Gauquelin, R. Gros, C. Lecareux and V. Baldy, Secondary metabolites of $\mathrm{P}$ inus halepensis alter decomposer organisms and litter decomposition during afforestation of abandoned agricultural zones, J. Ecol., 2014, 102, 411-424.

47 M. D. Summers, S. L. Blunk and B. M. Jenkins, How straw decomposes: Implications for straw bale construction, Ecological Building Network, 2003.
48 R. Wedmann, I. Ivanovic-Burmazovic and M. R. Filipovic, Nitrosopersulfide (SSNO-) decomposes in the presence of sulfide, cyanide or glutathione to give $\mathrm{HSNO} / \mathrm{SNO}-$ : consequences for the assumed role in cell signalling, Interface Focus, 2017, 7, 20160139.

49 S. A. van der Heijden and M. T. Jonker, Evaluation of liposome-water partitioning for predicting bioaccumulation potential of hydrophobic organic chemicals, Environ. Sci. Technol., 2009, 43, 8854-8859.

50 J. M. Conder, R. A. Hoke, W.d. Wolf, M. H. Russell and R. C. Buck, Are PFCAs bioaccumulative? A critical review and comparison with regulatory criteria and persistent lipophilic compounds, Environ. Sci. Technol., 2008, 42, 995-1003.

51 R. L. Williamson Jr, D. T. Burton, J. H. Clarke and L. E. Fleming, Gathering danger: the urgent need to regulate toxic substances that can bioaccumulate, Ecology LQ, 1993, 20, 605.

52 W. M. Meylan, P. H. Howard, R. S. Boethling, D. Aronson, H. Printup and S. Gouchie, Improved method for estimating bioconcentration/bioaccumulation factor from octanol/water partition coefficient, Environ. Toxicol. Chem., 1999, 18, 664-672.

53 D. K. Yadav and M. A. Quraishi, Application of some condensed uracils as corrosion inhibitors for mild steel: gravimetric, electrochemical, surface morphological, UV-visible, and theoretical investigations, Ind. Eng. Chem. Res., 2012, 51, 14966-14979.

54 F. Kuang, J. Zhang, C. Zou, T. Shi, Y. Wang, S. Zhang and H. Xu, Electrochemical Methods for Corrosion Monitoring: A Survey of Recent Patents, Recent Patents on Corrosion Science, 2010.

55 C. Page and P. Cunningham, Electro-chemical Methods of Corrosion Monitoring for Marine Concrete Structures, 1988.

56 M. Chigondo and F. Chigondo, Recent natural corrosion inhibitors for mild steel: an overview, J. Chem., 2016, 2016, 1-7.

57 C. Verma, E. E. Ebenso and M. Quraishi, Ionic liquids as green and sustainable corrosion inhibitors for metals and alloys: an overview, J. Mol. Liq., 2017, 233, 403-414.

58 C. Verma, E. Ebenso and M. Quraishi, Alkaloids as green and environmental benign corrosion inhibitors: An overview, Int. J. Corros. Scale Inhib., 2019, 8, 512-528.

59 P. Dohare, M. Quraishi, C. Verma, H. Lgaz, R. Salghi and E. Ebenso, Ultrasound induced green synthesis of pyrazolopyridines as novel corrosion inhibitors useful for industrial pickling process: experimental and theoretical approach, Results Phys., 2019, 13, 102344.

60 R. González-Olvera, V. Román-Rodríguez, G. E. NegrónSilva, A. Espinoza-Vázquez, F. J. Rodríguez-Gómez and R. Santillan, Multicomponent synthesis and evaluation of new 1, 2, 3-triazole derivatives of dihydropyrimidinones as acidic corrosion inhibitors for steel, Molecules, 2016, 21, 250.

61 I. Obot, D. Macdonald and Z. Gasem, Density functional theory (DFT) as a powerful tool for designing new organic corrosion inhibitors. Part 1: an overview, Corros. Sci., 2015, 99, 1-30. 
62 D. K. Verma, Density Functional Theory (DFT) as a Powerful Tool for Designing Corrosion Inhibitors in Aqueous Phase, Adv. Eng. Testing, 2018, 87.

63 L. H. Madkour, S. Kaya and I. B. Obot, Computational, Monte Carlo simulation and experimental studies of some arylazotriazoles (AATR) and their copper complexes in corrosion inhibition process, J. Mol. Liq., 2018, 260, 351-374.

64 R. M. Pidaparti, L. Fang and M. J. Palakal, Computational simulation of multi-pit corrosion process in materials, Comput. Mater. Sci., 2008, 41, 255-265.

65 N. O. Eddy, F. E. Awe, C. E. Gimba, N. O. Ibisi and E. E. Ebenso, QSAR, Experimental and computational chemistry simulation studies on the inhibition potentials of some amino acids for the corrosion of mild steel in $0.1 \mathrm{M} \mathrm{HCl}$, Int. J. Electrochem. Sci., 2011, 6, 931-957.

66 I. Obot, K. Haruna and T. Saleh, Atomistic simulation: a unique and powerful computational tool for corrosion inhibition research, Arabian J. Sci. Eng., 2019, 44, 1-32.

67 N. Obi-Egbedi, I. Obot, M. El-Khaiary, S. Umoren and E. Ebenso, Computational simulation and statistical analysis on the relationship between corrosion inhibition efficiency and molecular structure of some phenanthroline derivatives on mild steel surface, Int. J. Electrochem. Sci., 2011, 6, e5675.

68 S. Kaya, P. Banerjee, S. K. Saha, B. Tüzün and C. Kaya, Theoretical evaluation of some benzotriazole and phospono derivatives as aluminum corrosion inhibitors: DFT and molecular dynamics simulation approaches, $R S C A d v$, 2016, 6, 74550-74559.

69 E. E. Annastasia, F. A. Similoluwa, O. Esther, S. Adewale, S. Banjo and O. A. Kolawole, Anti-Corrosion Activity Study of 1,2,3-Triazole Derivatives on Carbon Steel in Acidic Media: Theoretical Approach, Anal. Bioanal. Electrochem., 2019, 11, 1414-1425.

70 M. Belghiti, Y. Karzazi, S. Tighadouini, A. Dafali, C. Jama, I. Warad, B. Hammouti and S. Radi, New hydrazine derivatives as corrosion for mild steel in phosphoric acid medium. Part B: Theoretical investigation, J. Mater. Environ. Sci., 2016, 7, 956-967.

71 D. S. Chauhan, M. Quraishi, A. Sorour, S. K. Saha and P. Banerjee, Triazole-modified chitosan: a biomacromolecule as a new environmentally benign corrosion inhibitor for carbon steel in a hydrochloric acid solution, RSC Adv., 2019, 9, 14990-15003.

72 I. Obot, N. Obi-Egbedi and S. Umoren, Antifungal drugs as corrosion inhibitors for aluminium in $0.1 \mathrm{M} \mathrm{HCl}$, Corros. Sci., 2009, 51, 1868-1875.

73 M. Yadav, P. Yadav and U. Sharma, Substituted imidazoles as corrosion inhibitors for N80 steel in hydrochloric acid, 2013.

74 M. K. Awad, M. R. Mustafa and M. M. A. Elnga, Computational simulation of the molecular structure of some triazoles as inhibitors for the corrosion of metal surface, THEOCHEM, 2010, 959, 66-74.

75 C. Verma, M. Quraishi, L. Olasunkanmi and E. E. Ebenso, L-Proline-promoted synthesis of 2-amino-4-arylquinoline3-carbonitriles as sustainable corrosion inhibitors for mild steel in $1 \mathrm{M} \mathrm{HCl}$ : experimental and computational studies, RSC Adv., 2015, 5, 85417-85430.

76 C. Verma, A. Singh, G. Pallikonda, M. Chakravarty, M. Quraishi, I. Bahadur and E. Ebenso, Aryl sulfonamidomethylphosphonates as new class of green corrosion inhibitors for mild steel in $1 \mathrm{M} \mathrm{HCl}$ : electrochemical, surface and quantum chemical investigation, J. Mol. Liq., 2015, 209, 306-319.

77 C. Verma, L. O. Olasunkanmi, I. Obot, E. E. Ebenso and M. Quraishi, 2,4-Diamino-5-(phenylthio)-5H-chromeno[2,3b]pyridine-3-carbonitriles as green and effective corrosion inhibitors: gravimetric, electrochemical, surface morphology and theoretical studies, RSC Adv., 2016, 6, 53933-53948.

78 K. Khaled, Monte Carlo simulations of corrosion inhibition of mild steel in $0.5 \mathrm{M}$ sulphuric acid by some green corrosion inhibitors, J. Solid State Electrochem., 2009, 13, 1743-1756.

79 M. Ramezanzadeh, G. Bahlakeh, Z. Sanaei and B. Ramezanzadeh, Corrosion inhibition of mild steel in $1 \mathrm{M} \mathrm{HCl}$ solution by ethanolic extract of eco-friendly Mangifera indica (mango) leaves: electrochemical, molecular dynamics, Monte Carlo and ab initio study, Appl. Surf. Sci., 2019, 463, 1058-1077.

80 K. Alaoui, M. Ouakki, A. Abousalem, H. Serrar, M. Galai, S. Derbali, K. Nouneh, S. Boukhris, M. E. Touhami and Y. El Kacimi, Molecular dynamics, Monte-Carlo simulations and atomic force microscopy to study the interfacial adsorption behaviour of some triazepine carboxylate compounds as corrosion inhibitors in acid medium, J. Bio-and Tribo-Corros., 2019, 5, 1.

81 M. Abdallah, H. Al-Tass, B. A. Jahdaly and A. Fouda, Inhibition properties and adsorption behavior of 5-arylazothiazole derivatives on 1018 carbon steel in $0.5 \mathrm{M} \mathrm{H}_{2} \mathrm{SO}_{4}$ solution, J. Mol. Liq., 2016, 216, 590-597.

82 E. A. Noor and A. H. Al-Moubaraki, Thermodynamic study of metal corrosion and inhibitor adsorption processes in mild steel/1-methyl-4 [4'(-X)-styryl pyridinium iodides/ hydrochloric acid systems, Mater. Chem. Phys., 2008, 110, 145-154.

83 M. Bahri, A. Mahdavi, A. Mirzaei, A. Mansouri and F. Haghighat, Integrated oxidation process and biological treatment for highly concentrated petrochemical effluents: a review, Chem. Eng. Process., 2018, 125, 183-196.

84 R. Gueccia, A. R. Aguirre, S. Randazzo, A. Cipollina and G. Micale, Diffusion Dialysis for Separation of Hydrochloric Acid, Iron and Zinc Ions from Highly Concentrated Pickling Solutions, Membranes, 2020, 10, 129.

85 A. Agrawal and K. Sahu, An overview of the recovery of acid from spent acidic solutions from steel and electroplating industries, J. Hazard. Mater., 2009, 171, 61-75.

86 M. Finšgar and J. Jackson, Application of corrosion inhibitors for steels in acidic media for the oil and gas industry: a review, Corros. Sci., 2014, 86, 17-41.

87 Y. Chen and W. Yang, Formulation of Corrosion Inhibitors, Water Chemistry, IntechOpen, 2019.

88 A. Singh, K. Ansari, D. S. Chauhan, M. Quraishi, H. Lgaz and I.-M. Chung, Comprehensive investigation of steel corrosion inhibition at macro/micro level by ecofriendly 
green corrosion inhibitor in $15 \% \mathrm{HCl}$ medium, J. Colloid Interface Sci., 2020, 560, 225-236.

89 K. Ansari and M. Quraishi, Experimental and quantum chemical evaluation of Schiff bases of isatin as a new and green corrosion inhibitors for mild steel in $20 \% \mathrm{H}_{2} \mathrm{SO}_{4}$, J. Taiwan Inst. Chem. Eng., 2015, 54, 145-154.

90 K. Ansari, M. Quraishi and A. Singh, Isatin derivatives as a non-toxic corrosion inhibitor for mild steel in $20 \% \mathrm{H}_{2} \mathrm{SO}_{4}$, Corros. Sci., 2015, 95, 62-70.

91 S. Kumar, D. Sharma, P. Yadav and M. Yadav, Experimental and quantum chemical studies on corrosion inhibition effect of synthesized organic compounds on N80 steel in hydrochloric acid, Ind. Eng. Chem. Res., 2013, 52, 14019-14029.

92 M. Yadav, D. Behera, S. Kumar and R. R. Sinha, Experimental and quantum chemical studies on the corrosion inhibition performance of benzimidazole derivatives for mild steel in HCl, Ind. Eng. Chem. Res., 2013, 52, 6318-6328.

93 M. Yadav, R. Sinha, S. Kumar and T. Sarkar, Corrosion inhibition effect of spiropyrimidinethiones on mild steel in $15 \% \mathrm{HCl}$ solution: insight from electrochemical and quantum studies, RSC Adv., 2015, 5, 70832-70848.

94 S. A. Umoren, M. M. Solomon, I. B. Obot and R. K. Suleiman, Comparative studies on the corrosion inhibition efficacy of ethanolic extracts of date palm leaves and seeds on carbon steel corrosion in $15 \% \mathrm{HCl}$ solution, J. Adhes. Sci. Technol., 2018, 32, 1934-1951.

95 M. Quraishi and D. Jamal, Corrosion inhibition of N-80 steel and mild steel in $15 \%$ boiling hydrochloric acid by a triazole compound-SAHMT, Mater. Chem. Phys., 2001, 68, 283-287.

96 Y. Jianguo, W. Lin, V. Otieno-Alego and D. Schweinsberg, Polyvinylpyrrolidone and polyethylenimine as inhibitors for the corrosion of a low carbon steel in phosphoric acid, Corros. Sci., 1995, 37, 975-985.

97 M. Hegazy, Novel cationic surfactant based on triazole as a corrosion inhibitor for carbon steel in phosphoric acid produced by dihydrate wet process, J. Mol. Liq., 2015, 208, 227-236.

98 Y. G. Avdeev, M. Tyurina and Y. I. Kuznetsov, Protection of low-carbon steel in phosphoric acid solutions by mixtures of a substituted triazole with sulfur-containing compounds, Int. J. Corros Scale Inhib., 2014, 3, 246-253.

99 S. H. Zaferani, M. Sharifi, D. Zaarei and M. R. Shishesaz, Application of eco-friendly products as corrosion inhibitors for metals in acid pickling processes-A review, J. Environ. Chem. Eng., 2013, 1, 652-657.

100 K. Haruna, T. A. Saleh and M. Quraishi, Expired metformin drug as green corrosion inhibitor for simulated oil/gas well acidizing environment, J. Mol. Liq., 2020, 315, 113716.

101 A. Singh and M. A. Quraishi, Acidizing corrosion inhibitors: a review, J. Mater. Environ. Sci., 2015, 6, 224-235.

102 E. Ituen, V. Mkpenie and E. Dan, Surface protection of steel in oil well acidizing fluids using L-theanine-based corrosion inhibitor formulations: Experimental and theoretical evaluation, Surf. Interfaces, 2019, 16, 29-42.

103 P. Rajeev, A. Surendranathan and C. S. Murthy, Corrosion mitigation of the oil well steels using organic inhibitors-a review, J. Mater. Environ. Sci., 2012, 3, 856-869.
104 D. S. Chauhan, M. J. Mazumder, M. Quraishi, K. Ansari and R. Suleiman, Microwave-assisted synthesis of a new Piperonal-Chitosan Schiff base as a bio-inspired corrosion inhibitor for oil-well acidizing, Int. J. Biol. Macromol., 2020, 158, 231-243.

105 K. Haruna, I. Obot, N. Ankah, A. Sorour and T. Saleh, Gelatin: A green corrosion inhibitor for carbon steel in oil well acidizing environment, J. Mol. Liq., 2018, 264, 515-525.

106 M. Quraishi and D. Jamal, CAHMT-a new and ecofriendly acidizing corrosion inhibitor, Corrosion, 2000, 56, 983-985.

107 T. Philibert, B. H. Lee and N. Fabien, Current status and new perspectives on chitin and chitosan as functional biopolymers, Appl. Biochem. Biotechnol., 2017, 181, 1314-1337.

108 D. Raafat and H. G. Sahl, Chitosan and its antimicrobial potential-a critical literature survey, Microb. Biotechnol., 2009, 2, 186-201.

109 P. Suresh, Enzymatic technologies of chitin and chitosan, Enzym. Technol. Mar. Polysaccharides, 2019, p. 449.

110 I. Hamed, F. Özogul and J. M. Regenstein, Industrial applications of crustacean by-products (chitin, chitosan, and chitooligosaccharides): A review, Trends Food Sci. Technol., 2016, 48, 40-50.

111 P. K. Dutta, J. Dutta and V. Tripathi, Chitin and chitosan: Chemistry, properties and applications, 2004.

112 S.-K. Kim and N. Rajapakse, Enzymatic production and biological activities of chitosan oligosaccharides (COS): A review, Carbohydr. Polym., 2005, 62, 357-368.

113 T. Imai, S. Shiraishi, H. Saitô and M. Otagiri, Interaction of indomethacin with low molecular weight chitosan, and improvements of some pharmaceutical properties of indomethacin by low molecular weight chitosans, Int. J. Pharm., 1991, 67, 11-20.

114 A. Singla and M. Chawla, Chitosan: Some pharmaceutical and biological aspects-an update, J. Pharm. Pharmacol., 2001, 53, 1047-1067.

115 R. R. Mohamed and A. Fekry, Antimicrobial and anticorrosive activity of adsorbents based on chitosan Schiff's base, Int. J. Electrochem. Sci., 2011, 6, 2488-2508.

116 M. M. Solomon, H. Gerengi, T. Kaya and S. A. Umoren, Enhanced corrosion inhibition effect of chitosan for St37 in $15 \% \mathrm{H}_{2} \mathrm{SO}_{4}$ environment by silver nanoparticles, Int. J. Biol. Macromol., 2017, 104, 638-649.

117 J. Carneiro, J. Tedim and M. Ferreira, Chitosan as a smart coating for corrosion protection of aluminum alloy 2024: A review, Prog. Org. Coat., 2015, 89, 348-356.

118 E. Avcu, F. E. Baştan, H. Z. Abdullah, M. A. U. Rehman, Y. Y. Avcu and A. R. Boccaccini, Electrophoretic deposition of chitosan-based composite coatings for biomedical applications: A review, Prog. Mater. Sci., 2019, 103, 69-108.

119 Z. Guo, R. Xing, S. Liu, Z. Zhong, X. Ji, L. Wang and P. Li, Antifungal properties of Schiff bases of chitosan, $\mathrm{N}$-substituted chitosan and quaternized chitosan, Carbohydr. Res., 2007, 342, 1329-1332.

120 E. Portes, C. Gardrat, A. Castellan and V. Coma, Environmentally friendly films based on chitosan and tetrahydrocurcuminoid 
derivatives exhibiting antibacterial and antioxidative properties, Carbohydr. Polym., 2009, 76, 578-584.

121 M. F. Goosen, Applications of Chitan and Chitosan, CRC Press, 1996.

122 S. A. Umoren, M. J. Banera, T. Alonso-Garcia, C. A. Gervasi and M. V. Mirífico, Inhibition of mild steel corrosion in $\mathrm{HCl}$ solution using chitosan, Cellulose, 2013, 20, 2529-2545.

123 T. Rabizadeh and S. Khameneh, Asl, Chitosan as a green inhibitor for mild steel corrosion: Thermodynamic and electrochemical evaluations, Mater. Corros., 2019, 70, 738-748.

124 N. K. Gupta, P. Joshi, V. Srivastava and M. Quraishi, Chitosan: A macromolecule as green corrosion inhibitor for mild steel in sulfamic acid useful for sugar industry, Int. J. Biol. Macromol., 2018, 106, 704-711.

125 A. Jmiai, B. El Ibrahimi, A. Tara, R. Oukhrib, S. El Issami, O. Jbara, L. Bazzi and M. Hilali, Chitosan as an eco-friendly inhibitor for copper corrosion in acidic medium: protocol and characterization, Cellulose, 2017, 24, 3843-3867.

126 K. El Mouaden, B. El Ibrahimi, R. Oukhrib, L. Bazzi, B. Hammouti, O. Jbara, A. Tara, D. S. Chauhan and M. A. Quraishi, Chitosan polymer as a green corrosion inhibitor for copper in sulfide-containing synthetic seawater, Int. J. Biol. Macromol., 2018, 119, 1311-1323.

127 Y. Brou, N. Coulibaly, D. N'gys, J. Creus and A. Trokourey, Chitosan biopolymer effect on copper corrosion in $3.5 \mathrm{wt} \%$ $\mathrm{NaCl}$ solution: Electrochemical and quantum chemical studies, Int. J. Corros. Scale Inhib., 2020, 9, 182-200.

128 H. Harmami, I. Ulfin, A. H. Sakinah and Y. L. Ni'mah, Water-soluble chitosan from shrimp and mussel shells as corrosion inhibitor on tinplate in $2 \% \mathrm{NaCl}$, Mal. J. Fund. Appl. Sci., 2019, 15, 212-217.

129 Q. Zhao, J. Guo, G. Cui, T. Han and Y. Wu, Chitosan derivatives as green corrosion inhibitors for P110 steel in a carbon dioxide environment, Colloids Surf., B, 2020, 111150.

130 G. A. El-Mahdy, A. M. Atta, H. A. Al-Lohedan and A. O. Ezzat, Influence of green corrosion inhibitor based on chitosan ionic liquid on the steel corrodibility in chloride solution, Int. J. Electrochem. Sci., 2015, 10, 5812-5826.

131 A. M. Alsabagh, M. Z. Elsabee, Y. M. Moustafa, A. Elfky and R. E. Morsi, Corrosion inhibition efficiency of some hydrophobically modified chitosan surfactants in relation to their surface active properties, Egypt. J. Pet., 2014, 23, 349-359.

132 S. M. El-Sawy, Y. M. Abu-Ayana and F. A. Abdel-Mohdy, Some chitin/chitosan derivatives for corrosion protection and waste water treatments, Anti-Corros. Methods Mater., 2001, 48, 227-235.

133 D. Suyanto, H. Darmokoesemo, R. Ruriyanti and L. S. Anggara, Application chitosan derivatives as inhibitor corrosion on steel with fluidization method, J. Chem. Pharm. Res., 2015, 2, 260-267.

134 D. S. Chauhan, M. J. Mazumder, M. Quraishi and K. Ansari, Chitosan-cinnamaldehyde Schiff base: A bioinspired macromolecule as corrosion inhibitor for oil and gas industry, Int. J. Biol. Macromol., 2020, 158, 127-138.

135 H. Li, H. Li, Y. Liu and X. Huang, Synthesis of polyamine grafted chitosan copolymer and evaluation of its corrosion inhibition performance, J. Korean Chem. Soc., 2015, 59, 142-147.

136 T. Chen, D. Zeng and S. Zhou, Study of Polyaspartic Acid and Chitosan Complex Corrosion Inhibition and Mechanisms, Pol. J. Environ. Stud., 2018, 27, 1441-1448.

137 R. G. M. de Araújo Macedo, N. do Nascimento Marques, J. Tonholo and R. de Carvalho Balaban, Water-soluble carboxymethylchitosan used as corrosion inhibitor for carbon steel in saline medium, Carbohydr. Polym., 2019, 205, 371-376.

138 J. Haque, V. Srivastava, D. S. Chauhan, H. Lgaz and M. A. Quraishi, Microwave-induced synthesis of chitosan Schiff bases and their application as novel and green corrosion inhibitors: experimental and theoretical approach, ACS Omega, 2018, 3, 5654-5668.

139 M. Quraishi, K. Ansari, D. S. Chauhan, S. A. Umoren and M. Mazumder, Vanillin modified chitosan as a new bioinspired corrosion inhibitor for carbon steel in oil-well acidizing relevant to petroleum industry, Cellulose, 2020, 27, 6425-6443.

140 R. Menaka and S. Subhashini, Chitosan Schiff base as ecofriendly inhibitor for mild steel corrosion in $1 \mathrm{M} \mathrm{HCl}$, J. Adhes. Sci. Technol., 2016, 30, 1622-1640.

141 M. Li, J. Xu, R. Li, D. Wang, T. Li, M. Yuan and J. Wang, Simple preparation of aminothiourea-modified chitosan as corrosion inhibitor and heavy metal ion adsorbent, J. Colloid Interface Sci., 2014, 417, 131-136.

142 G. E. Luckachan and V. Mittal, Anti-corrosion behavior of layer by layer coatings of cross-linked chitosan and poly (vinyl butyral) on carbon steel, Cellulose, 2015, 22, 3275-3290.

143 D. Chauhan, V. Srivastava, P. Joshi and M. Quraishi, PEG cross-linked chitosan: a biomacromolecule as corrosion inhibitor for sugar industry, Int. J. Ind. Chem., 2018, 9, 363-377.

144 K. E. Mouaden, D. Chauhan, M. Quraishi and L. Bazzi, Thiocarbohydrazide-crosslinked chitosan as a bioinspired corrosion inhibitor for protection of stainless steel in $3.5 \%$ NaCl, Sustainable Chem. Pharm., 2020, 15, 100213.

145 V. Srivastava, D. S. Chauhan, P. G. Joshi, V. Maruthapandian, A. A. Sorour and M. A. Quraishi, PEG-Functionalized Chitosan: A Biological Macromolecule as a Novel Corrosion Inhibitor, ChemistrySelect, 2018, 3, 1990-1998.

146 P. Kong, H. Feng, N. Chen, Y. Lu, S. Li and P. Wang, Polyaniline/chitosan as a corrosion inhibitor for mild steel in acidic medium, RSC Adv., 2019, 9, 9211-9217.

147 A. Sanmugam, D. Vikraman, K. Karuppasamy, J. Y. Lee and H.-S. Kim, Evaluation of the corrosion resistance properties of electroplated chitosan- $\mathrm{Zn}_{1-x} \mathrm{Cu}_{x} \mathrm{O}$ composite thin films, Nanomaterials, 2017, 7, 432.

148 S. John, A. Joseph, A. J. Jose and B. Narayana, Enhancement of corrosion protection of mild steel by chitosan/ZnO nanoparticle composite membranes, Prog. Org. Coat., 2015, 84, 28-34.

149 P. A. Rasheed, K. A. Jabbar, K. Rasool, R. P. Pandey, M. H. Sliem, M. Helal, A. Samara, A. M. Abdullah and 
K. A. Mahmoud, Controlling the biocorrosion of sulfatereducing bacteria (SRB) on carbon steel using $\mathrm{ZnO} /$ chitosan nanocomposite as an eco-friendly biocide, Corros. Sci., 2019, 148, 397-406.

150 Y. Liu, C. Zou, X. Yan, R. Xiao, T. Wang and M. Li, $\beta$-Cyclodextrin modified natural chitosan as a green inhibitor for carbon steel in acid solutions, Ind. Eng. Chem. Res., 2015, 54, 5664-5672.

151 G. Jena, B. Anandkumar, S. Vanithakumari, R. George, J. Philip and G. Amarendra, Graphene oxide-chitosan-silver composite coating on $\mathrm{Cu}-\mathrm{Ni}$ alloy with enhanced anticorrosive and antibacterial properties suitable for marine applications, Prog. Org. Coat., 2020, 139, 105444.

152 M. M. Solomon, H. Gerengi, T. Kaya and S. A. Umoren, Performance evaluation of a chitosan/silver nanoparticles composite on St37 steel corrosion in a $15 \% \mathrm{HCl}$ solution, ACS Sustainable Chem. Eng., 2017, 5, 809-820.

153 E. Tabesh, H. Salimijazi, M. Kharaziha, M. Mahmoudi and M. Hejazi, Development of an in-situ chitosan-copper nanoparticle coating by electrophoretic deposition, Surf. Coat. Technol., 2019, 364, 239-247.

154 S. Karimi, E. Salahinejad, E. Sharifi, A. Nourian and L. Tayebi, Bioperformance of chitosan/fluoride-doped diopside nanocomposite coatings deposited on medical stainless steel, Carbohydr. Polym., 2018, 202, 600-610.

155 X. Zhai, Y. Ren, N. Wang, F. Guan, M. Agievich, J. Duan and B. Hou, Microbial Corrosion Resistance and Antibacterial Property of Electrodeposited Zn-Ni-Chitosan Coatings, Molecules, 2019, 24, 1974.

156 S. John, A. Salam, A. M. Baby and A. Joseph, Corrosion inhibition of mild steel using chitosan/ $\mathrm{TiO}_{2}$ nanocomposite coatings, Prog. Org. Coat., 2019, 129, 254-259.

157 L. Cordero-Arias, S. Cabanas-Polo, H. Gao, J. Gilabert, E. Sanchez, J. Roether, D. Schubert, S. Virtanen and A. R. Boccaccini, Electrophoretic deposition of nanostructured$\mathrm{TiO}_{2} /$ chitosan composite coatings on stainless steel, RSC Adv., 2013, 3, 11247-11254.

158 P. Ledwig, M. Kot, T. Moskalewicz and B. Dubiel, Electrophoretic deposition of $\mathrm{nc}^{-\mathrm{TiO}_{2}} /$ chitosan composite coatings on X2CrNiMo17-12-2 stainless steel, Arch. Metall. Mater., 2017, 62, 405-410.

159 B.-D. Hahn, D.-S. Park, J.-J. Choi, J. Ryu, W.-H. Yoon, J.-H. Choi, H.-E. Kim and S.-G. Kim, Aerosol deposition of hydroxyapatite-chitosan composite coatings on biodegradable magnesium alloy, Surf. Coat. Technol., 2011, 205, 3112-3118.

160 S. Sutha, K. Kavitha, G. Karunakaran and V. Rajendran, In-vitro bioactivity, biocorrosion and antibacterial activity of silicon integrated hydroxyapatite/chitosan composite coating on $316 \mathrm{~L}$ stainless steel implants, Mater. Sci. Eng.: C, 2013, 33, 4046-4054.

161 A. Molaei, M. Yari and M. R. Afshar, Investigation of halloysite nanotube content on electrophoretic deposition (EPD) of chitosan-bioglass-hydroxyapatite-halloysite nanotube nanocomposites films in surface engineering, Appl. Clay Sci., 2017, 135, 75-81.
162 L. L.d. Sousa, V. P. Ricci, D. G. Prado, R. C. Apolinario, L. C. d. O. Vercik, E. C. d. S. Rigo, M. C. d. S. Fernandes and N. A. Mariano, Titanium coating with hydroxyapatite and chitosan doped with silver nitrate, Mater. Res., 2017, 20, 863-868.

163 M. Stevanović, M. Đošić, A. Janković, V. Kojic, M. VukasinovicSekulic, J. Stojanović, J. Odović, M. Crevar Sakač, K. Y. Rhee and V. Mišković-Stanković, Gentamicin-loaded bioactive hydroxyapatite/chitosan composite coating electrodeposited on titanium, ACS Biomater. Sci. Eng., 2018, 4, 3994-4007.

164 F. Ordikhani, E. Tamjid and A. Simchi, Characterization and antibacterial performance of electrodeposited chitosanvancomycin composite coatings for prevention of implantassociated infections, Mater. Sci. Eng.: C, 2014, 41, 240-248.

165 P. Sambyal, G. Ruhi, S. Dhawan, B. Bisht and S. Gairola, Enhanced anticorrosive properties of tailored poly (anilineanisidine)/chitosan $/ \mathrm{SiO}_{2}$ composite for protection of mild steel in aggressive marine conditions, Prog. Org. Coat., 2018, 119, 203-213.

166 D. Junying, L. Weihua, W. Maotao, Z. Xia and H. Baorong, Synthesis and inhibition studies of carboxymethl chitosan doped polianiline for mild steel in hydrochloric acid, Acta Polym. Sin., 2010, 588-593.

167 S. P. Damari, L. Cullari, D. Laredo, R. Nadiv, E. Ruse, R. Sripada and O. Regev, Graphene and boron nitride nanoplatelets for improving vapor barrier properties in epoxy nanocomposites, Prog. Org. Coat., 2019, 136, 105207.

168 M. Srivastava, S. Srivastava, G. Ji and R. Prakash, Chitosan based new nanocomposites for corrosion protection of mild steel in aggressive chloride media, Int. J. Biol. Macromol., 2019, 140, 177-187.

169 H. Ashassi-Sorkhabi, R. Bagheri and B. Rezaei-moghadam, Sonoelectrochemical synthesis of ppy-MWCNTs-chitosan nanocomposite coatings: Characterization and corrosion behavior, J. Mater. Eng. Perform., 2015, 24, 385-392.

170 M. Barman, S. Mahmood, R. Augustine, A. Hasan, S. Thomas and K. Ghosal, Natural halloysite nanotubes/ chitosan based bio-nanocomposite for delivering norfloxacin, an anti-microbial agent in sustained release manner, Int. J. Biol. Macromol., 2020, 162, 1849-1861.

171 U. Eduok, E. Ohaeri and J. Szpunar, Conversion of Imidazole to N-(3-Aminopropyl)imidazole toward Enhanced Corrosion Protection of Steel in Combination with Carboxymethyl Chitosan Grafted Poly(2-methyl-1-vinylimidazole), Ind. Eng. Chem. Res., 2019, 58, 7179-7192.

172 U. Eduok and J. Szpunar, Biocorrosion Reduction of Pipeline Steel in Desulfovibrio ferrophilus Culture in the Presence of Carboxymethyl Chitosan Grafted Poly (2-methyl-1-vinylimidazole)/ Cerium Molybdate Nanocomposite, ECS Meeting Abstracts, IOP Publishing, 2019, p. 853.

173 A. Farhadian, M. A. Varfolomeev, A. Shaabani, S. Nasiri, I. Vakhitov, Y. F. Zaripova, V. V. Yarkovoi and A. V. Sukhov, Sulfonated chitosan as green and high cloud point kinetic methane hydrate and corrosion inhibitor: Experimental and theoretical studies, Carbohydr. Polym., 2020, 236, 116035.

174 R. Farahati, A. Ghaffarinejad, H. J. Rezania, S. M. MousaviKhoshdel and H. Behzadi, Sulfonated aromatic polyamide 
as water-soluble polymeric corrosion inhibitor of copper in HCl, Colloids Surf., A, 2019, 578, 123626.

175 G. Ruhi, O. Modi and S. Dhawan, Chitosan-polypyrrole$\mathrm{SiO}_{2}$ composite coatings with advanced anticorrosive properties, Synth. Met., 2015, 200, 24-39.

176 M. W. Bauer, L. E. Driskill, W. Callen, M. A. Snead, E. J. Mathur and R. M. Kelly, An endoglucanase, EglA, from the hyperthermophilic ArchaeonPyrococcus furiosus hydrolyzes $\beta-1,4$ bonds in mixed-linkage $(1 \rightarrow 3),(1 \rightarrow 4)$ - $\beta$-D-glucans and cellulose, J. Bacteriol., 1999, 181, 284-290.

177 A. Akaracharanya, T. Taprig, J. Sitdhipol and S. Tanasupawat, Characterization of cellulase producing Bacillus and Paenibacillus strains from Thai soils, J. Appl. Pharm. Sci., 2014, 4, 6.

178 S. Kalia, B. Kaith and I. Kaur, Cellulose fibers: bio-and nanopolymer composites: green chemistry and technology, Springer Science \& Business Media, 2011.

179 S. Gawande, Cellulose: A Natural Polymer on the Earth, Int. J. Polym. Sci. Eng., 2017, 3, 32-37.

180 L. Walker and D. Wilson, Enzymatic hydrolysis of cellulose: an overview, Bioresour. Technol., 1991, 36, 3-14.

181 A. C. O'Sullivan, Cellulose: the structure slowly unravels, Cellulose, 1997, 4, 173-207.

182 S. A. Umoren and U. M. Eduok, Application of carbohydrate polymers as corrosion inhibitors for metal substrates in different media: a review, Carbohydr. Polym., 2016, 140, 314-341.

183 S. Umoren, M. Solomon, I. Udosoro and A. Udoh, Synergistic and antagonistic effects between halide ions and carboxymethyl cellulose for the corrosion inhibition of mild steel in sulphuric acid solution, Cellulose, 2010, 17, 635-648.

184 M. M. Solomon, H. Gerengi and S. A. Umoren, Carboxymethyl cellulose/silver nanoparticles composite: synthesis, characterization and application as a benign corrosion inhibitor for St37 steel in $15 \% \mathrm{H}_{2} \mathrm{SO}_{4}$ medium, ACS Appl. Mater. Interfaces, 2017, 9, 6376-6389.

185 M. N. El-Haddad, Hydroxyethylcellulose used as an ecofriendly inhibitor for $1018 \mathrm{c}$-steel corrosion in 3.5\% NaCl solution, Carbohydr. Polym., 2014, 112, 595-602.

186 I. Arukalam, I. Madufor, O. Ogbobe and E. Oguzie, Inhibition of mild steel corrosion in sulfuric acid medium by hydroxyethyl cellulose, Chem. Eng. Commun., 2015, 202, 112-122.

187 M. Mobin and M. Rizvi, Adsorption and corrosion inhibition behavior of hydroxyethyl cellulose and synergistic surfactants additives for carbon steel in $1 \mathrm{M} \mathrm{HCl}$, Carbohydr. Polym., 2017, 156, 202-214.

188 I. Arukalam, I. Madu, N. Ijomah, C. Ewulonu and G. Onyeagoro, Acid corrosion inhibition and adsorption behaviour of ethyl hydroxyethyl cellulose on mild steel corrosion, J. Mater., 2014, 2014, 1-11.

189 M. Deyab, Hydroxyethyl cellulose as efficient organic inhibitor of zinc-carbon battery corrosion in ammonium chloride solution: Electrochemical and surface morphology studies, J. Power Sources, 2015, 280, 190-194.

190 S. Nwanonenyi, H. Obasi and I. Eze, Hydroxypropyl Cellulose as an Efficient Corrosion Inhibitor for Aluminium in Acidic Environments: Experimental and Theoretical Approach, Chem. Africa, 2019, 2, 471-482.
191 I. Arukalam, I. Madufor, O. Ogbobe and E. Oguzie, Cellulosic polymers for corrosion protection of aluminium, Int. J. Eng. Tech. Res., 2015, 3, 163-169.

192 I. Arukalam, I. Madufor, O. Ogbobe and E. Oguzie, Experimental and theoretical studies of hydroxyethyl cellulose as inhibitor for acid corrosion inhibition of mild steel and aluminium, Open Corros. J., 2014, 6, 1-10.

193 K. Andarany, A. Sagir, A. Ahmad, S. Deni and W. Gunawan, Cellulose acetate layer effect toward aluminium corrosion rate in hydrochloric acid media, IOP Conference Series: Materials Science and Engineering, Institute of Physics Publishing, 2017.

194 O. Egbuhuzor, I. Madufor, S. Nwanonenyi and J. Bokolo, Adsorption behavior and corrosion rate model of sodium carboxymethyl cellulose (NA-CMC) polymer on aluminium in hcl solution, Niger. J. Technol., 2020, 39, 369-378.

195 I. O. Arukalam, I. K. Nleme and A. E. Anyanwu, Comparative inhibitive effect of hydroxyethylcellulose on mild steel and aluminium corrosion in $0.5 \mathrm{M} \mathrm{HCl}$ solution, Acad. Res. Int., 2011, 1, 492.

196 S. A. Umoren, A. A. AlAhmary, Z. M. Gasem and M. M. Solomon, Evaluation of chitosan and carboxymethyl cellulose as ecofriendly corrosion inhibitors for steel, Int. J. Biol. Macromol., 2018, 117, 1017-1028.

197 I. Arukalam, I. Madufor, O. Ogbobe and E. Oguzie, Acidic corrosion inhibition of copper by hydroxyethyl cellulose, Curr. J. Appl. Sci. Technol., 2014, 1445-1460.

198 M.-M. Li, Q.-J. Xu, J. Han, H. Yun and Y. Min, Inhibition action and adsorption behavior of green inhibitor sodium carboxymethyl cellulose on copper, Int. J. Electrochem. Sci., 2015, 10, 9028-9041.

199 M. S. Hasanin and S. A. Al Kiey, Environmentally benign corrosion inhibitors based on cellulose niacin nanocomposite for corrosion of copper in sodium chloride solutions, Int. J. Biol. Macromol., 2020, 161, 345-354.

200 T. Brinda, J. Mallika and V. Sathyanarayana, Moorthy, Synergistic effect between starch and substituted piperidin4-one on the corrosion inhibition of mild steel in acidic medium, J. Mater. Environ. Sci., 2015, 6, 191-200.

201 M. Mobin, M. Khan and M. Parveen, Inhibition of mild steel corrosion in acidic medium using starch and surfactants additives, J. Appl. Polym. Sci., 2011, 121, 1558-1565.

202 M. Bello, N. Ochoa, V. Balsamo, F. López-Carrasquero, S. Coll, A. Monsalve and G. González, Modified cassava starches as corrosion inhibitors of carbon steel: An electrochemical and morphological approach, Carbohydr. Polym., 2010, 82, 561-568.

203 R. Rosliza and W. W. Nik, Improvement of corrosion resistance of AA6061 alloy by tapioca starch in seawater, Curr. Appl. Phys., 2010, 10, 221-229.

204 X. Li and S. Deng, Cassava starch graft copolymer as an eco-friendly corrosion inhibitor for steel in $\mathrm{H}_{2} \mathrm{SO}_{4}$ solution, Korean J. Chem. Eng., 2015, 32, 2347-2354.

205 M. V. Fiori-Bimbi, P. E. Alvarez, H. Vaca and C. A. Gervasi, Corrosion inhibition of mild steel in HCL solution by pectin, Corros. Sci., 2015, 92, 192-199. 
206 S. A. Umoren, I. B. Obot, A. Madhankumar and Z. M. Gasem, Performance evaluation of pectin as ecofriendly corrosion inhibitor for X60 pipeline steel in acid medium: Experimental and theoretical approaches, Carbohydr. Polym., 2015, 124, 280-291.

207 A. N. Grassino, J. Halambek, S. Djaković, S. R. Brnčić, M. Dent and Z. Grabarić, Utilization of tomato peel waste from canning factory as a potential source for pectin production and application as tin corrosion inhibitor, Food Hydrocolloids, 2016, 52, 265-274.

208 M. M. Fares, A. Maayta and M. M. Al-Qudah, Pectin as promising green corrosion inhibitor of aluminum in hydrochloric acid solution, Corros. Sci., 2012, 60, 112-117.

209 R. Geethanjali, A. Sabirneeza and S. Subhashini, Watersoluble and biodegradable pectin-grafted polyacrylamide and pectin-grafted polyacrylic acid: electrochemical investigation of corrosion-inhibition behaviour on mild steel in 3.5\% NaCl media, Indian J. Mater. Sci., 2014, 2014, 1-9.

210 B. Charitha and P. Rao, Pectin as a Potential Green Inhibitor for Corrosion Control of $6061 \mathrm{Al}-15 \%(\mathrm{~V}) \mathrm{SiC}(\mathrm{P})$ Composite in Acid Medium: Electrochemical and Surface Studies, J. Fail. Anal. Prev., 2020, 1-13.

211 A. Biswas, D. Das, H. Lgaz, S. Pal and U. G. Nair, Biopolymer dextrin and poly (vinyl acetate) based graft copolymer as an efficient corrosion inhibitor for mild steel in hydrochloric acid: electrochemical, surface morphological and theoretical studies, J. Mol. Liq., 2019, 275, 867-878.

212 G. N. Devi, C. B. N. Unnisa, S. M. Roopan, V. Hemapriya, S. Chitra, I.-M. Chung, S.-H. Kim and M. Prabakaran, Floxacins: as Mediators in Enhancing the Corrosion Inhibition Efficiency of Natural Polymer Dextrin, Macromol. Res., 2020, 1-9.

213 A. Altin, M. Rohwerder and A. Erbe, Cyclodextrins as carriers for organic corrosion inhibitors in organic coatings, J. Electrochem. Soc., 2017, 164, C128.

214 S. Amiri and A. Rahimi, Anticorrosion behavior of cyclodextrins/inhibitor nanocapsule-based self-healing coatings, J. Coat. Technol. Res., 2016, 13, 1095-1102.

215 A. Khramov, N. Voevodin, V. Balbyshev and R. Mantz, Solgel-derived corrosion-protective coatings with controllable release of incorporated organic corrosion inhibitors, Thin Solid Films, 2005, 483, 191-196.

216 R. M. Hassan and I. A. Zaafarany, Kinetics of corrosion inhibition of aluminum in acidic media by water-soluble natural polymeric pectates as anionic polyelectrolyte inhibitors, Materials, 2013, 6, 2436-2451.

217 I. Zaafarany, Corrosion inhibition of aluminum in aqueous alkaline solutions by alginate and pectate water-soluble natural polymer anionic polyelectrolytes, Port. Electrochim. Acta, 2012, 30, 419-426.

218 S. M. Shaban, I. Aiad, A. H. Moustafa and O. H. Aljoboury, Some alginates polymeric cationic surfactants; surface study and their evaluation as biocide and corrosion inhibitors, J. Mol. Liq., 2019, 273, 164-176.

219 R. Hassan, I. Zaafarany, A. Gobouri and H. Takagi, A revisit to the corrosion inhibition of aluminum in aqueous alkaline solutions by water-soluble alginates and pectates as anionic polyelectrolyte inhibitors, Int. J. Corros., 2013, 2013, 1-8.

220 S. Umoren and E. Ebenso, Studies of the anti-corrosive effect of Raphia hookeri exudate gum-halide mixtures for aluminium corrosion in acidic medium, Pigment \& Resin Technology, (2008).

221 S. Umoren, I. Obot, E. Ebenso and P. Okafor, Eco-friendly inhibitors from naturally occurring exudate gums for aluminium corrosion inhibition in acidic medium, Port. Electrochim. Acta, 2008, 26, 267-282.

222 J. Buchweishaija and G. Mhinzi, Natural products as a source of environmentally friendly corrosion inhibitors: the case of gum exudate from Acacia seyal var. seyal, Port. Electrochim. Acta, 2008, 26, 257-265.

223 S. Umoren, I. Obot, E. Ebenso and N. Obi-Egbedi, The Inhibition of aluminium corrosion in hydrochloric acid solution by exudate gum from Raphia hookeri, Desalination, 2009, 247, 561-572.

224 S. Umoren, I. Obot and E. Ebenso, Corrosion inhibition of aluminium using exudate gum from Pachylobus edulis in the presence of halide ions in $\mathrm{HCl}, \mathrm{J}$. Chem., 2008, 5, 1-10.

225 J. Buchweishaija, Plants as a source of green corrosion inhibitors: the case of gum exudates from Acacia species (A. drepanolobium and A. senegal), Tanz. J. Sci., 2009, 35, 93-106.

226 F. Waanders, S. Vorster and A. Geldenhuys, Biopolymer corrosion inhibition of mild steel: electrochemical/mössbauer results, Hyperfine Interact., 2002, 139, 133-139.

227 S. A. Umoren and M. M. Solomon, Synergistic corrosion inhibition effect of metal cations and mixtures of organic compounds: a review, J. Environ. Chem. Eng., 2017, 5, 246-273.

228 D. E. Arthur, A. Jonathan, P. O. Ameh and C. Anya, A review on the assessment of polymeric materials used as corrosion inhibitor of metals and alloys, Int. J. Ind. Chem., 2013, 4, 2.

229 A. Peter, I. Obot and S. K. Sharma, Use of natural gums as green corrosion inhibitors: an overview, Int. J. Ind. Chem., 2015, 6, 153-164.

230 S. Mo, H.-Q. Luo and N.-B. Li, Plant extracts as "green" corrosion inhibitors for steel in sulphuric acid, Chem. Pap., 2016, 70, 1131-1143.

231 A. Miralrio and A. Espinoza Vázquez, Plant Extracts as Green Corrosion Inhibitors for Different Metal Surfaces and Corrosive Media: A Review, Processes, 2020, 8, 942.

232 A. Fateh, M. Aliofkhazraei and A. Rezvanian, Review of corrosive environments for copper and its corrosion inhibitors, Arabian J. Chem., 2020, 13, 481-544.

233 A. Hamilton-Amachree and N. B. Iroha, Corrosion inhibition of API 5L X80 pipeline steel in acidic environment using aqueous extract of Thevetia peruviana, Chem. Int., 2020, 6, 117-128.

234 V. Izionworu, C. Ukpaka and E. Oguzie, Green and eco-benign corrosion inhibition agents: Alternatives and options to chemical based toxic corrosion inhibitors, Chem. Int., 2020, 6, 232-259.

235 R. Yadav and M. Agarwala, Phytochemical analysis of some medicinal plants, J. Phytol., 2011, 3, 10-14. 
236 A. Altemimi, N. Lakhssassi, A. Baharlouei, D. G. Watson and D. A. Lightfoot, Phytochemicals: Extraction, isolation, and identification of bioactive compounds from plant extracts, Plants, 2017, 6, 42.

237 D. O. Kennedy and E. L. Wightman, Herbal extracts and phytochemicals: plant secondary metabolites and the enhancement of human brain function, Adv. Nutr., 2011, 2, 32-50.

238 G. Bahlakeh, M. Ramezanzadeh and B. Ramezanzadeh, Experimental and theoretical studies of the synergistic inhibition effects between the plant leaves extract (PLE) and zinc salt (ZS) in corrosion control of carbon steel in chloride solution, J. Mol. Liq., 2017, 248, 854-870.

239 N. O. Eddy, S. A. Odoemelam and A. O. Odiongenyi, Inhibitive, adsorption and synergistic studies on ethanol extract of Gnetum africana as green corrosion inhibitor for mild steel in $\mathrm{H}_{2} \mathrm{SO}_{4}$, Green Chem. Lett. Rev., 2009, 2, 111-119.

240 J. Tan, L. Guo, H. Yang, F. Zhang and Y. El Bakri, Synergistic effect of potassium iodide and sodium dodecyl sulfonate on the corrosion inhibition of carbon steel in $\mathrm{HCl}$ medium: a combined experimental and theoretical investigation, RSC Adv., 2020, 10, 15163-15170.

241 C. Verma, E. E. Ebenso, I. Bahadur and M. Quraishi, An overview on plant extracts as environmental sustainable and green corrosion inhibitors for metals and alloys in aggressive corrosive media, J. Mol. Liq., 2018, 266, 577-590.

242 M. Mehdipour, B. Ramezanzadeh and S. Arman, Electrochemical noise investigation of Aloe plant extract as green inhibitor on the corrosion of stainless steel in $1 \mathrm{M} \mathrm{H}_{2} \mathrm{SO}_{4}$, J. Ind. Eng. Chem., 2015, 21, 318-327.

243 M. N. Jane and T. M. Nakara, Determination of the Corrosion Inhibition Effect of Terminalia Ivorensis Leaves Extract on Galvanized and Mild Steel in Sulphuric Acid Media, American, J. Phys. Chem., 2019, 8, 11.

244 K. H. Hassan, A. A. Khadom and N. H. Kurshed, Citrus aurantium leaves extracts as a sustainable corrosion inhibitor of mild steel in sulfuric acid, S. Afr. J. Chem. Eng., 2016, 22, 1-5.

245 P. Okafor, I. Uwah, O. Ekerenam and U. Ekpe, Combretum bracteosum extracts as eco-friendly corrosion inhibitor for mild steel in acidic medium, Pigm. Resin Technol., 2009, 38, 236-241.

246 S. Umoren, U. Eduok, M. Solomon and A. Udoh, Corrosion inhibition by leaves and stem extracts of Sida acuta for mild steel in $1 \mathrm{M} \mathrm{H} 2 \mathrm{SO} 4$ solutions investigated by chemical and spectroscopic techniques, Arabian J. Chem., 2016, 9, S209-S224.

247 P. Muthukrishnan, B. Jeyaprabha and P. Prakash, Mild steel corrosion inhibition by aqueous extract of Hyptis suaveolens leaves, Int. J. Ind. Chem., 2014, 5, 5.

248 A. Abdulrahman, K. Ganiyu and I. Kobe, A. Caroline, The corrosion inhibition of mild steel in sulphuric acid solution by adsorption of African Perquetina leaves extract, Int. J. Innovative Res. Sci. Eng. Technol., 2015, 4, 1809-1821.

249 V. Vasudha and K. S. Priya, Corrosion inhibition of mild steel in $\mathrm{H} 2 \mathrm{SO} 4$ media using Polyalthia longifolia leaves, Chem. Sci. Rev. Lett., 2014, 2, 435-443.
250 K. Ramya and N. Muralimohan, Study on Corrosion Inhibitor in Mild Steel by Various Habitual Plant Extract-Review, Int. J. Chem. Concepts, 2016, 2, 70-75.

251 R. Lopes-Sesenes, J. Gonzalo Gonzalez-Rodruguez, G. Francisca Dominguez-Patino and A. Marinez-Villafane, Corrosion inhibition of carbon steel by extract of Buddleia perfoliata, J. Electrochem. Sci. Eng., 2012, 2, 77-90.

252 A. Singh, Cassia tora Leaves Extract as Mild Steel Corrosion Inhibitor in Sulphuric Acid Solution, Imp. J. Interdiscip. Res., 2016, 2, 1-3.

253 O. A. Omotosho, O. O. Ajayi, O. S. Fayomi and V. O. Ifepe, Assessing the deterioration behaviour of mild steel in $2 \mathrm{M}$ sulphuric acid using Bambusa glauscescens, Int. J. Appl. Eng. Res., Dindigul, 2011, 2, 406-418.

254 J. Bhawsar, P. Jain and P. Jain, Experimental and computational studies of Nicotiana tabacum leaves extract as green corrosion inhibitor for mild steel in acidic medium, Alex. Eng. J., 2015, 54, 769-775.

255 A. Caroline, A. Abdulrahaman, I. Kobe, K. Ganiyu and S. Adams, Inhibitive performance of bitter leaf root extract on mild steel corrosion in sulphuric acid solution, Am. J. Mater. Eng. Technol., 2015, 3, 35-45.

256 O. O. Dominic and O. Monday, Optimization of The Inhibition Efficiency Of Mango Extract As Corrosion Inhibitor Of Mild Steel In $1.0 \mathrm{MH}_{2} \mathrm{SO}_{4}$ Using Response Surface Methodology, J. Chem. Technol. Metall., 2016, 51, 302-314.

257 M. Al-Ghorbani, B. Begum, M. S. Zabiulla and S. A. Khanum, J. Chem. Pharm. Res., 2015, 7(5), 281-301.

258 F. O. Nwosu, L. A. Nnanna and K. Okeoma, Corrosion inhibition for mild steel in $0.5 \mathrm{M} \mathrm{H} 2 \mathrm{SO} 4$ solution using Achyranthes aspera L. leaf extract, Afr. J. Pure Appl. Chem., 2013, 7, 56-60.

259 S. A. Kumar, A. Sankar and S. Rameshkumar, Oxystelma esculentum leaves extracts as corrosion inhibitor for mild steel in acid medium, Int. J. Sci. Technol. Res., 2013, 2, 55-58.

260 P. Ejikeme, S. Umana, M. Menkiti and O. Onukwuli, Inhibition of Mild Steel and Aluminium Corrosion in $1 \mathrm{M}$ $\mathrm{H}_{2} \mathrm{SO}_{4}$ by Leaves Extract of African Breadfruit, Int. J. Mater. Chem., 2015, 5, 14-23.

261 O. U. Abakedi, V. F. Ekpo and E. E. John, Corrosion inhibition of mild steel by Stachytarpheta indica leaf extract in acid medium, Pharm. Chem. J., 2016, 3, 165-171.

262 J. Omotoyinbo, D. Oloruntoba and S. Olusegun, Corrosion Inhibition of Pulverized Jatropha Curcas Leaves on Medium Carbon Steel in $0.5 \mathrm{M} \mathrm{H} 2 \mathrm{SO} 4$ and $\mathrm{NaCl}$ Environments, Int. J. Sci. Technol., 2013, 2, 510-514.

263 U. Eduok, S. Umoren and A. Udoh, Synergistic inhibition effects between leaves and stem extracts of Sida acuta and iodide ion for mild steel corrosion in $1 \mathrm{M} \mathrm{H}_{2} \mathrm{SO}_{4}$ solutions, Arabian J. Chem., 2012, 5, 325-337.

264 N. Patel, S. Jauhariand, G. Mehta, S. Al-Deyab, I. Warad and B. Hammouti, Mild steel corrosion inhibition by various plant extracts in $0.5 \mathrm{M}$ sulphuric acid, Int. J. Electrochem. Sci., 2013, 8, 2655.

265 I. Uwah, P. Okafor and V. Ebiekpe, Inhibitive action of ethanol extracts from Nauclea latifolia on the corrosion of 
mild steel in $\mathrm{H}_{2} \mathrm{SO}_{4}$ solutions and their adsorption characteristics, Arabian J. Chem., 2013, 6, 285-293.

266 A. El-Etre, Inhibition of acid corrosion of carbon steel using aqueous extract of olive leaves, J. Colloid Interface Sci., 2007, 314, 578-583.

267 M. Mahat, M. Kamarudin, J. Isa, N. Bonnia and N. Jani, Azadirachta excelsa as green corrosion inhibitor for mild steel in acidic medium, Business, Engineering and Industrial Applications (ISBEIA), 2012 IEEE Symposium on, IEEE, 2012, pp. 538-541.

268 K. Rose, B.-S. Kim, K. Rajagopal, S. Arumugam and K. Devarayan, Surface protection of steel in acid medium by Tabernaemontana divaricata extract: Physicochemical evidence for adsorption of inhibitor, J. Mol. Liq., 2016, 214, 111-116.

269 F. E. Awe, S. O. Idris, M. Abdulwahab and E. E. Oguzie, Theoretical and experimental inhibitive properties of mild steel in $\mathrm{HCl}$ by ethanolic extract of Boscia senegalensis, Cogent Chem., 2015, 1, 1112676.

270 K. Anupama, K. Ramya and A. Joseph, Electrochemical and computational aspects of surface interaction and corrosion inhibition of mild steel in hydrochloric acid by Phyllanthus amarus leaf extract (PAE), J. Mol. Liq., 2016, 216, 146-155.

271 A. Rajendran and C. Karthikeyan, The inhibitive effect of extract of flowers of Cassia auriculata in $2 \mathrm{M} \mathrm{HCl}$ on the corrosion of aluminium and mild steel, Int. J. Plant Res., 2012, 2, 9-14.

272 V. Rajeswari, D. Kesavan, M. Gopiraman, P. Viswanathamurthi, K. Poonkuzhali and T. Palvannan, Corrosion inhibition of Eleusine aegyptiaca and Croton rottleri leaf extracts on cast iron surface in $1 \mathrm{M} \mathrm{HCl}$ medium, Appl. Surf. Sci., 2014, 314, 537-545.

273 S. Umoren, Z. Gasem and I. Obot, Date palm (Phoenix dactylifera) leaf extract as an eco-friendly corrosion inhibitor for carbon steel in 1M hydrochloric acid solution, Anti-Corros. Methods Mater., 2015, 62, 19-28.

274 K. Anupama, K. Ramya, K. Shainy and A. Joseph, Adsorption and electrochemical studies of Pimenta dioica leaf extracts as corrosion inhibitor for mild steel in hydrochloric acid, Mater. Chem. Phys., 2015, 167, 28-41.

275 K. Anupama, K. Shainy and A. Joseph, Excellent anticorrosion behavior of Ruta Graveolens extract (RGE) for mild steel in hydrochloric acid: electro analytical studies on the effect of time, temperature, and inhibitor concentration, J. Bio-and Tribo-Corros., 2016, $2,2$.

276 T. Ibrahim, H. Alayan and Y. Al Mowaqet, The effect of Thyme leaves extract on corrosion of mild steel in $\mathrm{HCl}$, Prog. Org. Coat., 2012, 75, 456-462.

277 J. Rosaline Vimala, A. Leema Rose and S. Raja, A study on the phytochemical analysis and corrosion inhibition on mild steel by Annona Muricata. L leaves extract in $1 \mathrm{~N}$ Hydrochloric Acid, Der Chem. Sin., 2012, 3, 582-588.

278 A. Lecante, F. Robert, P. Blandinières and C. Roos, Anticorrosive properties of S. tinctoria and G. ouregou alkaloid extracts on low carbon steel, Curr. Appl. Phys., 2011, 11, 714-724.
279 L. Li, W. Xu, J. Lei, J. Wang, J. He, N. Li and F. Pan, Experimental and theoretical investigations of Michelia alba leaves extract as a green highly-effective corrosion inhibitor for different steel materials in acidic solution, RSC Adv., 2015, 5, 93724-93732.

280 M. Jokar, T. S. Farahani and B. Ramezanzadeh, Electrochemical and surface characterizations of morus alba pendula leaves extract (MAPLE) as a green corrosion inhibitor for steel in $1 \mathrm{M} \mathrm{HCl}$, J. Taiwan Inst. Chem. Eng., 2016, 63, 436-452.

281 L. Nnanna, W. John, E. Emenike, U. Ihekoronye and I. Dike, Corrosion Inhibition Effect of Anthocleista Djalonensis on Mild Steel in 1.0 M HCL, Int. J. Eng. Res. Rev., 2015, 3, 31-36.

282 K. Krishnaveni, J. Ravichandran and A. Selvaraj, Effect of Morinda tinctoria leaves extract on the corrosion inhibition of mild steel in acid medium, Arabian J. Chem., 2013, 26, 321-327.

283 P. Muthukrishnan, P. Prakash, B. Jeyaprabha and K. Shankar, Stigmasterol extracted from Ficus hispida leaves as a green inhibitor for the mild steel corrosion in $1 \mathrm{M} \mathrm{HCl}$ solution, Arab. J. Chem., 2015, 12, 3345-3356.

284 K. Hema, A. Sirajunnisa, B. Venkatraman and A. Subramania, The Effect of Solanam Xanthocarpum Leaves Extract on Corrosion Inhibition of Carbon Steel in Acidic Medium, Int. J. Adv. Res. Chem. Sci., 2015, 2, 10-20.

285 A. Sirajunnisa, M. F. Mohamed, A. Subramania and B. Venkatraman, The inhibitive effect of Ziziphus jujuba leaves extract on the alkaline corrosion of aluminium, Eur. J. Appl. Sci. Technol., 2014, 1, 23-31.

286 A. Okoronkwo, S. Olusegun and O. Olaniran, Acid extract of Gliricidia sepium leaves as green corrosion inhibitor for mild steel in $\mathrm{HCl}$ solutions, African Corr. J., 2015, 1, 30-35.

287 P. Deivanayagam, I. Malarvizhi and S. Selvaraj, Alcoholic extract of "Gymnema Sylvestre" leaves on mild steel in acid medium Quinquefasciatus say, Int. J. Adv. Sci. Res., 2016, 1, 21-27.

288 M. ur Rahman, S. Gul, M. Umair, A. Anwar and A. Achakzai, Anticorrosive Activity of Rosemarinus officinalis L. Leaves Extract Against Mild Steel in Dilute Hydrochloric Acid, Int. J. Innovative Res. Adv. Eng., 2016, 3, 38-43.

289 G. Ji, S. K. Shukla, P. Dwivedi, S. Sundaram and R. Prakash, Inhibitive effect of Argemone mexicana plant extract on acid corrosion of mild steel, Ind. Eng. Chem. Res., 2011, 50, 11954-11959.

290 S. Ulaeto, U. Ekpe, M. Chidiebere and E. Oguzie, Corrosion inhibition of mild steel in hydrochloric acid by acid extracts of Eichhornia crassipes, Int. J. Mater. Chem., 2012, 2, 158-164.

291 P. M. Krishnegowda, V. T. Venkatesha, P. K. M. Krishnegowda and S. B. Shivayogiraju, Acalypha torta leaf extract as green corrosion inhibitor for mild steel in hydrochloric acid solution, Ind. Eng. Chem. Res., 2013, 52, 722-728.

292 A. Sharmila, A. A. Prema and P. A. Sahayaraj, Influence of Murraya koenigii (curry leaves) extract on the corrosion 
inhibition of carbon steel in HCL solution, Rasayan J. Chem., 2010, 3, 74-81.

293 M. N. Fathima, A. Prithiba, S. Leelavathi and R. Rajalakshmi, Investigation of Podranea ricasolianaLeaves Extract as Green Corrosion Inhibitor for Mild Steel in $1 \mathrm{M} \mathrm{HCl}$, Int. J. Adv. Sci. Res. Manage., 2016, 1, 123-130.

294 S. Muthumanickam, B. Jeyaprabha, R. Karthik, A. Elangovan and P. Prakash, Adsorption and corrosion inhibiting behavior of Passiflora foetida leaf extract on mild steel corrosion, Int. J. Corros. Scale Inhib., 2015, 4, 365-381.

295 S. Kuppusamy, T. Palanisami, M. Megharaj, K. Venkateswarlu and R. Naidu, In-situ remediation approaches for the management of contaminated sites: a comprehensive overview, Reviews of Environmental Contamination and Toxicology, Springer, 2016, vol. 236, pp. 1-115.

296 M. Ikpi, I. Udoh, P. Okafor, U. Ekpe and E. Ebenso, Corrosion inhibition and adsorption behaviour of extracts from Piper guineensis on mild steel corrosion in acid media, Int. J. Electrochem. Sci., 2012, 7, 12193-12206.

297 I. Iloamaeke, T. Onuegbu, V. Ajiwe and U. Umeobika, Corrosion inhibition of mild steel by pterocarpus soyauxi leaves extract in HCL Medium, Int. J. Plant, Anim. Environ. Sci., 2012, 2, 22-28.

298 S. Firdausi and F. Kurniawan, Corrosion Inhibition by Tithonia diversifolia (Hemsl) A. Gray leaves extract for 304 SS in hydrochloric acid solution, J. Phys.: Conf. Ser., 2016, 012042.

299 M. Bodude and O. Sanni, Evaluation of Inhibitive Performance of Some Plants Extracts on Low Carbon Steel Corrosion, Stud. Eng. Technol., 2014, 1, 21-28.

300 L. A. Nnanna and I. O. Owate, Electrochemical Study of Corrosion Inhibition of Mild Steel in Acidic Solution Using Gnetum africana Leaves Extracts, Br. J. Appl. Sci. Technol., 2015, 5, 556.

301 R. D'Souza and A. Chattree, Emblica Officinalis Leaves Extract as Corrosion Inhibitor, Chem. Sci. Trans., 2015, 4, 865-870.

302 G. M. Al-Senani, S. I. Al-Saeedi and R. Almufarij, Green corrosion inhibitors for carbon steel by green leafy vegetables extracts in $1 \mathrm{M} \mathrm{HCl}$, Orient. J. Chem., 2015, 31, 2077-2086.

303 H. H. Al-Sahlanee, A.-W. A. Sultan and M. M. Al-Faize, Corrosion Inhibition of Carbon Steel in 1M HCl Solution Using Sesbania Sesban Extract, Aqua. Sci. Technol., 2013, 1, 135-151.

304 D. K. Verma and F. Khan, Corrosion inhibition of mild steel by extract of Bryophyllum pinnatum leaves in acidic solution, Chem. Mater. Res., 2015, 7, 69-76.

305 E. E. Oguzie, Corrosion inhibition of aluminium in acidic and alkaline media by Sansevieria trifasciata extract, Corros. Sci., 2007, 49, 1527-1539.

306 A. Singh, I. Ahamad and M. A. Quraishi, Piper longum extract as green corrosion inhibitor for aluminium in $\mathrm{NaOH}$ solution, Arabian J. Chem., 2016, 9, S1584-S1589.

307 O. K. Abiola, J. Otaigbe and O. Kio, Gossipium hirsutum L. extracts as green corrosion inhibitor for aluminum in NaOH solution, Corros. Sci., 2009, 51, 1879-1881.
308 D. I. Njoku, G. N. Onuoha, E. E. Oguzie, K. L. Oguzie, A. A. Egbedina and A. N. Alshawabkeh, Nicotiana tabacum leaf extract protects aluminium alloy AA3003 from acid attack, Arabian J. Chem., 2016, 12, 4466-4478.

309 O. K. Abiola and J. Otaigbe, The effects of Phyllanthus amarus extract on corrosion and kinetics of corrosion process of aluminum in alkaline solution, Corros. Sci., 2009, 51, 2790-2793.

310 N. Chaubey, D. K. Yadav, V. K. Singh and M. Quraishi, A comparative study of leaves extracts for corrosion inhibition effect on aluminium alloy in alkaline medium, Ain Shams Eng. J., 2015, 8, 673-682.

311 S. Deng and X. Li, Inhibition by Jasminum nudiflorum Lindl. leaves extract of the corrosion of aluminium in $\mathrm{HCl}$ solution, Corros. Sci., 2012, 64, 253-262.

312 K. Ajanaku, C. Ajanaku, A. Akinsiku, A. Falomo, A. Edobor-Osoh and M. John, Eco-friendly Impact of Vernonia amygdalina as corrosion inhibitor on aluminium in acidic media, Chem. J., 2012, 2, 153-157.

313 N. Raghavendra and J. I. Bhat, Green approach to inhibition of corrosion of aluminum in $0.5 \mathrm{M} \mathrm{HCl}$ medium by tender arecanut seed extract: insight from gravimetric and electrochemical studies, Res. Chem. Intermed., 2016, 42, 6351-6372.

314 A. Khadraoui, A. Khelifa, K. Hachama and R. Mehdaoui, Thymus algeriensis extract as a new eco-friendly corrosion inhibitor for 2024 aluminium alloy in $1 \mathrm{M} \mathrm{HCl}$ medium, J. Mol. Liq., 2016, 214, 293-297.

315 O. K. Abiola and Y. Tobun, Cocos nucifera L. water as green corrosion inhibitor for acid corrosion of aluminium in HCl solution, Chin. Chem. Lett., 2010, 21, 1449-1452.

316 O. Abakedi and I. Moses, Aluminium corrosion inhibition by Maesobatrya barteri root extract in hydrochloric acid solution, Am. Chem. Sci. J., 2016, 10, 1-10.

317 K. Krishnaveni and J. Ravichandran, Effect of aqueous extract of leaves of Morinda tinctoria on corrosion inhibition of aluminium surface in $\mathrm{HCl}$ medium, Trans. Nonferrous Met. Soc. China, 2014, 24, 2704-2712.

318 G. Gece, Drugs: A review of promising novel corrosion inhibitors, Corros. Sci., 2011, 53, 3873-3898.

319 R. Pathak and P. Mishra, Drugs as corrosion inhibitors: a review, Int. J. Sci. Res., 2016, 5, 671-677.

320 Y. Liangtian, M. Zhang, C. Shidong, T. Yunji and W. Haixia, Investigation of Corrosion Inhibition Effect of Enprofylline Drug on Mild Steel Corrosion in Sulphuric Acid Solution, Int. J. Electrochem. Sci., 2020, 15, 5102-5114.

321 M. Alfakeer, M. Abdallah and A. Fawzy, Corrosion Inhibition Effect of Expired Ampicillin and Flucloxacillin Drugs for Mild Steel in Aqueous Acidic Medium, Int. J. Electrochem. Sci., 2020, 15, 3283-3297.

322 C. Verma, D. Chauhan and M. Quraishi, Drugs as environmentally benign corrosion inhibitors for ferrous and nonferrous materials in acid environment: an overview, J. Mater. Environ. Sci. (JMES), 2017, 8, 4040-4051.

323 M. Abdallah, Antibacterial drugs as corrosion inhibitors for corrosion of aluminium in hydrochloric solution, Corros. Sci., 2004, 46, 1981-1996. 
324 H. I. Al-Shafey, R. A. Hameed, F. Ali, A.-M. Ae-AS and M. Salah, Effect of expired drugs as corrosion inhibitors for carbon steel in 1M HCL solution, Int. J. Pharm. Sci. Rev. Res., 2014, 27, 146-152.

325 P. Singh, D. S. Chauhan, K. Srivastava, V. Srivastava and M. Quraishi, Expired atorvastatin drug as corrosion inhibitor for mild steel in hydrochloric acid solution, Int. J. Ind. Chem., 2017, 8, 363-372.

326 N. Vaszilcsin, D.-A. Duca, A. Flueraş and M.-L. Dana, Expired drugs as inhibitors in electrochemical processesa mini-review, Stud. Univ. Babes-Bolyai, Chem., 2019, 3, 17-32.

327 P. Singh, D. Chauhan, S. Chauhan, G. Singh and M. Quraishi, Chemically modified expired Dapsone drug as environmentally benign corrosion inhibitor for mild steel in sulphuric acid useful for industrial pickling process, J. Mol. Liq., 2019, 286, 110903.

328 G. Golestani, M. Shahidi and D. Ghazanfari, Electrochemical evaluation of antibacterial drugs as environment-friendly inhibitors for corrosion of carbon steel in $\mathrm{HCl}$ solution, Appl. Surf. Sci., 2014, 308, 347-362.

329 C. Verma, M. Quraishi and N. K. Gupta, 2-(4-\{[4-Methyl-6(1-methyl-1H-1, 3-benzodiazol-2-yl)-2-propyl-1H-1, 3-benzodiazol-1-yl] methyl\} phenyl) benzoic acid as green corrosion inhibitor for mild steel in $1 \mathrm{M}$ hydrochloric acid, Ain Shams Eng. J., 2018, 9, 1225-1233.

330 L. Yanhong, L. Changcheng, Y. Liangmin, N. Chunhua and Z. Shizheng, Development Progress of Antifouling Agents and Accelerated Test Methods for Antifouling Coatings, Shanghai Coat., 2013, 1, https://en.cnki.com.cn/Article_en/ CJFDTotal-SHTL201301009.htm.

331 I. B. Obot, E. E. Ebenso and M. M. Kabanda, Metronidazole as environmentally safe corrosion inhibitor for mild steel in $0.5 \mathrm{M} \mathrm{HCl}$ : experimental and theoretical investigation, J. Environ. Chem. Eng., 2013, 1, 431-439.

332 G. Karthik and M. Sundaravadivelu, Studies on the inhibition of mild steel corrosion in hydrochloric acid solution by atenolol drug, Egypt. J. Pet., 2016, 25, 183-191.

333 I. Reza, A. Saleemi and S. Naveed, Corrosion inhibition of mild steel in $\mathrm{HCl}$ solution by Tinidazole, Pol. J. Chem. Technol., 2011, 13, 67-71.

334 J. Aldana-González, A. Espinoza-Vázquez, M. RomeroRomo, J. Uruchurtu-Chavarin and M. Palomar-Pardavé, Electrochemical evaluation of cephalothin as corrosion inhibitor for API 5L X52 steel immersed in an acid medium, Arabian J. Chem., 2019, 12, 3244-3253.

335 A. Singh, A. Gupta, A. K. Rawat, K. Ansari, M. Quraishi and E. E. Ebenso, Cimetidine as an effective corrosion inhibitor for mild steel in hydrochloric acid, Int. J. Electrochem. Sci., 2014, 9, 7614-7628.

336 A. Samide, B. Tutunaru, C. Ionescu, P. Rotaru and L. Simoiu, Aminophylline: thermal characterization and its inhibitory properties for the carbon steel corrosion in acidic environment, J. Therm. Anal. Calorim., 2014, 118, 631-639.

337 N. O. Eddy, E. E. Ebenso and U. J. Ibok, Adsorption, synergistic inhibitive effect and quantum chemical studies of ampicillin (AMP) and halides for the corrosion of mild steel in $\mathrm{H}_{2} \mathrm{SO}_{4}$, J. Appl. Electrochem., 2010, 40, 445-456.

338 I. Akpan and N. Offiong, Electrochemical Linear Polarization Studies of Amodiaquine Drug as a Corrosion Inhibitor for Mild Steel in 0.1 M HCL Solution, Chem. Mater. Res., 2015, 7, 17-20.

339 S. K. Shukla and M. Quraishi, The effects of pharmaceutically active compound doxycycline on the corrosion of mild steel in hydrochloric acid solution, Corros. Sci., 2010, 52, 314-321.

340 N. Eddy, S. Odoemelam and A. Mbaba, Inhibition of the corrosion of mild steel in $\mathrm{HCl}$ by sparfloxacin, Afr. J. Pure Appl. Chem., 2008, 2, 132-138.

341 S. K. Shukla, A. K. Singh, I. Ahamad and M. Quraishi, Streptomycin: A commercially available drug as corrosion inhibitor for mild steel in hydrochloric acid solution, Mater. Lett., 2009, 63, 819-822.

342 I. Obot and N. Obi-Egbedi, Adsorption properties and inhibition of mild steel corrosion in sulphuric acid solution by ketoconazole: experimental and theoretical investigation, Corros. Sci., 2010, 52, 198-204.

343 I. Reza, E. Ahmad and F. Kareem, Corrosion inhibition mechanism of Piperacillin Sodium for mild steel protection in acidic media, Afinidad, 2012, 69, 47-52.

344 A. K. Singh and M. Quraishi, Effect of Cefazolin on the corrosion of mild steel in HCl solution, Corros. Sci., 2010, 52, 152-160.

345 I. A. Akpan and N.-A. O. Offiong, Inhibition of mild steel corrosion in hydrochloric acid solution by Ciprofloxacin drug, Int. J. Corros., 2013, 2013, 1-5.

346 I. Ahamad, R. Prasad and M. A. Quraishi, Experimental and theoretical investigations of adsorption of fexofenadine at mild steel/hydrochloric acid interface as corrosion inhibitor, J. Solid State Electrochem., 2010, 14, 2095-2105.

347 P. Singh, M. Quraishi and E. E. Ebenso, Investigation of gliclazide drug as novel corrosion inhibitor for mild steel in $1 \mathrm{M} \mathrm{HCl}$ solution, Int. J. Electrochem. Sci., 2012, 7, 12270-12282.

348 S. K. Shukla and M. Quraishi, Ceftriaxone: a novel corrosion inhibitor for mild steel in hydrochloric acid, J. Appl. Electrochem., 2009, 39, 1517-1523.

349 C. Verma, M. Quraishi and E. Ebenso, Electrochemical Studies of 2-amino-1, 9-dihydro-9-((2-hydroxyethoxy) methyl)-6H-purin-6-one as Green Corrosion Inhibitor for Mild Steel in 1.0 M Hydrochloric Acid Solution, Int. J. Electrochem. Sci., 2013, 8, 7401-7413.

350 A. K. Singh and M. Quraishi, Inhibitive effect of diethylcarbamazine on the corrosion of mild steel in hydrochloric acid, Corros. Sci., 2010, 52, 1529-1535.

351 I. Naqvi, A. Saleemi and S. Naveed, Cefixime: A drug as efficient corrosion inhibitor for mild steel in acidic media. Electrochemical and thermodynamic studies, Int. J. Electrochem. Sci., 2011, 6, 146-161.

352 P. Singh, A. Singh, M. Quraishi and E. E. Ebenso, Cetirizine: a new and effective corrosion inhibitor for mild steel in $1 \mathrm{M}$ HCl solution, Int. J. Electrochem. Sci., 2012, 7, 7065-7079. 
353 J. I. Bhat and V. D. Alva, Meclizine hydrochloride as a potential non-toxic corrosion inhibitor for mild steel in hydrochloric acid medium, Arch. Appl. Sci. Res., 2011, 3, 343-356.

354 P. B. Matad, P. B. Mokshanatha, N. Hebbar, V. T. Venkatesha and $\mathrm{H}$. C. Tandon, Ketosulfone drug as a green corrosion inhibitor for mild steel in acidic medium, Ind. Eng. Chem. Res., 2014, 53, 8436-8444.

355 A. Singh, E. E. Ebenso and M. Quraishi, Theoretical and electrochemical studies of metformin as corrosion inhibitor for mild steel in hydrochloric acid solution, Int. J. Electrochem. Sci., 2012, 7, 4766-4779.

356 R. Farahati, S. M. Mousavi-Khoshdel, A. Ghaffarinejad and H. Behzadi, Experimental and computational study of penicillamine drug and cysteine as water-soluble green corrosion inhibitors of mild steel, Prog. Org. Coat., 2020, 142, 105567.

357 K. Haruna, T. A. Saleh and M. Quraishi, Expired metformin drug as green corrosion inhibitor for simulated oil/gas well acidizing environment, J. Mol. Liq., 2020, 113716.

358 J. S. Wilkes, A short history of ionic liquids-from molten salts to neoteric solvents, Green Chem., 2002, 4, 73-80.

359 K. N. Marsh, J. A. Boxall and R. Lichtenthaler, Room temperature ionic liquids and their mixtures-a review, Fluid Phase Equilib., 2004, 219, 93-98.

360 K. E. Johnson, What's an ionic liquid?, Interface-Electrochem. Soc., 2007, 16, 38-41.

361 N. Bicak, A new ionic liquid: 2-hydroxy ethylammonium formate, J. Mol. Liq., 2005, 116, 15-18.

362 S. Carda-Broch, A. Berthod and D. Armstrong, Solvent properties of the 1-butyl-3-methylimidazolium hexafluorophosphate ionic liquid, Anal. Bioanal. Chem., 2003, 375, 191-199.

363 N. V. Plechkova and K. R. Seddon, Applications of ionic liquids in the chemical industry, Chem. Soc. Rev., 2008, 37, 123-150.

364 D. R. MacFarlane, N. Tachikawa, M. Forsyth, J. M. Pringle, P. C. Howlett, G. D. Elliott, J. H. Davis, M. Watanabe, P. Simon and C. A. Angell, Energy applications of ionic liquids, Energy Environ. Sci., 2014, 7, 232-250.

365 J. Lu, F. Yan and J. Texter, Advanced applications of ionic liquids in polymer science, Prog. Polym. Sci., 2009, 34, 431-448.

366 D. Wei and A. Ivaska, Applications of ionic liquids in electrochemical sensors, Anal. Chim. Acta, 2008, 607, 126-135.

367 M. Deyab, Understanding the anti-corrosion mechanism and performance of ionic liquids in desalination, petroleum, pickling, de-scaling, acid cleaning applications, J. Mol. Liq., 2020, 113107.

368 E. K. Ardakani, E. Kowsari and A. Ehsani, Imidazoliumderived polymeric ionic liquid as a green inhibitor for corrosion inhibition of mild steel in 1.0 M HCl: Experimental and computational study, Colloids Surf., A, 2020, 586, 124195.

369 R. Ratti, Ionic Liquids: Synthesis and Applications in Catalysis, Adv. Chem, 2014, 2014, 1-16.
370 A. N. Masri, A. M. Mi and J.-M. Leveque, A review on dicationic ionic liquids: classification and application, Ind. Eng. Manag., 2016, 5, 197-204.

371 C. A. Angell, Y. Ansari and Z. Zhao, Ionic liquids: past, present and future, Faraday Discuss., 2012, 154, 9-27.

372 S. Amiril, E. Rahim and S. Syahrullail, A review on ionic liquids as sustainable lubricants in manufacturing and engineering: Recent research, performance, and applications, J. Cleaner Prod., 2017, 168, 1571-1589.

373 S. Cao, D. Liu, P. Zhang, L. Yang, P. Yang, H. Lu and J. Gui, Green Brönsted acid ionic liquids as novel corrosion inhibitors for carbon steel in acidic medium, Sci. Rep., 2017, 7, 1-14.

374 P. Hu, Z. Wu, J. Wang, Y. Huang, Q. Liu and S.-F. Zhou, Corrosion inhibiting performance and mechanism of protic ionic liquids as green brass inhibitors in nitric acid, Green Energy Environ., 2020, 5, 214-222.

375 T. Zhou, J. Yuan, Z. Zhang, X. Xin and G. Xu, The comparison of imidazolium Gemini surfactant [C14-4C14im] Br2 and its corresponding monomer as corrosion inhibitors for A3 carbon steel in hydrochloric acid solutions: Experimental and quantum chemical studies, Colloids Surf., A, 2019, 575, 57-65.

376 Y. Qiang, S. Zhang, L. Guo, X. Zheng, B. Xiang and S. Chen, Experimental and theoretical studies of four allyl imidazoliumbased ionic liquids as green inhibitors for copper corrosion in sulfuric acid, Corros. Sci., 2017, 119, 68-78.

377 B. Anandkumar, R. George and J. Philip, Efficacy of imidazolium and piperidinium based ionic liquids on inhibiting biofilm formation on titanium and carbon steel surfaces, Anal. Chim. Acta, 2020, 1126, 38-51.

378 N. V. Likhanova, M. A. Domínguez-Aguilar, O. OlivaresXometl, N. Nava-Entzana, E. Arce and H. Dorantes, The effect of ionic liquids with imidazolium and pyridinium cations on the corrosion inhibition of mild steel in acidic environment, Corros. Sci., 2010, 52, 2088-2097.

379 C. Verma, L. O. Olasunkanmi, I. Bahadur, H. Lgaz, M. Quraishi, J. Haque, E.-S. M. Sherif and E. E. Ebenso, Experimental, density functional theory and molecular dynamics supported adsorption behavior of environmental benign imidazolium based ionic liquids on mild steel surface in acidic medium, J. Mol. Liq., 2019, 273, 1-15.

380 E. Kowsari, M. Payami, R. Amini, B. Ramezanzadeh and M. Javanbakht, Task-specific ionic liquid as a new green inhibitor of mild steel corrosion, Appl. Surf. Sci., 2014, 289, 478-486.

381 S. Ullah, M. A. Bustam, A. M. Shariff, G. Gonfa and K. Izzat, Experimental and quantum study of corrosion of A36 mild steel towards 1-butyl-3-methylimidazolium tetrachloroferrate ionic liquid, Appl. Surf. Sci., 2016, 365, 76-83.

382 H. Ashassi-Sorkhabi and M. Es'Haghi, Corrosion inhibition of mild steel in acidic media by [BMIm] Br Ionic liquid, Mater. Chem. Phys., 2009, 114, 267-271.

383 I. Lozano, E. Mazario, C. Olivares-Xometl, N. Likhanova and P. Herrasti, Corrosion behaviour of API 5LX52 steel in $\mathrm{HCl}$ and $\mathrm{H}_{2} \mathrm{SO}_{4}$ media in the presence of 1, 3-dibencilimidazolio acetate and 1, 3-dibencilimidazolio dodecanoate 
ionic liquids as inhibitors, Mater. Chem. Phys., 2014, 147, 191-197.

384 P. Kannan, J. Karthikeyan, P. Murugan, T. S. Rao and N. Rajendran, Corrosion inhibition effect of novel methyl benzimidazolium ionic liquid for carbon steel in $\mathrm{HCl}$ medium, J. Mol. Liq., 2016, 221, 368-380.

385 A. L. Chong, J. I. Mardel, D. R. MacFarlane, M. Forsyth and A. E. Somers, Synergistic corrosion inhibition of mild steel in aqueous chloride solutions by an imidazolinium carboxylate salt, ACS Sustainable Chem. Eng., 2016, 4, 1746-1755.

386 Y. Ma, F. Han, Z. Li and C. Xia, Acidic-functionalized ionic liquid as corrosion inhibitor for 304 stainless steel in aqueous sulfuric acid, ACS Sustainable Chem. Eng., 2016, 4, 5046-5052.

387 D. Yang, M. Zhang, J. Zheng and H. Castaneda, Corrosion inhibition of mild steel by an imidazolium ionic liquid compound: the effect of $\mathrm{pH}$ and surface pre-corrosion, $R S C$ Adv., 2015, 5, 95160-95170.

388 X. Zheng, S. Zhang, M. Gong and W. Li, Experimental and theoretical study on the corrosion inhibition of mild steel by 1-octyl-3-methylimidazolium L-prolinate in sulfuric acid solution, Ind. Eng. Chem. Res., 2014, 53, 16349-16358.

389 D. Guzmán-Lucero, O. Olivares-Xometl, R. Martínez-Palou, N. V. Likhanova, M. A. Domínguez-Aguilar and V. GaribayFebles, Synthesis of selected vinylimidazolium ionic liquids and their effectiveness as corrosion inhibitors for carbon steel in aqueous sulfuric acid, Ind. Eng. Chem. Res., 2011, 50, 7129-7140.

390 J. Li, D. Li, F. Zhou, D. Feng, Y. Xia and W. Liu, Tribological and corrosive properties of ionic liquids containing triazole functional groups, Industrial Lubrication and Tribology, 2015.

391 E.-S. M. Sherif, H. S. Abdo and S. Z. E. Abedin, Corrosion inhibition of cast iron in arabian gulf seawater by two different ionic liquids, Materials, 2015, 8, 3883-3895.

392 A. Zarrouk, M. Messali, H. Zarrok, R. Salghi, A. Ali, B. Hammouti, S. Al-Deyab and F. Bentiss, Synthesis, characterization and comparative study of new functionalized imidazolium-based ionic liquids derivatives towards corrosion of C38 steel in molar hydrochloric acid, Int. J. Electrochem. Sci., 2012, 7, 6998-7015.

393 M. Messali and M. Asiri, A green ultrasound-assisted access to some new 1-benzyl-3-(4-phenoxybutyl) imidazolium-based ionic liquids derivatives-Potential corrosion inhibitors of mild steel in acidic environment, J. Mater. Environ. Sci., 2013, 5, 770-785.

394 N. Subasree and J. A. Selvi, Imidazolium based ionic liquid derivatives; synthesis and evaluation of inhibitory effect on mild steel corrosion in hydrochloric acid solution, Heliyon, 2020, 6, e03498.

395 K. Qiao and Y. Zeng, Comparative study on two imidazoliumbased ionic liquid surfactants as corrosion inhibitors for N80 steel in 15\% hydrochloric acid solution, Mater. Corros., 2020, 71, 1913-1926.

396 P. D. Pancharatna, S. Lata and G. Singh, Imidazolium based ionic liquid as an efficient and green corrosion constraint for mild steel at acidic pH levels, J. Mol. Liq., 2019, 278, 467-476.

397 S. Cao, D. Liu, H. Ding, J. Wang, H. Lu and J. Gui, Taskspecific ionic liquids as corrosion inhibitors on carbon steel in $0.5 \mathrm{M} \mathrm{HCl}$ solution: an experimental and theoretical study, Corros. Sci., 2019, 153, 301-313.

398 M. C. Luna, T. Le Manh, R. C. Sierra, J. M. Flores, L. L. Rojas and E. A. Estrada, Study of corrosion behavior of API 5L X52 steel in sulfuric acid in the presence of ionic liquid 1-ethyl 3-methylimidazolium thiocyanate as corrosion inhibitor, J. Mol. Liq., 2019, 289, 111106.

399 M. Corrales-Luna, T. Le Manh, M. Romero-Romo, M. PalomarPardavé and E. M. Arce-Estrada, 1-Ethyl 3-methylimidazolium thiocyanate ionic liquid as corrosion inhibitor of API 5L X52 steel in H2SO4 and HCl media, Corros. Sci., 2019, 153, 85-99.

400 Y. Guo, B. Xu, Y. Liu, W. Yang, X. Yin, Y. Chen, J. Le and Z. Chen, Corrosion inhibition properties of two imidazolium ionic liquids with hydrophilic tetrafluoroborate and hydrophobic hexafluorophosphate anions in acid medium, J. Ind. Eng. Chem., 2017, 56, 234-247.

401 G. Vastag, A. Shaban, M. Vraneš, A. Tot, S. Belić and S. Gadžurić, Influence of the N-3 alkyl chain length on improving inhibition properties of imidazolium-based ionic liquids on copper corrosion, J. Mol. Liq., 2018, 264, 526-533.

402 J. Lei, Y. Gao, X. Zhao, Y. Zhu, C. Zhang, Y. Ma, K. Zhao and F. Du, The dilational rheology and splashing behavior of ionic liquid-type imidazolium Gemini surfactant solutions: Impact of alkyl chain length, J. Mol. Liq., 2019, 283, 725-735.

403 S. M. Ali, K. M. Emran and M. Messali, Improved protection performance of modified sol-gel coatings with pyridiniumbased ionic liquid for cast iron corrosion in 0.5 M HCL solution, Prog. Org. Coat., 2019, 130, 226-234.

404 F. Hajjaji, E. Ech-chihbi, N. Rezki, F. Benhiba, M. Taleb, D. S. Chauhan and M. Quraishi, Electrochemical and theoretical insights on the adsorption and corrosion inhibition of novel pyridinium-derived ionic liquids for mild steel in $1 \mathrm{M} \mathrm{HCl}$, J. Mol. Liq., 2020, 113737.

405 K. Shalabi, A. Helmy, A. El-Askalany and M. Shahba, New pyridinium bromide mono-cationic surfactant as corrosion inhibitor for carbon steel during chemical cleaning: Experimental and theoretical studies, J. Mol. Liq., 2019, 293, 111480.

406 E. E. El-Katori and A. S. Abousalem, Impact of some pyrrolidinium ionic liquids on copper dissolution behavior in acidic environment: experimental, morphological and theoretical insights, RSC Adv., 2019, 9, 20760-20777.

407 O. A. Al-Rashed and A. A. Nazeer, Ionic liquids with superior protection for mild steel in acidic media: effects of anion, cation, and alkyl chain length, J. Mol. Liq., 2019, 288, 111015.

408 I. Otero, E. R. López, M. Reichelt and J. Fernández, Tribochemical reactions of anion in pyrrolidinium salts for steel-steel contact, Tribol. Int., 2014, 77, 160-170.

409 P. Arellanes-Lozada, O. Olivares-Xometl, N. V. Likhanova, I. V. Lijanova, J. R. Vargas-García and R. E. HernándezRamírez, Adsorption and performance of ammonium-based 
ionic liquids as corrosion inhibitors of steel, J. Mol. Liq., 2018, 265, 151-163.

410 C. Gabler, C. Tomastik, J. Brenner, L. Pisarova, N. Doerr and G. Allmaier, Corrosion properties of ammonium based ionic liquids evaluated by SEM-EDX, XPS and ICP-OES, Green Chem., 2011, 13, 2869-2877.

411 O. Olivares-Xometl, E. Álvarez-Álvarez, N. V. Likhanova, I. V. Lijanova, R. E. Hernández-Ramírez, P. ArellanesLozada and J. L. Varela-Caselis, Synthesis and corrosion inhibition mechanism of ammonium-based ionic liquids on API 5L X60 steel in sulfuric acid solution, J. Adhes. Sci. Technol., 2018, 32, 1092-1113.

412 T. Nesane, S. S. Mnyakeni-Moleele and L. C. Murulana, Exploration of synthesized quaternary ammonium ionic liquids as unharmful anti-corrosives for aluminium utilizing hydrochloric acid medium, Heliyon, 2020, 6, e04113.

413 A. Rafat, M. Atilhan and R. Kahraman, Corrosion behavior of carbon steel in $\mathrm{CO}_{2}$ saturated amine and imidazolium-, ammonium-, and phosphonium-based ionic liquid solutions, Ind. Eng. Chem. Res., 2016, 55, 446-454.

414 Q. Zhang and Y. Hua, Corrosion inhibition of aluminum in hydrochloric acid solution by alkylimidazolium ionic liquids, Mater. Chem. Phys., 2010, 119, 57-64.

415 S. K. Shetty and A. N. Shetty, Ionic liquid as an effective corrosion inhibitor on $6061 \mathrm{Al}-15$ Vol. Pct. SiC (p) composite in $0.1 \mathrm{M} \mathrm{H}_{2} \mathrm{SO}_{4}$ medium-an ecofriendly approach, Can. Chem. Trans., 2015, 3, 41-64.

416 P. Arellanes-Lozada, O. Olivares-Xometl, D. GuzmánLucero, N. V. Likhanova, M. A. Domínguez-Aguilar, I. V. Lijanova and E. Arce-Estrada, The inhibition of aluminum corrosion in sulfuric acid by poly (1-vinyl-3-alkyl-imidazolium hexafluorophosphate), Materials, 2014, 7, 5711-5734.

417 Q. Zhang, Z. Gao, F. Xu and X. Zou, Adsorption and corrosion inhibitive properties of gemini surfactants in the series of hexanediyl-1, 6-bis-(diethyl alkyl ammonium bromide) on aluminium in hydrochloric acid solution, Colloids Surf., A, 2011, 380, 191-200.

418 F. Trombetta, R. F. de Souza, M. O. de Souza, C. B. Borges, N. F. Panno and E. M. A. Martini, Stability of aluminium in 1-butyl-3-methylimidazolium tetrafluoroborate ionic liquid and ethylene glycol mixtures, Corros. Sci., 2011, 53, 51-58.

419 X. Li, S. Deng and H. Fu, Inhibition by tetradecylpyridinium bromide of the corrosion of aluminium in hydrochloric acid solution, Corros. Sci., 2011, 53, 1529-1536.

420 M.-D. Bermúdez, A.-E. Jiménez and G. Martínez-Nicolás, Study of surface interactions of ionic liquids with aluminium alloys in corrosion and erosion-corrosion processes, Appl. Surf. Sci., 2007, 253, 7295-7302.

421 K. M. Manamela, L. C. Murulana, M. M. Kabanda and E. E. Ebenso, Adsorptive and DFT studies of some imidazolium based ionic liquids as corrosion inhibitors for zinc in acidic medium, Int. J. Electrochem. Sci., 2014, 9, 3029-3046.

422 S. Fashu, C. Gu, X. Wang and J. Tu, Structure, composition and corrosion resistance of Zn-Ni-P alloys electrodeposited from an ionic liquid based on choline chloride, J. Electrochem. Soc., 2014, 161, D3011.
423 M. Scendo and J. Uznanska, The effect of ionic liquids on the corrosion inhibition of copper in acidic chloride solutions, Int. J. Corros., 2011, 2011, 1-13.

424 T. Espinosa, J. Sanes, A.-E. Jiménez and M.-D. Bermúdez, Surface interactions, corrosion processes and lubricating performance of protic and aprotic ionic liquids with OFHC copper, Appl. Surf. Sci., 2013, 273, 578-597.

425 J. Chen, S. K. Spear, J. G. Huddleston and R. D. Rogers, Polyethylene glycol and solutions of polyethylene glycol as green reaction media, Green Chem., 2005, 7, 64-82.

426 F. Bailey Jr and J. Koleske, Poly (ethylene oxide), Academic Press, New York, NY, USA, 1976.

427 D. Candy and J. Belsey, Macrogol (polyethylene glycol) laxatives in children with functional constipation and faecal impaction: a systematic review, Arch. Dis. Child., 2009, 94, 156-160.

428 A. A. D'souza and R. Shegokar, Polyethylene glycol (PEG): a versatile polymer for pharmaceutical applications, Expert Opin. Drug Delivery, 2016, 13, 1257-1275.

429 M. Roberts, M. Bentley and J. Harris, Chemistry for peptide and protein PEGylation, Adv. Drug Delivery Rev., 2002, 54, 459-476.

430 G. Totten and N. Clinton, Poly (ethylene glycol) and derivatives as phase transfer catalysts, 1998.

431 F. M. Kerton and R. Marriott, Alternative solvents for green chemistry, Royal Society of chemistry, 2013.

432 N. F. Leininger, R. Clontz, J. L. Gainer and D. J. Kirwan, Aqueous polyglycol solutions as alternative solvents, ACS Publications, 2002.

433 D. J. Heldebrant and P. G. Jessop, Liquid poly (ethylene glycol) and supercritical carbon dioxide: a benign biphasic solvent system for use and recycling of homogeneous catalysts, J. Am. Chem. Soc., 2003, 125, 5600-5601.

434 K. Kocheva, T. Kartseva, S. Landjeva and G. Georgiev, Parameters of cell membrane stability and levels of oxidative stress in leaves of wheat seedlings treated with PEG 6000, Gen. Appl. Plant Physiol., 2009, 35, 127-133.

435 Y. Li, H. Zhang, Y. Yao, T. Gong, R. Dong, D. Li, Y. Liu and B. Lei, Promoted off-on recognition of $\mathrm{H} 2 \mathrm{O} 2$ based on the fluorescence of silicon quantum dots assembled twodimensional $\mathrm{PEG}-\mathrm{MnO}_{2}$ nanosheets hybrid nanoprobe, Microchim. Acta, 2020, 187, 347.

436 A. R. Kiasat, M. Zayadi, T. F. Mohammad and M. M. Fallah, Simple, Practical and Eco-friendly Reduction of Nitroarenes with Zinc in the Presence of Polyethylene Glycol Immobilized on Silica Gel as a New Solid-liquid Phase Transfer Catalyst in Water, 2011.

437 E. Rytting, K. A. Lentz, X.-Q. Chen, F. Qian and S. Venkatesh, A quantitative structure-property relationship for predicting drug solubility in PEG 400/water cosolvent systems, Pharm. Res., 2004, 21, 237-244.

438 H. Yang, J. J. Morris and S. T. Lopina, Polyethylene glycolpolyamidoamine dendritic micelle as solubility enhancer and the effect of the length of polyethylene glycol arms on the solubility of pyrene in water, J. Colloid Interface Sci., 2004, 273, 148-154. 
439 H. Ashassi-Sorkhabi and N. Ghalebsaz-Jeddi, Inhibition effect of polyethylene glycol on the corrosion of carbon steel in sulphuric acid, Mater. Chem. Phys., 2005, 92, 480-486.

440 H. Ashassi-Sorkhabi and N. Ghalebsaz-Jeddi, Effect of ultrasonically induced cavitation on inhibition behavior of polyethylene glycol on carbon steel corrosion, Ultrason. Sonochem., 2006, 13, 180-188.

441 S. Umoren, O. Ogbobe, P. Okafor and E. Ebenso, Polyethylene glycol and polyvinyl alcohol as corrosion inhibitors for aluminium in acidic medium, J. Appl. Polym. Sci., 2007, 105, 3363-3370.

442 S. Umoren, O. Ogbobe, I. Igwe and E. Ebenso, Inhibition of mild steel corrosion in acidic medium using synthetic and naturally occurring polymers and synergistic halide additives, Corros. Sci., 2008, 50, 1998-2006.

443 S. A. Umoren, Synergistic inhibition effect of polyethylene glycol-polyvinyl pyrrolidone blends for mild steel corrosion in sulphuric acid medium, J. Appl. Polym. Sci., 2011, 119, 2072-2084.

444 S. John, M. Kuruvilla and A. Joseph, Surface morphological and impedance spectroscopic studies on the interaction of polyethylene glycol (PEG) and polyvinyl pyrrolidone (PVP) with mild steel in acid solutions, Res. Chem. Intermed., 2013, 39, 1169-1182.

445 S. Umoren, O. Ogbobe and E. Ebenso, The adsorption characteristics and synergistic inhibition between polyethylene glycol and halide ions for the corrosion of mild steel in acidic medium, Bull. Electrochem., 2006, 22, 155-168.

446 M. Mobin and M. A. Khan, Adsorption and corrosion inhibition behavior of polyethylene glycol and surfactants additives on mild steel in $\mathrm{H}_{2} \mathrm{SO}_{4}, J$. Mater. Eng. Perform., 2014, 23, 222-229.

447 A. Algaber, E. M. El-Nemma and M. M. Saleh, Effect of octylphenol polyethylene oxide on the corrosion inhibition of steel in 0.5 $\mathrm{M} \mathrm{H}_{2} \mathrm{SO}_{4}$, Mater. Chem. Phys., 2004, 86, 26-32.

448 S. Deng, X. Li and J. Sun, Adsorption and inhibition effect of polyethylene glycol 20000 on steel in $\mathrm{H}_{2} \mathrm{SO}_{4}$ solution, Clean. World, 2011, 4, https://en.cnki.com.cn/Article_en/ CJFDTotal-HXQX201104004.htm.

449 H. Ashassi-Sorkhabi, N. Ghalebsaz-Jeddi, F. Hashemzadeh and H. Jahani, Corrosion inhibition of carbon steel in hydrochloric acid by some polyethylene glycols, Electrochim. Acta, 2006, 51, 3848-3854.

450 M. M. Fares, A. Maayta and J. A. Al-Mustafa, Synergistic corrosion inhibition of aluminum by polyethylene glycol and ciprofloxacin in acidic media, J. Adhes. Sci. Technol., 2013, 27, 2495-2506.

451 M. Awad, M. Metwally, S. Soliman and A. El-Zomrawy, Experimental and quantum chemical studies of the effect of poly ethylene glycol as corrosion inhibitors of aluminum surface, J. Ind. Eng. Chem., 2014, 20, 796-808.

452 H. Boudellioua, Y. Hamlaoui, L. Tifouti and F. Pedraza, Comparison between the inhibition efficiencies of two modification processes with PEG-ceria based layers against corrosion of mild steel in chloride and sulfate media, J. Mater. Eng. Perform., 2017, 26, 4402-4414.
453 H. Boudellioua, Y. Hamlaoui, L. Tifouti and F. Pedraza, Effects of polyethylene glycol (PEG) on the corrosion inhibition of mild steel by cerium nitrate in chloride solution, Appl. Surf. Sci., 2019, 473, 449-460.

454 S. Božović, S. Martinez and V. Grudić, A novel environmentally friendly synergistic mixture for steel corrosion inhibition in $0.51 \mathrm{M} \mathrm{NaCl}$, Acta Chim. Slov., 2019, 66, 112.

455 S. A. El Wanees, A. A. El Aal and E. A. El Aal, Effect of polyethylene glycol on pitting corrosion of cadmium in alkaline solution, Br. Corros. J., 1993, 28, 222-226.

456 Y. Ein-Eli, M. Auinat and D. Starosvetsky, Electrochemical and surface studies of zinc in alkaline solutions containing organic corrosion inhibitors, J. Power Sources, 2003, 114, 330-337.

457 D. Gelman, I. Lasman, S. Elfimchev, D. Starosvetsky and Y. Ein-Eli, Aluminum corrosion mitigation in alkaline electrolytes containing hybrid inorganic/organic inhibitor system for power sources applications, J. Power Sources, 2015, 285, 100-108.

458 M. Quraishi and D. Jamal, Development and testing of all organic volatile corrosion inhibitors, Corrosion, 2002, 58, 387-391.

459 R. C. Cioc, E. Ruijter and R. V. Orru, Multicomponent reactions: advanced tools for sustainable organic synthesis, Green Chem., 2014, 16, 2958-2975.

460 C. G. Lima, N. M. Moreira, M. W. Paixao and A. G. Corrêa, Heterogenous green catalysis: Application of zeolites on multicomponent reactions, Curr. Opin. Green Sustainable Chem., 2019, 15, 7-12.

461 Y. Gu, Multicomponent reactions in unconventional solvents: state of the art, Green Chem., 2012, 14, 2091-2128.

462 J. B. Bariwal, J. C. Trivedi and E. V. Van der Eycken, Microwave irradiation and multicomponent reactions, Synthesis of Heterocycles via Multicomponent Reactions II, Springer, 2010, pp. 169-230.

463 R. S. Varma, “Greener” chemical syntheses using mechanochemical mixing or microwave and ultrasound irradiation, Green Chem. Lett. Rev., 2007, 1, 37-45.

464 W. Liu, K. Zhu, S. J. Teat, B. J. Deibert, W. Yuan and J. Li, A mechanochemical route toward the rational, systematic, and cost-effective green synthesis of strongly luminescent copper iodide based hybrid phosphors, J. Mater. Chem. C, 2017, 5, 5962-5969.

465 M. Kidwai, R. Mohan and S. Saxena, Solid-supported Hantzsch-Biginelli reaction for syntheses of pyrimidine derivatives, Russ. Chem. Bull., 2003, 52, 2457-2460.

466 R. S. Varma, Solvent-free organic syntheses. using supported reagents and microwave irradiation, Green Chem., 1999, 1, 43-55.

467 J. Haque, K. Ansari, V. Srivastava, M. Quraishi and I. Obot, Pyrimidine derivatives as novel acidizing corrosion inhibitors for N80 steel useful for petroleum industry: a combined experimental and theoretical approach, J. Ind. Eng. Chem., 2017, 49, 176-188.

468 M. Yadav, L. Gope, N. Kumari and P. Yadav, Corrosion inhibition performance of pyranopyrazole derivatives for 
mild steel in $\mathrm{HCl}$ solution: Gravimetric, electrochemical and DFT studies, J. Mol. Liq., 2016, 216, 78-86.

469 C. Verma, M. Quraishi and A. Singh, 5-Substituted $1 \mathrm{H}$-tetrazoles as effective corrosion inhibitors for mild steel in $1 \mathrm{M}$ hydrochloric acid, J. Taibah Univ. Sci., 2016, 10, 718-733.

470 C. Verma, M. Quraishi, E. Ebenso, I. Obot and A. El Assyry, 3-Amino alkylated indoles as corrosion inhibitors for mild steel in 1M $\mathrm{HCl}$ : Experimental and theoretical studies, J. Mol. Liq., 2016, 219, 647-660.

471 P. Singh, V. Srivastava and M. Quraishi, Novel quinoline derivatives as green corrosion inhibitors for mild steel in acidic medium: electrochemical, SEM, AFM, and XPS studies, J. Mol. Liq., 2016, 216, 164-173.

472 M. Jeeva, M. Susai Boobalan and G. V. Prabhu, Adsorption and anticorrosion behavior of 1-((pyridin-2-ylamino)(pyridin4-yl) methyl) pyrrolidine-2, 5-dione on mild steel surface in hydrochloric acid solution, Res. Chem. Intermed., 2018, 44, 425-454.

473 C. Verma, M. A. Quraishi, K. Kluza, M. Makowska-Janusik, L. O. Olasunkanmi and E. E. Ebenso, Corrosion inhibition of mild steel in $1 \mathrm{M} \mathrm{HCl}$ by $\mathrm{D}$-glucose derivatives of dihydropyrido [2, 3-d: 6, 5-d'] dipyrimidine-2, 4, 6, $8(1 \mathrm{H}$, 3H, 5H, 7H)-tetraone, Sci. Rep., 2017, 7, 44432.

474 C. Verma, L. Olasunkanmi, I. Obot, E. E. Ebenso and M. Quraishi, 5-Arylpyrimido-[4, 5-b] quinoline-diones as new and sustainable corrosion inhibitors for mild steel in $1 \mathrm{M} \mathrm{HCl}$ : a combined experimental and theoretical approach, RSC Adv., 2016, 6, 15639-15654.

475 N. K. Gupta, C. Verma, R. Salghi, H. Lgaz, A. Mukherjee and M. Quraishi, New phosphonate based corrosion inhibitors for mild steel in hydrochloric acid useful for industrial pickling processes: experimental and theoretical approach, New J. Chem., 2017, 41, 13114-13129.

476 M. A. Quraishi, 2-Amino-3, 5-dicarbonitrile-6-thio-pyridines: new and effective corrosion inhibitors for mild steel in $1 \mathrm{M}$ HCl, Ind. Eng. Chem. Res., 2014, 53, 2851-2859.

477 M. Bahrami, S. Hosseini and P. Pilvar, Experimental and theoretical investigation of organic compounds as inhibitors for mild steel corrosion in sulfuric acid medium, Corros. Sci., 2010, 52, 2793-2803.

478 C. Verma, M. Quraishi and A. Singh, 2-Amino-5-nitro-4, 6-diarylcyclohex-1-ene-1, 3, 3-tricarbonitriles as new and effective corrosion inhibitors for mild steel in $1 \mathrm{M} \mathrm{HCl}$ : Experimental and theoretical studies, J. Mol. Liq., 2015, 212, 804-812.

479 A. K. Singh and M. Quraishi, Inhibiting effects of 5-substituted isatin-based Mannich bases on the corrosion of mild steel in hydrochloric acid solution, J. Appl. Electrochem., 2010, 40, 1293-1306.

480 M. Jeeva, G. V. Prabhu, M. S. Boobalan and C. M. Rajesh, Interactions and inhibition effect of urea-derived Mannich bases on a mild steel surface in HCl, J. Phys. Chem. C, 2015, 119, 22025-22043.

481 K. Ansari and M. Quraishi, Experimental and computational studies of naphthyridine derivatives as corrosion inhibitor for N80 steel in 15\% hydrochloric acid, Phys. E, 2015, 69, 322-331.

482 P. Singh, M. Makowska-Janusik, P. Slovensky and M. Quraishi, Nicotinonitriles as green corrosion inhibitors for mild steel in hydrochloric acid: Electrochemical, computational and surface morphological studies, J. Mol. Liq., 2016, 220, 71-81.

483 K. Ansari, M. Quraishi and A. Singh, Pyridine derivatives as corrosion inhibitors for N80 steel in 15\% HCl: Electrochemical, surface and quantum chemical studies, Measurement, 2015, 76, 136-147.

484 K. Ansari, M. Quraishi and A. Singh, Corrosion inhibition of mild steel in hydrochloric acid by some pyridine derivatives: an experimental and quantum chemical study, J. Ind. Eng. Chem., 2015, 25, 89-98.

485 V. Srivastava, J. Haque, C. Verma, P. Singh, H. Lgaz, R. Salghi and M. Quraishi, Amino acid based imidazolium zwitterions as novel and green corrosion inhibitors for mild steel: Experimental, DFT and MD studies, J. Mol. Liq., 2017, 244, 340-352.

486 P. Singh, M. Quraishi, S. Gupta and A. Dandia, Investigation of the corrosion inhibition effect of 3-methyl-6-oxo-4-(thiophen-2yl)-4, 5, 6, 7-tetrahydro-2H-pyrazolo [3, 4-b] pyridine-5-carbonitrile (TPP) on mild steel in hydrochloric acid, J. Taibah Univ. Sci., 2016, 10, 139-147.

487 C. Verma and M. Quraishi, Adsorption behavior of 8, 9-bis (4 (dimethyl amino) phenyl) benzo $[4,5]$ imidazo $[1,2-\mathrm{a}]$ pyridine-6, 7-dicarbonitrile on mild steel surface in $1 \mathrm{M}$ HCl, J. Assoc. Arab Univ. Basic Appl. Sci., 2017, 22, 55-61.

488 P. Singh, A. Singh and M. Quraishi, Thiopyrimidine derivatives as new and effective corrosion inhibitors for mild steel in hydrochloric acid: Electrochemical and quantum chemical studies, J. Taiwan Inst. Chem. Eng., 2016, 60, 588-601.

489 C. Verma and M. Quraishi, 2-Amino-4-(2, 4-dihydroxyphenyl) quinoline-3-carbonitrile as sustainable corrosion inhibitor for SAE 1006 steel in $1 \mathrm{M} \mathrm{HCl}$ : Electrochemical and surface investigation, J. Assoc. Arab Univ. Basic Appl. Sci., 2017, 23, 29-36.

490 D. K. Yadav, B. Maiti and M. Quraishi, Electrochemical and quantum chemical studies of 3, 4-dihydropyrimidin-2 $(1 \mathrm{H})$-ones as corrosion inhibitors for mild steel in hydrochloric acid solution, Corros. Sci., 2010, 52, 3586-3598.

491 C. B. Verma, E. E. Ebenso and M. Quraishi, Electrochemical investigation of substituted aniline, melamine and formaldehydebBased terpolymers as effective corrosion inhibitors for mild steel in 1M hydrochloric acid solution, 2014.

492 S. Gupta, A. Dandia, P. Singh and M. Qureishi, Green synthesis of pyrazolo [3, 4-b] pyridine derivatives by ultrasonic technique and their application as corrosion inhibitor for mild steel in acid medium, J. Mater. Einviron. Sci., 2015, 6, 168-177.

493 C. Verma, M. Quraishi and E. Ebenso, Green ultrasound assisted synthesis of N 2, N 4, N 6-tris ((pyridin-2-ylamino) methyl)-1, 3, 5-triazine-2, 4, 6-triamine as effective corrosion inhibitor for mild steel in $1 \mathrm{M}$ hydrochloric acid medium, Int. J. Electrochem. Sci., 2013, 8, 10864-10877.

494 C. Verma, M. Quraishi and E. Ebenso, Mannich bases derived from melamine, formaldehyde alkanoleamines as 
novel corrosion inhibitors for mild steel in hydrochloric acid medium, Int. J. Electrochem. Sci., 2013, 8, 10851-10863.

495 A. Dandia, S. Gupta, P. Singh and M. Quraishi, Ultrasoundassisted synthesis of pyrazolo [3, 4-b] pyridines as potential corrosion inhibitors for mild steel in $1.0 \mathrm{M} \mathrm{HCl}$, ACS Sustainable Chem. Eng., 2013, 1, 1303-1310.

496 M. Yadav, D. Sharma, S. Kumar, I. Bahadur and E. Ebenso, Electrochemical and theoretical studies on amino phosphonates as efficient corrosion inhibitor for N80 steel in hydrochloric acid solution, Int. J. Electrochem. Sci., 2014, 9, 6580-6593.

497 K. Ansari, Sudheer, A. Singh and M. Quraishi, Some pyrimidine derivatives as corrosion inhibitor for mild steel in hydrochloric acid, J. Dispersion Sci. Technol., 2015, 36, 908-917.

498 M. Quraishi, The corrosion inhibition effect of aryl pyrazolo pyridines on copper in hydrochloric acid system: computational and electrochemical studies, RSC Adv., 2015, 5, 41923-41933.

499 C. B. Verma, M. Quraishi and E. Ebenso, Electrochemical and Thermodynamic Investigation of Some Soluble Terpolymers as effective corrosion inhibitors for Mild Steel in $1 \mathrm{M}$ hydrochloric acid solution, Int. J. Electrochem. Sci., 2013, 8, 12894-12906.

500 K. Ansari, M. Quraishi, A. Singh, S. Ramkumar and I. B. Obote, Corrosion inhibition of N80 steel in $15 \% \mathrm{HCl}$ by pyrazolone derivatives: electrochemical, surface and quantum chemical studies, RSC Adv., 2016, 6, 24130-24141.

501 K. Ansari, M. Quraishi and A. Singh, Chromenopyridin derivatives as environmentally benign corrosion inhibitors for N80 steel in 15\% HCl, J. Assoc. Arab Univ. Basic Appl. Sci., 2017, 22, 45-54.

502 R. Korde, C. B. Verma, E. Ebenso and M. Quraishi, Electrochemical and Thermo Dynamical Investigation of 5-ethyl 4-(4-methoxyphenyl)-6-methyl-2-thioxo-1, 2, 3, 4 tetrahydropyrimidine-5-carboxylate on Corrosion Inhibition Behavior of Aluminium in $1 \mathrm{M}$ Hydrochloric Acid Medium, Int. J. Electrochem. Sci., 2015, 10, 1081-1093.

503 C. O. Kappe, Controlled microwave heating in modern organic synthesis, Angew. Chem., Int. Ed., 2004, 43, 6250-6284.

504 W. Ao, J. Fu, X. Mao, Q. Kang, C. Ran, Y. Liu, H. Zhang, Z. Gao, J. Li and G. Liu, Microwave assisted preparation of activated carbon from biomass: A review, Renewable Sustainable Energy Rev., 2018, 92, 958-979.

505 B. B. Goldberg, J.-B. Liu and F. Forsberg, Ultrasound contrast agents: a review, Ultrasound Med. Biol., 1994, 20, 319-333.

506 S. Nain, R. Singh and S. Ravichandran, Importance of Microwave Heating in Organic Synthesis, Adv. J. Chem., Sect. A, 2019, 2, 94-104.

507 M. E. Brown, Introduction to thermal analysis: techniques and applications, Springer Science \& Business Media, 2001.

508 C. Marcos and I. Rodríguez, Expansibility of vermiculites irradiated with microwaves, Appl. Clay Sci., 2011, 51, 33-37.

509 V. K. Tyagi and S.-L. Lo, Microwave irradiation: A sustainable way for sludge treatment and resource recovery, Renewable Sustainable Energy Rev., 2013, 18, 288-305.
510 D. N. K. Reddy, K. B. Chandrasekhar, Y. S. S. Ganesh, G. R. Reddy, J. P. Kumar, R. K. Kapavarapu and M. Pal, FeF 3-catalyzed MCR in PEG-400: ultrasound assisted synthesis of N-substituted 2-aminopyridines, RSC Adv., 2016, 6, 67212-67217.

511 M. Dell'Acqua, G. Abbiati and E. Rossi, Palladium-catalyzed, microwave-enhanced three-component synthesis of isoquinolines with aqueous ammonia, Synlett, 2010, 2672-2676.

512 N. A. Khan and S. H. Jhung, Synthesis of metal-organic frameworks (MOFs) with microwave or ultrasound: Rapid reaction, phase-selectivity, and size reduction, Coord. Chem. Rev., 2015, 285, 11-23.

513 A. Lew, P. O. Krutzik, M. E. Hart and A. R. Chamberlin, Increasing rates of reaction: microwave-assisted organic synthesis for combinatorial chemistry, J. Comb. Chem., 2002, 4, 95-105.

514 M. Palomar-Pardavé, M. Romero-Romo, H. Herrera-Hernández, M. Abreu-Quijano, N. V. Likhanova, J. Uruchurtu and J. JuárezGarcía, Influence of the alkyl chain length of 2 amino 5 alkyl 1, 3, 4 thiadiazole compounds on the corrosion inhibition of steel immersed in sulfuric acid solutions, Corros. Sci., 2012, 54, 231-243.

515 Q. Deng, H.-W. Shi, N.-N. Ding, B.-Q. Chen, X.-P. He, G. Liu, Y. Tang, Y.-T. Long and G.-R. Chen, Novel triazolyl bis-amino acid derivatives readily synthesized via click chemistry as potential corrosion inhibitors for mild steel in HCl, Corros. Sci., 2012, 57, 220-227.

516 A. Dutta, S. K. Saha, P. Banerjee and D. Sukul, Correlating electronic structure with corrosion inhibition potentiality of some bis-benzimidazole derivatives for mild steel in hydrochloric acid: combined experimental and theoretical studies, Corros. Sci., 2015, 98, 541-550.

517 H. I. Beltrán, R. Esquivel, A. Sosa-Sánchez, J. L. SosaSánchez, H. Höpfl, V. Barba, N. Farfán, M. Galicia García, O. Olivares-Xometl and L. S. Zamudio-Rivera, Microwave assisted stereoselective synthesis of cis-substituted tinIV phthalocyanine dicarboxylates. Application as corrosion inhibitors, Inorg. Chem., 2004, 43, 3555-3557.

518 J. Halambek, M. Jukić, K. Berković and J. Vorkapić-Furač, Investigation of novel heterocyclic compounds as inhibitors of $\mathrm{Al}-3 \mathrm{Mg}$ alloy corrosion in hydrochloric acid solutions, Int. J. Electrochem. Sci., 2012, 7, 1580-1601.

519 P. Singh, M. Quraishi, E. Ebenso and C. B. Verma, Ultrasound assisted synthesis of chalcones as green corrosion inhibitors for mild steel in $1 \mathrm{M}$ hydrochloric solution, Int. J. Electrochem. Sci., 2014, 9, 7446-7459.

520 A. Ehsani, R. Moshrefi and M. Ahmadi, Electrochemical investigation of inhibitory of new synthesized 3-(4-iodophenyl)-2-imino-2, 3-dihydrobenzo [d] oxazol-5-yl 4-methylbenzenesulfonate on corrosion of stainless steel in acidic medium, J. Electrochem. Sci. Technol., 2015, 6, 7-15.

521 S. Mallakpour and M. Dinari, Ionic liquids as green solvents: progress and prospects, Green Solvents II, Springer, 2012, pp. 1-32.

522 T. W. Bentley and G. E. Carter, The SN2-SN1 spectrum. 4. The SN2 (intermediate) mechanism for solvolyses of 
tert-butyl chloride: a revised Y scale of solvent ionizing power based on solvolyses of 1-adamantyl chloride, J. Am. Chem. Soc., 1982, 104, 5741-5747.

523 N. M. Aljamali, Review: General Principles in Chemistry, 2018, ch. 5, pp. 60-91, ISBN: 978-93-87905-41-2.

524 P. G. Jessop, Searching for green solvents, Green Chem., 2011, 13, 1391-1398.

525 J. M. DeSimone, Practical approaches to green solvents, Science, 2002, 297, 799-803.

526 M. Reslow, P. Adlercreutz and B. Mattiasson, On the importance of the support material for bioorganic synthesis: Influence of water partition between solvent, enzyme and solid support in water-poor reaction media, Eur. J. Biochem., 1988, 172, 573-578.

527 H. Zhao, S. Xia and P. Ma, Use of ionic liquids as 'green' solvents for extractions, J. Chem. Technol. Biotechnol.: Int. Res. Process, Environ. Clean Technol., 2005, 80, 1089-1096.

528 S. M. Tawfik, Ionic liquids based gemini cationic surfactants as corrosion inhibitors for carbon steel in hydrochloric acid solution, J. Mol. Liq., 2016, 216, 624-635.

529 A. Simoes, D. Tallman and G. Bierwagen, Use of ionic liquids for the electrochemical characterization of water transport in organic coatings, Electrochem. Solid-State Lett., 2005, 8, B60.

530 Z. Li, X. Wang, Y. Zhang and C. Jing, Enhancing the Corrosion Resistance of Epoxy Coatings by Impregnation with a Reduced Graphene Oxide-Hydrophobic Ionic Liquid Composite, ChemElectroChem, 2018, 5, 3300-3306.

531 S. P. Nalawade, F. Picchioni and L. Janssen, Supercritical carbon dioxide as a green solvent for processing polymer melts: Processing aspects and applications, Prog. Polym. Sci., 2006, 31, 19-43.

532 Á. L. Santana, D. T. Santos and M. A. A. Meireles, Perspectives on small-scale integrated biorefineries using supercritical $\mathrm{CO}_{2}$ as a green solvent, Curr. Opin. Green Sustainable Chem., 2019, 18, 1-12.

533 W. Wu, W. Li, B. Han, T. Jiang, D. Shen, Z. Zhang, D. Sun and B. Wang, Effect of organic cosolvents on the solubility of ionic liquids in supercritical $\mathrm{CO}_{2}, \mathrm{~J}$. Chem. Eng. Data, 2004, 49, 1597-1601.

534 P. G. Jessop, R. R. Stanley, R. A. Brown, C. A. Eckert, C. L. Liotta, T. T. Ngo and P. Pollet, Neoteric solvents for asymmetric hydrogenation: supercritical fluids, ionic liquids, and expanded ionic liquids, Green Chem., 2003, 5, 123-128. 